\title{
The Role of Cyclic Nucleotides in the CNS
}

\author{
JOHN W. PHILLIS
}




\section{CONTENTS}

A. Introduction $\ldots \ldots \ldots \ldots \ldots \ldots \ldots \ldots$

B. General Features of Chemical Transmission Between Nerve Cells ...154

I. Electrophysiology of Synaptic

Transmission ........................ 154

(1) Fast Synapses $\ldots \ldots \ldots \ldots \ldots \ldots \ldots .154$

(2) Slow Synapses ................155

(3) Presynaptic Inhibition ............156

II. Identification of Synaptic Transmitters ...156

C. Metabolism and Functional

Characteristics of Cyclic

Nucleotides ................... 157

I. Components of the Cyclic Nucleotide System

(1) Adenylate Cyclase ............... 157

(2) Guanylate Cyclase $\ldots \ldots \ldots \ldots \ldots \ldots 157$

(3) Protein Kinases ................ 157

(4) Phosphodiesterase .............. 158

(5) Phosphoprotein Phosphatases ....... 158

II. Criteria for Acceptance of Cyclic

Nucleotides as Second Messengers...... 158

D. Formation of Cyclic

Nucleotides in the CNS ...........159

I. Preparations used for Studies on

Cyclic Nucleotides .................. 159

(1) Investigations in vivo ........... 159

(2) Brain Slice Preparations .......... 159

(3) Cells from Neuronal or Glial Cultures .................. 160

(4) Cell-free Preparations of Adenylate Cyclase .............. 160

II. Neurotransmitters Affecting Cyclic

Nucleotide Formation .............. 160

(1) Norepinephrine $\ldots \ldots \ldots \ldots \ldots \ldots, 160$

(2) Dopamine $\ldots \ldots \ldots \ldots \ldots \ldots \ldots \ldots, 161$

(3) Serotonin $\ldots \ldots \ldots \ldots \ldots \ldots \ldots, 161$
(4) Histamine $\ldots \ldots \ldots \ldots \ldots, \ldots \ldots, \ldots, \ldots 161$

(5) Adenosine $\ldots \ldots \ldots \ldots \ldots \ldots \ldots \ldots 161$

(6) Acetylcholine and Substance P ......162

(7) Amino Acids . . . . . . . . . . . . . 162

(8) Prostaglandins . . . . . . . . . . . 162

E. Nucleotides and Transmission at Selected Synapses ............... 163

I. Sympathetic Ganglia 163

II. Central "Aminergic" Transmission ....... 165

(1) Norepinephrine-Mediated Synapses.... 165

(a) Cerebellar Purkinje Cells and Hippocampal

Pyramidal Neurons ...............165

(b) Cerebral Cortex ..............165

(c) Spinal Motoneurons ...........166

(2) Dopamine-Mediated Synapses .........166

(3) Serotonin-Mediated Synapses . . . . . . 167

(4) Histamine-Mediated Synapses ..........167

III. Depressant Actions of Cyclic and Non-

Cyclic Adenine Nucleotides ........... 168

(1) Cerebellar Purkinje Cells ........... 168

(2) Cerebral Cortical Neurons .......... 170

(3) Other Regions of the Brain........ 173

(4) Spinal Cord $\ldots \ldots \ldots \ldots \ldots \ldots \ldots, 173$

IV. Presynaptic Actions of Cyclic AMP ..... 174

V. Acetylcholine and Cyclic GMP ........ 176

VI. Phosphodiesterase Inhibitors .......... 177

VII. Prostaglandins ................... 177

F. Amines, Calcium and $\mathrm{Na}^{+}, \mathrm{K}^{+}$ -ATPase ................... 178

G. Cyclic Nucleotides and Memory ..... 183

H. Conclusions . . . . . . . . . . . . . . 184

I. Acknowledgements .............. 185

J. References .................. 185 


\title{
The Role of Cyclic Nucleotides in the CNS
}

\author{
JOHN W. PHILLIS
}

SUMMARY: On the basis of the information presented in this review, it is difficult to reach any firm decision regarding the role of cyclic AMP (or cyclic GMP) in synaptic transmission in the brain. While it is clear that cyclic nucleotide levels can be altered by the exposure of newral tissues to various neurotransmitters, it would be premature to claim that these nacleotides are, or are not, essential to the transmission process in the pre- or post-synaptic components of the synapse. In future experiments with cyclic AMP it will be necessary to consider more critically whether the extracellularly applied nucleotide merely provides a source of adenosine and is thus activating an extracellularly located adenosine receptor, or whether it is actually reaching the hypothetical sites at which it might act as a second messenger. The application of cyclic AMP by intracellular injection techniques should minimize this particular problem, although possibly at the ex-

RÉSUMÉ: En se basant sur l'information donnée dans cette revue, il est difficile d'en arriver à une décision ferme en ce qui concerne le rôle de l'AMP cyclique (ou GMP cyclique) dans la transmission synaptique dans le cerveau. Tandis qu'il est clair que les niveaux de nucleotide cyclique peuvent ètre modifiés par l'exposition des tissus nerveax à divers nearotransmettears, il serait prématuré de prétendre que ces nucleotides sont, ou ne sont pas, essentiels au processus de transmission dans les composantes pré- our post-synaptiques de la synapse. Dans les expériences futures avec l'AMP cyclique, il sera nécessaire de considérer de façon plus critique se le nucleotide appliqué extracellalairement procure simple-

From the Department of Physiology, College of Medicine, University of Saskatchewan, Saskatoon, Saskatchewan

Reprint requests to Prof. J. W. Phillis, Dept. of Physiology, College of Medicine, University of Saskatchewan, Saskatoon, Saskatchewan, Canada. S7N 0W0. pense of new difficulties. Prior blockade of the adenosine receptor with agents such as theophylline or adenine xylofuranoside may also assist in the categorization of responses to extracellularly applied cyclic AMP as being a result either of activation of the adenosine receptor or of some other mechanism. Ultimately, the development of highly specific inhibitors for adenylate cyclase should provide a firm basis from which to draw conclusions about the role of cyclic AMP in synaptic transmission. Similar considerations apply to the actions of cyclic GMP and the role of its synthesizing enzyme, guanylate cyclase.

The use of phosphodiesterase inhibitors in studies on cyclic nucleotides mast also be approached with calution. The diverse actions of many of these compounds, which include calcium mobilization and block of adenosine uptake. could account for many of the results that have been reported in the literature.

ment une source d'adénosine et active ainsi un réceptuer d'adénosine localisé extracellulairement, on si il rejoint en fait les sites hypothétiques qui peuvent agir comme second messager. L'application d'AMP cyclique par techniques d'injection intracellulaire doivent minimiser ce problème particulier, quoique possiblement au coût de nouvelles difficultés. Un bloc préalable du réceptear d'adénosine avec des agents comme la théophylline ou l'adénine rylofuranoside peut aussi aider dans la classification des réponses à l'AMP cyclique appliquée extracellalairement, comme étant un résultat soit d'activation du récepteur. d'adénosine ou d'autres mécanismes. Finalement, le développement d'inhibi(Continued on page 185)

\section{A. INTRODUCTION}

Cyclic AMP (cAMP, adenosine $3^{\prime}, 5^{\prime}$-monophosphate) was initially discovered by Sutherland and Rall (1958) as a heat stable factor accumulated in liver homogenates exposed to epinephrine or glucagon which mediated the glycogenolytic action of these hormones on the liver. Further investigations have led to the concept that cyclic AMP may be involved as an intracellular mediator of the actions of other hormones and of various putative synaptic transmitters. According to this concept, first messengers, the hormones or transmitters themselves, travel from their cells of origin and induce the formation of intracellular cyclic AMP in their target cells. Cyclic AMP, by activating an appropriate sequence of enzymes, can evoke the specific response of a target cell to the hormone (Sutherland et al., 1968).

Examples of systems in which cyclic AMP is thought to function in a second messenger capacity include the liver, where as noted above cyclic AMP mediates the actions of epinephrine and glucagon by modulating carbohydrate metabolism, stimulating glycogen breakdown and promoting the formation of glucose from metabolites such as amino acids and lactate. In pancreatic cells, it stimulates the secretion of insulin in response to glucagon and possibly to glucose. In fat cells it mediates the actions of hormones such as epinephrine and glucagon which stimulate lipolysis and inhibit lipogenesis. Similar processes involving cyclic AMP are thought to govern other types of secretory cells. For example, the actions of many trophic hormones (ACTH, TSH, FSH) may be mediated through cyclic AMP. In kidney tubule cells, cAMP stimu- 
lates the reabsorption of water in response to antidiuretic hormone; in the myocardium it enhances the rate and force of cardiac contraction in response to epinephrine; and in the bones it mediates the action of parathyroid hormone in stimulating bone resorption and thus regulates the levels of serum calcium. Cyclic AMP has also been implicated in many of the processes of cell regulation in which hormones may not be directly involved.

During the course of research on cAMP, a second cyclic nucleotide, guanosine $3^{\prime}, 5^{\prime}$-monophosphate (cGMP) was discovered (Ashman et al., 1963). Cyclic GMP is now thought to act as a second messenger for the actions of various neurotransmitters, including acetylcholine. Biomedical research into the mediator roles of cyclic nucleotides has expanded in an explosive fashion in the past two decades and, as already mentioned, these compounds have been implicated in a plethora of biological processes. A particularly intriguing question is how can one or two compounds accomplish such a multitude of roles? It must be appreciated from the outset that the detailed mechanisms of hormone-cAMP action have been elucidated for only one system the epinephrine and glucagoninduced regulation of glycogen breakdown and synthesis. The biological effects of cyclic nucleotides generated in response to neurotransmitters are thought to be the result of activation of a class of enzymes known as protein kinases, and the specificity and nature of the response depend on the substrate specificity of the particular kinase affected and the accessibility of endogenous protein substrates. Currently, however, there is little pertinent information regarding the macromolecular components which link these kinases to alterations in neuronal excitability.

Other problems which have hampered the establishment of cyclic nucleotides as second messengers for the expression of transmitter action include the difficulty of establishing whether effects occur in the pre- or post-synaptic elements and an increasing awareness of the existence of extracellular adenosine receptors on nerve cells. Activation of these receptors must therefore be considered as a possible complication when CAMP is administered extracellularly - the route adopted by most investigators.

The present chapter will examine current knowledge of the role of cyclic nucleotides in synaptic transmission in the central nervous system. In particular, the possibility that cyclic nucleotides act as intracellular mediators of the action of various neurotransmitters will receive a critical examination. To achieve this objective it will first be necessary to describe briefly the nature of chemical transmission between nerve cells and to introduce the reader to the putative transmitter substances which are thought to mediate intercellular transmission. The electrophysiology of synaptic transmission will be described with special attention devoted to the so--called slow synaptic phenomena, which have time courses longer than those traditionally associated with chemical transmission.

The third section of this paper discusses in some depth the various components of the cyclic nucleotide systems, including enzymatic formation, degradation and expression of nucleotide action, within the single cell. The traditional criteria for acceptance of cyclic nucleotides as intracellular mediators of transmitter or hormonal action are then enumerated.

An account of the effects of the putative neurotransmitters on cyclic nucleotide formation in sympathetic ganglia and the central nervous system follows with a detailed analysis of the electrophysiological, pharmacological and cytochemical evidence favoring an involvement of cyclic nucleotides at certain catecholamine-mediated synapses. The possibility that other membrane constituents such as $\mathrm{Ca}^{++}$and $\mathrm{Na}^{+}, \mathrm{K}^{+}-\mathrm{A}$ TPase may be involved in the expression of neurotransmitter action, either in conjuction with, or independently of cyclic nucleotides, is explored in some detail.

Finally, other potential aspects of cyclic nucleotide function, such as the generation of neuronal memory traces at the single cell level, will be introduced.

\section{B. GENERAL FEATURES OF CHEMICAL TRANSMISSION BETWEEN NERVE CELLS}

Before proceeding to a description of the components of the cyclic nucleotide system in the central nervous system, it is essential to understand the general processes involved in the transmission of information between nerve cells. As the identity of the chemicals which convey this information across the synapses is still controversial, it is also necessary to introduce a summary of the criteria by which these transmitters are tentatively identified.

\section{ELECTROPHYSIOLOGY OF \\ SYNAPTIC TRANSMISSION}

Chemically transmitting synapses are divisible into two categories. At what may be called the "classical" type of synapse, the presynaptically released transmitter acts upon receptors on the subsynaptic membrane to cause a rapid increase in membrane permeability to selected ions. More recently another type of chemical synapse has been identified at which the transmitter alters the membrane potential of the postsynaptic cell in the absence of any decrease in membrane resistance; indeed resistance may even be increased. At some of these latter types of junction it appears that the transmitter alters the activity of metabolic systems in the postsynaptic neuron.

\section{(1) Fast Synapses}

At the excitatory synapses formed by dorsal root afferents on spinal cord motoneurons excitatory transmission is now considered to have chemical and possibly electrical components. The excitatory postsynaptic potential (EPSP) generated by activity in these fibers has an extremely short time course, which is associated with an increase in membrane conductance and a reversal potential more positive than the membrane potential (Rall et al., 1967; Jack et al., 1971). The lack of 
clear conductance changes or a reversal level for the EPSP's recorded from some motoneurones has been ascribed to a component of electrical transmission. The currents which generate the EPSP have been measured directly by voltage clamping monosynaptically activated motoneurons (Araki and Terzuolo, 1962). The current has an initial intense phase which rises to a peak in about $0.7 \mathrm{msec}$ and a total duration of about $2.5 \mathrm{msec}$. Current flow is possible because of the increase in postsynaptic membrane permeability to sodium and potassium ions that accompanies activation by the excitatory transmitter of its receptors.

The inhibitory synaptic action of Ia afferents on antagonist motoneurons in the spinal cord is revealed as a brief hyperpolarization of the membrane. 'The inhibitory postsynaptic potential (IPSP) is approximately a mirror image of the Ia EPSP and is generated by an outward current across the subsynaptic membrane. The inhibitory current, as measured by voltage clamp techniques (Araki and Terzuolo, 1962) has a rapid time course, reaching a maximum in about $0.8 \mathrm{msec}$ and having a total duration of some 2.5 msec. The generation of the inhibitory current is a consequence of a brief increase in membrane conductance (Coombs et al., 1955; Smith et al., 1967). The IPSP reverses from a hyperpolarizing to a depolarizing potential at a membrane potential of about $-80 \mathrm{mV}$ and was initially considered to be generated by increases in membrane permeability to potassium and chloride ions. More recently, however, Lux has challenged the assumption that chloride is passively distributed across the membrane, with an $E_{C 1}$ near the resting potential $(-70 \mathrm{mV})$, and has proposed the existence of an outwardly directed chloride pump in motoneurons, with an $E_{C l}$ more negative than the resting membrane potential (Lux et al., 1970; Lux, 1971). The evidence for this suggestion is derived from the blockage of the chloride extruding mechanism by externally applied ammonium ions. Changes in chloride extrusion were paralleled by changes in the reversal potential for the IPSP, suggesting that alterations in chloride conductance are of major significance in the generation of the IPSP. Another example of a chloride-dependent IPSP has been established in cat trochlear motoneurons, where the IPSP has a reversal potential that is more negative than the potassium-dependent action potential after hyperpolarization (Llinas and Baker, 1972). These IPSP's are reversed by intracellular chloride injection, implying that chloride ion carries most of the IPSP current and that intracellular chloride is actively maintained at a lower concentration than would be expected from passive chloride distribution.

\section{(2) Slow Synapses}

The most fully documented examples of synapses at which transmission occurs in the absence of a decrease in membrane resistance are found in the sympathetic ganglia of mammals and amphibians. The slow EPSP generated at muscarinic cholinergic receptors on the ganglion cell membrane occurs either with no change in resistance (rabbit, frog) (Kobayashi and Libet, 1968; Nishi et al., 1969) or in conjunction with an increased resistance (frog) (Weight and Votava, 1970). The slow IPSP in sympathetic ganglion cells from mammals evoked by synaptically released catecholamines is also generated without any change in membrane resistance (Kobayashi and Libet, 1968, 1970).

Much of the evidence implicating cyclic nucleotides in synaptic transmission is derived from experiments on sympathetic ganglia, and an account of the mechanisms underlying the generation of slow ganglionic EPSP's and IPSP's is therefore particularly relevant. The slow EPSP of frog ganglion cells, in contrast to the fast EPSP which precedes it, is increased by depolarization, decreased by hyperpolarization, and reverses into a hyperpolarization at a membrane potential close to the potassium equilibrium potential (Weight and Votava, 1970; but, see Kobayashi and Libet, 1974). It was postulated that the potential is gen- erated by a decrease in the resting potassium conductance of the membrane. Metabolic inhibitors such as 2,4-dinitrophenol and sodium azide appear to have a selective inhibitory action on the slow EPSP (Kobayashi and Libet, 1968), suggesting that activation of metabolic pathways in the postsynaptic neuron may be involved in its generation.

The behavior of the slow IPSP of sympathetic ganglion cells is not that which would be expected of a potential generated by increased membrane permeability to certain ions. Membrane resistance may either be unchanged (rabbit) (Kobayashi and Libet, 1968) or increased (frog) (Weight and Padjen, 1973a). During depolarization the slow IPSP is depressed, reaching zero at about 20 $\mathrm{mV}$ depolarization. With moderate hyperpolarization the IPSP is increased in size (Nishi and Koketsu. 1968; Libet, 1970).

Libet and his colleagues (Libet and Tosaka, 1968; Libet and Owman, 1974) have proposed that dopamine is the specific synaptic transmitter responsible for generation of the slow IPSP in the rabbit, but there is no general agreement on this point and norepinephrine may serve this function in both the rabbit and other mammalian species (Noon et al., 1975; Lindl and Cramer, 1975; Eranko, 1976). In amphibia the slow inhibitory transmitter is considered to be either acetylcholine (Weight and Padjen, 1973b) or a catecholamine (Libet and Kobayashi, 1974). In both mammals and amphibians, the catecholamines in ganglia which mediate the slow IPSP are present in small chromaffin-like cells possessing the synaptic structures of interneurons (Matthews and Raisman, 1969; Jacobowitz, 1970; Williams et al., 1975; Eranko, 1976; Taxi and Mikulajova, 1976).

Nishi and Koketsu (1968) have proposed that the slow IPSP in frog sympathic ganglia is generated by an electrogenic sodium pump, as ouabain, metabolic inhibitors and low extracellular potassium depress the slow IPSP. Such a pump would actively extrude sodium ions from the 
ganglion cells, creating a net outward current, and thus hyperpolarize them. This interpretation has been disputed by Kobayashi and Libet (1968) on the grounds that ouabain also depressed the fast EPSP, and that depletion of extracellular potassium did not selectively depress the slow IPSP in relation to the EPSP. Weight and Padjen (1973a) have proposed that the slow IPSP in frog sympathetic ganglion cells is generated by a decrease in the resting sodium conductance, a mechanism which would account for the reported increase in membrane resistance during the slow inhibitory potential.

Other examples of slow synaptic transmission systems have been observed in the cerebellar cortex and hippocampus. Fibers from the nucleus locus coeruleus hyperpolarize both Purkinje cells and hippocampal pyramidal cells by a mechanism which is associated with an increase in membrane resistance (Hoffer et al., 1973; Segal and Bloom, 1974; Oliver and Segal, 1974). The ionic mechanism underlying these hyperpolarizations, or those evoked by norepinephrine, has still to be determined. The actions of norepinephrine on neurons in the brain will be discussed in more detail in section $\mathrm{E}$.

\section{(3) Presynaptic Inhibition}

The potential importance of presynaptic actions of transmitter agents is becoming increasingly evident to neuropharmacologists. As originally postulated by Eccles (1963) for the cat spinal cord, presynaptic inhibition was effected by a reduction in the amount of transmitter released from a presynaptic nerve terminal during its invasion by an action potential, when the terminal had itself been depolarized by a transmitter released from another nerve terminal. Although depolarization makes the affected terminals more excitable, it also reduces the amplitude of action potentials invading them by an amount at least equal to the amount of the depolarization. Additionally, because the membrane permeability change which causes the depolarization may involve chloride and potassium ions as well as sodium, there is a tendency for the action potential to be reduced as a result of compensatory movements of these ions, which attempt to keep the membrane potential near their own equilibria potentials. The net result of both effects is to reduce the amplitude of the presynaptic action potential and thus the amount of transmitter released (Schmidt, 1971). Presynaptic inhibition of this type is blocked by picrotoxin and bicuculline, antagonists of the monocarboxylic amino acid, $\gamma$-aminobutyric acid (GABA). GABA depolarizes nerve terminals and is therefore a likely candidate for the role of a presynaptic inhibitory transmitter.

Somewhat different inhibitory presynaptic actions may be associated with other putative transmitter agents. Extrinsic acetylcholine $(A C h)$ significantly reduces $\mathrm{ACh}$ release from motor nerve terminals in skeletal muscle and at the same time increases terminal excitability (Ciani and Edwards, 1963; Hubbard et al., 1965). Similar effects have been observed in sympathetic ganglia (Nishi, 1970; Ginsborg, 1971). In both muscle and ganglia the presynaptic $\mathrm{ACh}$ receptors are nicotinic. In the central nervous system ACh may also have an inhibitory action on its own release (Szerb and Somogyi, 1973) and on that of dopamine and norepinephrine (Reader et al., 1976) from the cerebral cortex. In this instance, the receptors are muscarinic in type.

Catecholamines act presynaptically in increasing $\mathrm{ACh}$ release at skeletal neuromuscular junctions (Krnjevic and Miledi, 1958; Jenkinson et al., 1968; Goldberg and Singer, 1969) but depress ACh release from preganglionic nerve terminals in sympathetic ganglia (Weir and McLennan, 1963; Christ and Nishi, 1971; Dun and Nishi, 1974). Nishi and his colleagues believe that the primary action of catecholamines on sympathetic ganglia is to decrease $\mathrm{ACh}$ output from presynaptic nerve terminals and that their post-synaptic action, a weak hyperpolarization, plays a secondary role in the depression of ganglionic transmission.
II. IDENTIFICATION OF SYNAPTIC TRANSMITTERS

The problem of transmitter identification at a given synaptic junction is a complex one and the criteria which have been developed have been discussed in detail elsewhere (Werman, 1966; McLennan, 1970; Phillis, 1970). Factors that must be considered include: (1) that the substance should be present in the appropriate nerve endings together with the enzymes for its synthesis; (2) evidence for release of the substance by impulses in the appropriate nerve fibers; and (3) demonstration of a postsynaptic action that is identical to that of the endogenously released transmitter, including selective antagonism by compounds acting at the postsynaptic receptor. These criteria were developed for peripherally innervated junctions and are rather more difficult to apply at the complex junctions in the central nervous system. In practice, neuropharmacologists have relied heavily on histochemical techniques for the localization of fiber tracts containing particular putative transmitters or the enzymes involved in their synthesis. Evidence on the release of transmitters in the CNS would be most meaningful if it were possible to detect and measure the release evoked at the appropriate nerve terminals by a controlled, brief stimulus applied to a homogenous group of nerve cells of fibers. This has not yet been achieved and with the techniques currently employed the transmitter is usually collected at some distance from the site of release and a relatively lengthy period of stimulation may be required to obtain detectable levels of the transmitter.

Due to the difficulties associated with intracellular recording from central neurons it is often difficult to establish that the candidate transmitter substance has an identical action on membrane potential and conductance to that of the endogenously released transmitter. In practice pharmacological tests, in which the candidate substance can be shown to be affected in an identical manner to the synaptically released transmitter by the appropriate antagonists or 
potentiators, are often employed to satisfy the criterion of identity of action. Although it has been assumed that only one transmitter is released at a given junction, it is becoming increasingly possible to envisage nerve terminals which release two or more substances having significantly different actions (Burnstock, 1976), in which case the criterion of identity of action could not easily be applied. Similar difficulties may arise when putative transmitter substances activate more than one set of receptors on the neuron. For instance, there is now evidence that $\mathrm{ACh}$ may have both excitant and depressant effects on corticospinal neurons, both of which are antagonized by the muscarinic blocker, atropine (Bevan et al., 1975).

Substances which are presently considered to be potential neurotransmitters in the central nervous system include the mono- and dicarboxylic amino acids (glycine, GABA, aspartate and glutamate), acetylcholine, dopamine (DA), norepinephrine (NE), epinephrine, serotonin (5-HT), histamine, substance $P$, adenosine and adenine nucleotides. The effects of these agents on brain levels of cAMP and cGMP will be assessed in the next section.

\section{METABOLISM AND FUNCTIONAL CHARACTER- ISTICS OF CYCLIC NUCLEOTIDES}

\section{COMPONENTS OF THE CYCLIC NUCLEOTIDE SYSTEM}

The nucleotides, cAMP and cGMP, are formed from intracellular ATP and GTP respectively, by the action of cyclase enzymes (adenylate cyclase or guanylate cyclase). These cyclases are activated when the hormone or neurotransmitter attaches to its receptor on the cell membrane, thus raising the intracellular level of the cyclic nucleotide. The diverse biological effects of the nucleotides are manifested through activation of a family of enzymes known as protein kinases which can phosphorylate other enzymes or structural proteins in the cell mem- brane or within the cell and thus evoke the appropriate physiological response. The cyclic nucleotides are degraded by specific 3', 5'-phosphodiesterases to their respective 5'-monophosphates. Termination of the physiological effects initiated by the cyclic nucleotides may occur by concurrent activation of phosphoprotein phosphatases which hydrolyze phosphorylated proteins, thus restoring them to their original inactive state.

\section{(1) Adenylate Cyclase}

This enzyme catalyzes the reactions in which ATP, in the presence of $\mathrm{Mg}^{++}$, is converted to cAMP and pyrophosphate (Rall and Sutherland, 1962; Sutherland et al., 1962; Drummond and Ma, 1975). Brain contains high levels of adenylate cyclases, associated with plasma membranes (Perkins, 1973; Burkard, 1975). Levels are higher in gray than in white matter and vary considerably in different areas of the brain; the overall activity being high in the cerebral cortex and cerebellum (Klainer et al., 1962; Weiss and Costa, 1968; Ebadi et al., 1971; Schmidt et al., 1971; Steiner et al., 1972; Wellmann and Schwabe, 1973). The enzyme is present in both neuronal and glial-enriched fractions from rat and rabbit brain (Palmer, 1973) and in cultured neuroblastoma and glioma cells (Chlapowski et al., 1975). In brain homogenates, high levels of both cAMP and adenylate cyclase have been reported in fractions enriched with nerve terminal membranes (De Robertis et al., 1967; Johnson et al., 1973).

The activity of adenylate cyclase in brain homogenates is enhanced by magnesium or manganese ions: calcium ions may have either stimulant or depressant actions. Sodium fluoride has a stimulant action on the enzyme in cell free preparations but not in whole cells (Bradham et al., 1970; Perkins and Moore, 1971; Perkins, 1973; Von Hungen and Roberts, 1974). 5'-guanylimidodiphosphate, an analogue of GTP which stimulates adenylate cyclase in many peripheral tissues, also stimulates adenylate cyclase in monkey cerebral cortex (Ahn et al.,
1976). Adenylate cyclase must therefore contain sites for a divalent metal and GTP as well as sites capable of binding with its substrate ATP (Rodbell et al., 1975). The mechanism by which sodium fluoride is able to stimulate the enzyme is still uncertain.

Cell free preparations of adenylate cyclase from brain tissue usually respond minimally to neurotransmitters (Rall and Sattin, 1970; Von Hungen and Roberts, 1974; Daly, 1975; but see Chasin et al., 1974) and slices of brain tissue have therefore been utilized in most studies on receptor-mediated regulation of cyclic AMP levels.

\section{(2) Guanylate Cyclase}

Guanylate cyclase and cyclic GMP are present in brain and sympathetic ganglia, although their levels are usually one order of magnitude lower than those of adenylate cyclase and cyclic AMP (Goldberg et al., 1970; Goldberg et al., 1973; Hardman and Sutherland, 1969; Steiner et al., 1972; Kuo et al.. 1972; Ferrendelli et al., 1970; Ferrendelli et al., 1972; Ferrendelli et al., 1973). Cyclic GMP levels are particularly high in the cerebellum, where in some rodents the amounts are nearly as high as those of cyclic AMP. A major portion of guanylate cyclase in brain homogenates appears to be membrane bound (Sulakhe et al., 1976), although activity is also present in the cell cytoplasm. Manganese seems to be absolutely required for brain guanylate cyclase basal activity (Nakazawa and Sano, 1974), and in the presence of low levels of $\mathrm{Mn}^{++}, \mathrm{Ca}^{++}$has a stimulant action on the enzyme. Fluoride ions do not alter basal activity.

\section{(3) Protein Kinases}

Cyclic AMP-dependent protein kinases in brain homogenates are found in both soluble and particulate fractions, including those enriched with synaptosomes (Miyamoto et al., 1969a and 1969b; Miyamoto et al., 1971). These kinases catalyze the phosphorylation of serine residues in a variety of protein substrates including histones, glycogen synthetase, synaptosomes and microtubules (Goldberg and O'Toole, 
1969; Kuo and Greengard, 1969a, b, 1970a, b; Miyamoto et al., 1969a, b; Goldberg et al., 1970; Johnson et al., 1971; Maeno et al., 1971; Schmidt and Sokoloff, 1973; Weller and Rodnight, 1973). Phosphorylation of two species of synaptic membrane protein (Protein I and Protein II) was greatly increased by cyclic AMP (Johnson et al., 1973; Ueda et al., 1973). The cyclic AMP-activated protein kinases require $\mathrm{Mg}^{++}$or $\mathrm{Mn}^{++}$and are inhibited by $\mathrm{Ca}^{++}$. Cyclic GMP activates these kinases only at high concentrations.

Cyclic GMP-activated protein kinases appear to be present in brain preparations and catalyze the phosphorylation of histones (Kuo and Greengard, 1973; Kuo, 1974). These kinases require $\mathrm{Mg}^{++}$for activity and are inhibited by $\mathrm{Ca}^{++}$. Cyclic AMP-dependent protein kinases have been described in neuroblastoma (Greengard and Kuo, 1970) and glioma cells (Perkins et al., 1971; Opler and Makman, 1973). As in other tissues, cyclic nucleotideactivated kinases from brain are dissociable into regulatory units which bind cyclic AMP and the functional catalytic units (Inoue et al., 1973). The relatively inactive complex of regulatory and catalytic units is dissociated and thereby activated in the presence of cyclic AMP.

(4) Phosphodiesterase

3', 5'-Phosphodiesterases are the enzymes which catabolize cyclic nucleotides by splitting the 3' leg of the cyclic phosphate bond yielding the 5'-purinoside monophosphate (Appleman et al., 1973; Amer and Kreighbaum, 1975; Kakiuchi et al., 1975). Levels of cyclic AMP phosphodiesterases fluctuate considerably between different brain regions and between species (Weiss and Costa, 1968; Breckenridge and Johnston, 1969; Dalton et al., 1974). Phosphodiesterases have been found in both soluble and particulate fractions from brain homogenates (De Robertis et al., 1967) and they are present in homogenates from cultured neuroblastoma and glioma cells (Weiss, 1975; Schwartz et al., 1973; Uzunov et al., 1973). Histochemical studies have shown that phosphodiesterase in rat cortical slices is localized at postsynaptic membranes on dendritic processes (Florendo et al., 1971), and in glial cells (Shanta et al., 1966).

The total phosphodiesterase activity in brain is a result of a variety of different enzymes which vary in their properties with regard to substrate specificity and affinity, electrophoretic mobility and sensitivity to cations (Kakiuchi et al., 1975; Amer and Kreighbaum, 1975). At least two major forms of the enzyme, one with a high affinity for cyclic AMP and another with low affinity, occur in most regions of the brain. These two enzymes follow different patterns of development in the rat (Weiss and Strada, 1972). Certain phosphodiesterases will catabolize both cyclic nucleotides, although they may show some specificity for one or the other substrate, and the rate of catabolism is often influenced by the level of the other cyclic nucleotide.

Phosphodiesterase activity in the soluble fraction of brain homogenates is stimulated by low concentrations of $\mathrm{Ca}^{++}$in the presence of a protein activator. In contrast to particulate phosphodiesterases, which apparently hydrolyze cyclic AMP at a higher rate than cyclic GMP, the soluble enzymes have a higher affinity for cyclic GMP than for cyclic AMP. $\mathrm{Ca}^{++}$release into the cytoplasm may therefore be an important factor in the regulation of cyclic GMP levels (Appleman and Terasaki, 1975; Kakiuchi et al., 1975).

Brain phosphodiesterases are inhibited by a variety of compounds, including methylxanthines such as theophylline, theobromine and caffeine, imidazole, papaverine, dipyridamole, chlordiazepoxide, dia-; zepam, tricyclic antidepressants, chlorpromazine and other phenothiazines, phentolamine, adenosine, RO 20-1724 (4-[3-butoxy-4-methoxy] 2-imidazolidinone) and SQ 20,009 (1-ethyl-4-isopropylidene hydrazino) (1H-pyrazolo [3,4- $\beta]$ pyridine-5carboxylate, ethylester) (Weiss, 1973; Amer and Kreighbaum, 1975; Daly, 1975). The existence of mul- tiple forms of phosphodiesterase in the brain with potentially variable drug sensitivities will make it essential that a better understanding of the pharmacology of the individual isoenzymes be obtained before the effects of inhibitors on functional systems can be assessed in a meaningful manner.

(5) Phosphoprotein Phosphatases

If the phosphorylation of membrane proteins is an essential event in synaptic transmission, enzymes (phosphatases) should be present to restore the protein molecule to its original state at the termination of the synaptic event. Phosphoprotein phosphatases have been found in the rat cerebral cortex (Maeno and Greengard, 1972; Ueda et al., 1973; Maeno et al., 1975) and are concentrated in the synaptic membranecontaining subfractions.

\section{CRITERIA FOR ACCEPTANCE OF CYCLIC NUCLEOTIDES AS SECOND MESSENGERS}

The criteria by which the synaptic transmitter at a given junction can be identified were discussed in Section B. Sutherland and his colleagues (Sutherland et al., 1968; Robison et al., 1971) established a series of four criteria which must be satisfied before a cyclic nucleotide can be accepted as the mediator of hormonal action. These criteria have been adapted for use at synaptic junctions.

First, cyclic nucleotide levels in the postsynaptic cell should respond appropriately to stimulation of the afferent pathway or to the transmitter substance. (2) The change in cyclic nucleotide levels should precede the physiological response. (3) The effects of activation of the synaptic pathway or of application of the transmitter should be potentiated by agents which inhibit phosphodiesterase activity. (4) It may be possible in some instances to mimic the effects of synaptic activation by the addition of exogenous cyclic AMP or GMP. A further criterion proposed by Kuo and Greengard (1969a, b; see Bloom, 1975) is that activation of a phosphotransferase reaction will be the major mechanism by 
which cyclic nucleotides express their effects.

In practice, the first two criteria are difficult to satisfy since the methods employed for measuring cyclic nucleotides are usually applied to tissues containing large numbers of cells and are not sufficiently rapid to detect changes occurring within the latencies of onset of synaptic potentials. Immunofluorescent assays of cyclic AMP and cyclic GMP which enable semiquantitative measurements of cyclic nucleotide formation in individual nerve cells to be made should offer some prospect of satisfying the demands of these criteria (Bloom et al., 1972; Kebabian et al., 1975). The third criterion - potentiation of the effects of the synaptic pathway by phosphodiesterase inhibitors - has been extensively employed in studies on the cyclic nucleotides, but it too is not without its hazards. Many of the agents which are currently used as phosphodiesterase inhibitors have other potent actions which may be responsible for the effects observed. The methylxanthines, caffeine and theophylline, cause $\mathrm{Ca}^{++}$release from the sarcoplasmic reticulum of muscle and possibly from the plasma membrane (Isaacson and Sandow, 1967; Johnson and Inesi, 1969; Blinks et al., 1972; Berridge, 1975). Effects of these agents may result from increases in intracellular calcium levels rather than elevation of cyclic AMP levels. Theophylline and caffeine also block an extracellularly located adenosine receptor (Huang and Daly, 1974). Papaverine, another extensively utilized phosphodiesterase inhibitor, prevents the uptake of adenosine, and may interfere with cell excitability by potentiating the actions of adenosine, either released from adjacent tissues or formed from exogenously applied cyclic AMP. Interpretation of the effects of exogenously applied cyclic nucleotides may also be difficult. Cyclic nucleotides do not readily cross cell membranes and, when applied to the exterior of the cell, are exposed to the action of phosphodiesterases which may catabolize them to 5 '-nucleotides. Even when these dif- ficulties are circumvented by the use of synthetic nucleotides, which are more lipid soluble and resistant to phosphodiesterase action (Simon et al., 1973; Miller et al., 1973), there is the problem of uncontrolled access of the nucleotides to multiple active sites within the cell. Indeed, Borle (1974) has shown that cyclic AMP can stimulate $\mathrm{Ca}^{++}$release from mitochondria in a variety of tissues and extracellularly applied cyclic AMP or an analog could thus affect cell excitability through a $\mathrm{Ca}^{++}$dependent mechanism quite independently of any transmitter-related actions.

In summary, it can be stated that complete satisfaction of the criteria is extremely difficult and that even the satisfaction of criteria (3) and (4) is fraught with hazards. The presence of cyclic AMP in almost every cell has led to the now widely accepted view that this compound must have a universal role as a second messenger. It is difficult to avoid the conclusion that in their enthusiasm to accept this view, many investigators have not displayed a sufficiently cautious approach to the interpretation of their data. There can be little doubt that many agents which affect nerve cell excitability also alter their cyclic nucleotide levels. The question that must be asked is "Do these alterations in cyclic nucleotide levels cause (or mediate) the electrophysiological effects of the applied agent or do there merely occur in parallel with, or as a result of, the electrophysiological effects?" The role of calcium ions as second messengers has been largely overlooked as investigators concentrated on the cyclic nucleotides. In subsequent sections attention will be focussed on the potential role of this ion as a mediator of the effects of neurotransmitters, and on the possibility of a cooperative interaction between $\mathrm{Ca}^{+-}$and the cyclic nucleotides (Rasmussen, 1970; Rasmussen et al., 1972; Borle, 1973; Berridge, 1975).

\section{FORMATION OF CYCLIC NUCLEOTIDES IN THE CNS}

\section{PREPARATIONS USED FOR} STUDIES ON CYCLIC NUCLEOTIDES

Cyclic nucleotide levels have been studied in intact brain, brain slices, brain homogenates and in cultured neuronal and glial cell lines.

\section{(1) Investigations in vivo}

Cyclic AMP levels in intact brain tissue rise rapidly after decapitation (Breckenridge, 1964; Kakiuchi and Rall, 1968a), and rapid fixation by microwave irradiation (Schmidt et al., 1971) or freeze-blowing (Lust et al., 1973) is required. Cyclic GMP levels in intact brain do not undergo such marked changes on decapitation (Goldberg et al., 1970; Steiner et al., 1972). The factors involved in post-decapitation increases in cyclic AMP levels in brain are not as yet firmly established, but it is probable that anoxia leads to an accumulation of adenosine, which then stimulates the formation of cyclic AMP (Berne et al., 1974).

Several investigators have reported on the alterations in cyclic nucleotide levels in brain in the presence of agents, including catecholamines and D-lysergic acid diethylamide, which affect the central nervous system excitability (Chou et al., 1971; Burkard, 1972; Uzunov and Weiss, 1972; Opmeer et al., 1976).

However, the difficulties associated with post-decapitation increases in cyclic AMP referred to above have hindered the interpretation and comparison of data obtained from studies on intact brain and from experiments on brain slice preparations, the experimental preparation favored by most investigators.

\section{(2) Brain Slice Preparations}

The ability of certain putative neurotransmitters to enhance cyclic AMP, and to a lesser extent cyclic GMP, levels in brain slices has been documented by a number of investigators. Cyclic nucleotide accumulation has been measured either by direct assay or by determination of the extent of radioactive cyclic nucleotide formation from labelled pre- 
cursors such as adenine or adenosine. Adenine or adenosine are incorporated into intracellular nucleotides by the action of adenine phosphoribosyltransferase or adenosine kinase respectively.

Brain slices from different regions of the brain and a variety of species have been investigated, and this preparation has undoubtedly provided a valuable indication of the factors involved in the regulation of brain nucleotide levels.

\section{(3) Cells from Neuronal or Glial Cul-} tures

The brain slice contains multiple cell types and investigations utilizing this preparation have yielded results which are difficult to ascribe to any one particular cell type. For this reason, the use of cell cultures has become an attractive alternative. Cultures have been prepared from reaggregated systems derived from fetal mouse or rat brain, although these probably still contain relatively normal proportions of neurons and glia (Seeds, 1971). Results obtained from pure neuronal and glial cell cultures must be interpreted with some caution since the tumor cell lines from which these are derived may show greatly altered enzyme levels or responsiveness to neurotransmitters compared to that of the parent tumor cell or normal cells. For example, clones of glioma cells often lose their responsiveness to various agents with time (Perkins, 1973). The age of the culture may be significant for other reasons. Cell cultures from fetal or embryonic brain may be relatively refractory during the early period of their reaggregation to agents which elevate cyclic AMP levels in mature brain preparations. For instance, embryonic mouse brain cells do not respond to norepinephrine with an increase in cyclic AMP at 15 hours when aggregation was essentially complete, though the response is manifest at 9 days (Schmidt et al., 1970). These results are reminiscent of the finding that norepinephrine does not stimulate cyclic AMP formation in rat brain slices from animals under 4 days of age.

At certain times during culture glioma cell lines respond to norepinephrine with remarkable increases in cyclic AMP formation. In one study with rat glioma cells, the maximal responses to norepinephrine were not observed until many days after the cells had become confluent (Schwartz et al., 1973), while in another study with human glioma cells the maximal responses to norepinephrine were attained before the cells had formed a confluent mono-layer, and declined after further culture (Clark and Perkins, 1971).

(4) Cell-free Preparations of Adenylate Cyclase

Klainer et al. (1962), in one of the early reports on brain adenylate cyclase, stated that activity in brain cell-free preparations could be stimulated by various catecholamines. Stimulation was most often observed in cerebellar preparations, but was variable and inconsistent. Until recently, attempts to reproduce these findings were largely unsuccessful, and it is apparent that the adenylate cyclase system in brain tissue is especially prone to loss of sensitivity to neurotransmitters as a result of tissue disruption. However, methods of brain homogenization that yield vesicular preparations which retain receptor-modulated adenylate cyclases have been reported (Chasin et al., 1974; Von Hungen et al., 1974).

Cell-free preparations differ from those containing intact nerve cells in that fluoride ions activate adenylate cyclase in the former, although they have no effect on intact cells (Perkins, 1973). Fluoride may act at the catalytic site of the enzyme, causing stabilization as well as activation of adenylate cyclase activity (Swislocki and Tierney, 1973).

\section{NEUROTRANSMITTERS AFFECTING CYCLIC NUCLEOTIDE FORMATION}

The mass of information on transmitter-stimulation of cyclic nucleotide formation in brain slices has recently been reviewed by Daly $(1975,1976)$ and presented in tabular form by Bloom (1975). It is difficult to make generalizations across species or for different areas of the brain: Each tissue appears to have its own pattern of responsiveness. The experiments on cyclic AMP formation have yielded valuable information about the nature of the neurotransmitter receptors in brain slices and have provided specific agonists and antagonists which have been used to elucidate the role of the corresponding cyclic AMP-systems in the intact brain. A limitation of the studies on brain slices is that unless they are combined with prior destruction of selected pathways, they do not yield a clear understanding of whether the transmitter-activated cyclases are located in pre- or postsynaptic structures or even in glial cells. These experiments therefore serve only to establish the existence of receptor-coupled cyclases; they define neither the site nor the nature of any physiological responses which result in or from the accumulation of cyclic AMP. Neurochemists have been tempted to conclude that cyclic AMP plays a pivotal role in the generation of the inhibitory responses to catecholamines, serotonin and histamine, throughout the central nervous system. This conclusion is based, however, on satisfaction of but the first of the criteria outlined in section $\mathrm{C}$, namely that the transmitter can influence the formation of cyclic AMP. Further critical investigations will be required to establish the conclusion's general validity.

\section{(1) Norepinephrine}

Norepinephrine causes an accumulation of cyclic AMP in all the areas of the brain on which it has been tested, including cerebral cortex, cerebellum, limbic system, hypothalamus and caudate nucleus. The observed increases in basal adenylate cyclase activity range from just detectable to up to 20 fold in the guinea pig cerebellum. Pharmacological investigations have revealed that the adrenergic receptors in brain do not fit the classical definitions of peripheral $\alpha$ - and $\beta$-receptors, since in most regions of the brain both alpha and beta blockers are partial antagonists. The extent of activation of cyclic AMP generating systems by $\alpha$ - or 
$\beta$-receptor interactions appears to differ markedly in the same brain area of different species and, in addition, varies greatly in different brain regions of the same species. Cerebral cortical responses to norepinephrine range from nearly pure $\alpha$-adrenergic in the guinea pig (Huang et al., 1971), to a mixture of $\alpha$ - and $\beta$-adrenergic in the rat (Huang et al., 1973; Perkins and Moore, 1973) to nearly pure $\beta$-adrenergic in mouse and man (Schultz and Daly, 1973a; Shimizu et al., 1971). The $\beta$-agonist, isoproterenol, has only one half the maximal effect seen with norepinephrine in rat cortical slices, and its effects are completely blocked by $\beta$-antagonists but unaffected by $\alpha$-antagonists. In cerebellar slices from rat, guinea pig or rabbit, the responses to norepinephrine are completely blocked by $\beta$-antagonists, while $\alpha$-antagonists are ineffective (Skolnick et al., 1976; Chasin et al., 1971; Kakiuchi and Rall, 1968b). Neuroleptics such as fluphenazine reduced the response of rat cerebellar cortex to norepinephrine by $50-60$ percent (Hoffer et al., 1976). Norepinephrine may also activate dopaminesensitive adenylate cyclases such as those present in slices of caudate nucleus (Forn et al., 1974).

Studies on cultured cells of neuronal or glial origin have shown that norepinephrine and dopamine can markedly stimulate the accumulation of cyclic AMP in some neuroblastoma clones (Prasad et al., 1974; Sahu and Prasad, 1975; Schubert et al., 1976). Norepinephrine also elicits cyclic AMP and cyclic GMP formation in various glioma cell lines (Perkins, 1973; Daly, 1975; Schwartz, 1976; Schubert et al., 1976).

Immunocytochemical studies on the rat cerebellar cortex have shown that topically applied norepinephrine or stimulation of norepinephrine-containing afferents from the locus coeruleus cause a striking increase in cyclic AMP levels in the postsynaptic neurons, the Purkinje cells (Siggins et al., 1973). There is less information regarding the effects of norepinephrine on adenylate cyclase in presynaptic terminals (Von Hungen and Roberts, 1974). It is of some interest therefore that the existence of adenylate cyclase-coupled $\alpha$-receptors on norepineprhine-containing nerve terminals has been proposed (Dismukes and Mulder, 1976). Activation of these receptors markedly reduces norepinephrine release from rat brain slices.

Norepinephrine stimulates both cyclic AMP and cyclic GMP formation in mouse cerebellar slices at concentrations as low as $1 \mu \mathrm{M}$ (Ferrendelli et al., 1975). The accumulation of cyclic GMP, but not of cyclic AMP, is blocked by omission of $\mathrm{Ca}^{++}$from the incubation medium. The receptor sites mediating the cyclic nucleotide accumulation appear to have both $\alpha$ - and $\beta$-adrenergic sensitivities.

\section{(2) Dopamine}

Dopamine-sensitive adenylate cyclases have been reported in homogenates or slices from the caudate nucleus, nucleus accumbens and olfactory tubercle (ClementCormier et al., 1974; ClementCormier et al., 1975; Horn et al., 1974; Iversen, 1975), and cerebral cortex (Dismukes and Daly, 1974; Nahorski and Rogers, 1976; Ahn et al., 1976).

High ( $1 \mathrm{mM})$ concentrations of dopamine elevate cyclic AMP and depress cyclic GMP levels in mouse cerebellar slices (Ferrendelli et al., 1975). Dopamine-stimulated adenylate cyclases are present in various neuroblastoma cell lines (Sahu and Prasad, 1975).

Systemically administered apomorphine, a direct dopaminergic agonist, elevates cyclic GMP levels in rat and mouse cerebella (Burkard et al., 1976; Gumulka et al., 1976). Muscarinic antagonists block this effect in rats but not in mice, implying the existence of a cholinergic link in the rat.

\section{(3) Serotonin}

Serotonin elicits small accumulations of cyclic AMP in rabbit cerebral cortical and cerebellar slices (Kakiuchi and Rall, 1968a, 1968b). In guinea pig and rat cerebral cortex its effects are minimal except in the presence of adenosine and a phos- phodiesterase inhibitor (Schultz and Daly, 1973b; Dismukes and Daly, 1974; Daly, 1975). Serotonin elicits a significant 2-fold increase in cyclic AMP levels in the squirrel monkey polysensory cortex, an area containing multiple serotonergic nerve endings (Skolnick et al., 1973). Cell free preparations from the superior and inferior colliculus of very young rats contain adenylate cyclase systems which are highly responsive to serotonin. The response diminishes with age and is relatively insignificant in collicular preparations of adult rats (Von Hungen et al., 1975).

\section{(4) Histamine}

Histamine-sensitive cyclic AMP generating systems have been reported in slices from a variety of species and brain regions, including the cerebral cortex, cerebellum, hippocampus and thalamus (Daly, 1975; Hegstrand et al., 1976). The responses appear to be mediated through both $\mathrm{H}_{1}$ and $\mathrm{H}_{2}$ receptors although the relative importance of the two receptor types may vary. For instance, in the guinea pig cerebral cortex the responses are mediated through an interaction with both $\mathrm{H}_{1}$ and $\mathrm{H}_{2}$ receptors (Baudry et al., 1975; Dismukes et al., 1976), while in the rat and chicken cortex $\mathrm{H}_{2}$ receptors predominate (Dismukes et al., 1975; Nahorski et al., 1974).

Histamine elicits cyclic AMP accumulations in certain glioma cell lines (Clark and Perkins, 1971). Cyclic AMP levels in neuroblastoma cells are unaffected by histamine, even in the presence of phosphodiesterase inhibitors (Gilman and Nirenberg, 1971; Schultz and Hamprecht, 1973; Prasad et al., 1974).

\section{(5) Adenosine}

Adenosine elicits an accumulation of cyclic AMP in slices from all brain regions and virtually all species evaluated (Rall and Sattin, 1970; Sattin and Rall, 1970; Daly, 1975, 1976). Adenosine's action is shared by the adenine nucleotides such as 5'-AMP, ADP, ATP and cyclic AMP (Sattin and Rall, 1970; Rall and Sattin, 1970), which are thought to undergo extracellular hydrolysis to adenosine in order to exert their effects. The stimulatory effects of 
ATP and cyclic AMP on adenylate cyclase are nearly completely blocked by adenosine deaminase. As ATP and cyclic AMP are not substrates for this enzyme it is evident that prior hydrolysis to adenosine is necessary before they can activate the cyclic AMP generating system (Mah and Daly, 1976). The observation that adenosine can elicit an accumulation of cyclic AMP from pre-labelled stores of intracellular ATP provides evidence that adenosine stimulates adenylate cyclase by activation of an adenosine receptor (Daly, 1975), rather than acting as a precursor for substrate ATP. This concept of an adenylate cyclase-coupled adenosine receptor is strengthened by the finding that certain analogs of adenosine, such as 2-chloro-adenosine, stimulate accumulation of cyclic AMP but do not serve as precursors for the cyclic nucleotide thus formed (Sturgill et al., 1975). Fairly conclusive evidence for the extracellular location of the receptor was obtained in studies with compounds which inhibit adenosine uptake into tissue, including dipyridamole, hexobendine, papaverine and $p$-nitrophenylthioguanosine. These agents enhance the response to low concentrations of adenosine, while concomittantly inhibiting the incorporation of adenosine into the tissue by 70 - 90 percent (Huang and Daly, 1974). One striking property of the adenosine receptors is that they are competitively blocked by the methylxanthine phosphodiesterase inhibitors, including theophylline, caffeine and 3-isobutyl-l-methylxanthine (Huang et al., 1972; Mah and Daly, 1976).

Adenosine displays a remarkable synergism with various other agents with respect to enhancement of cyclic AMP formation in brain slices. Substances which have synergistic actions with adenosine include the biogenic amines, norepinephrine, serotonin and histamine (Sattin and Rall, 1970; Schultz and Daly, 1973b; Mah and Daly, 1976) glutamate and aspartate (Shimizu et al., 1974) and depolarizing agents such as potassium, veratridine, batrachotoxin and ouabain (Daly, 1975). The effects of the excitant amino acids and depolarizing agents are partially antagonized by theophylline, indicating that adenosine release within the slice is involved (Shimizu et al., 1974; Daly, 1975; Mah and Daly, 1976). Sattin et al. (1975) recently proposed the idea that adenosine and a catecholamine or histamine may act as either dependent or independent co-activators of brain adenylate cyclases.

Adenosine and its analogs act as potent activators of adenylate cyclase in neuroblastoma and glioma cell lines (Clark and Gross, 1974; Blume and Foster, 1975; Daly, 1975; Clark and Seney, 1976; Penit et al., 1976; Green and Stanberry, 1977).

(6) Acetylcholine and substance P

There are relatively few reports on the effects of $\mathrm{ACh}$ or other cholinomimetic agents on cyclic AMP levels in brain slices or other in vitro preparations. An AChsensitive adenylate cyclase has been demonstrated in cultured neuroblastoma cells (Prasad et al., 1974; Sahu and Prasad, 1975). In rabbit cerebral and cerebellar cortical slices, ACh and muscarinic agonists reportedly elicit an increase in cyclic GMP levels (Lee et al., 1972; Kuo et al., 1972; Palmer and Duszynski, 1975). The effects were antagonized by atrophine. However, other investigators, using brain slices from cortex and cerebellum of several species, have been unable to replicate these observations (Kinscherf et al., 1976). Parenterally administered oxotremorine, a muscarinic agonist, causes increases in cyclic GMP in the mouse cerebral cortex and cerebellum, with a concomitant decrease in cyclic AMP levels. Atropine prevents these effects of oxotremorine on cyclic GMP levels (Ferrendelli et al., 1970).

Substance $P$, a polypeptide present in brain, spinal and some primary afferent fibers, excites neurons at several levels of the neural axis, and may be the transmitter released at the central terminals of some dorsal root afferent fibers (Nicoll, 1976; Phillis, 1977). Preliminary reports indicate that substance $P$ activates adenylate cyclase in rat and human brain homogenates (Duffy et al., 1975).

\section{(7) Amino Acids}

Cyclic AMP and cyclic GMP formation in cerebral and cerebellar brain slices is stimulated by the excitant dicarboxylic amino acids, L-glutamic acid and L-aspartic acid (Shimizu et al., 1974; Chasin et al., 1974; Ferrendelli et al., 1974; Kinscherf et al., 1976). The inhibitory monocarboxylic amino acids, GABA and glycine, elicited a small decrease and a small increase respectively in cyclic AMP levels in mouse cerebellar slices, and both agents enhanced cyclic GMP levels in mouse cerebellum, but not in cerebral or cerebellar slices from rabbit, guinea pig, cat or rat (Ferrendelli et al., 1974; Kinscherf et al., 1976). The stimulatory effects of the excitant amino acids on cyclic AMP levels are reduced under $\mathrm{Ca}^{++}$-free conditions or in the presence of the adenosine antagonists, theophylline and 3-isobutyl-l-methylxanthine, suggesting that a depolarization-induced release of adenosine accounts for part of their action (Ferrendelli et al., 1974; Shimizu et al., 1974), Glutamate and the biogenic amines have synergistic effects on the formation of cyclic AMP in guinea pig cortical slices.

The stimulatory effect of the amino acids on cyclic GMP accumulation requires the presence of theophylline (Ferrendelli et al., 1974). Mao et al. (1974a, b) have reported that a relationship may exist between GABA and cyclic GMP in rat cerebellum. Drug treatments in vivo which lowered GABA levels were associated with an increase in cyclic GMP, and intracerebroventricular injections of GABA decreased cerebellar cyclic GMP levels.

\section{(8) Prostaglandins}

Although the role of prostaglandins in intercellular communication in the central nervous system is presently uncertain, a variety of findings suggest that prostaglandins of the E series do play a significant part in central nervous function (Siggins et al., 1971b). Prostaglandins have been reported to have no effect on 
cyclic AMP levels in brain cortical slices and homogenates from a variety of mammals, as well as on norepinephrine-stimulation of cyclic AMP formation (Forn and Krishna, 1971; Palmer et al., 1973; Zanella and Rall, 1973). However in two investigations prostaglandins $\mathrm{E}_{1}$ and $E_{2}$ elicited accumulations of cyclic AMP in rat cortical slices (Berti et al., 1972; Kuehl et al., 1972). In a recent study, prostaglandin $E_{1}$ was found to elicit significant accumulations of cyclic AMP in slices from rat cortex, midbrain and hippocampus (Dismukes and Daly, 1975). Little or no stimulating effect was seen in slices from cerebellum or ponsmedulla. Studies with combinations of prostaglandin $E_{1}$ and norepinephrine suggested that prostaglandin $E_{1}$ antagonized the $\beta$-adrenergic component of the norepinephrine response and at the same time elicited an accumulation of cyclic AMP (Dismukes and Daly, 1975). Prostaglandins $E_{1}$ and $E_{2}$ activate adenylate cyclase in neuroblastoma cell lines (Gilman and Nirenberg, 1971; Hamprecht and Schultz, 1973; Sahu and Prasad, 1974; Penit et al., 1976) and in certain glioma cell lines (Minna and Gilman, 1973; Perkins, 1973).

\section{E. NUCLEOTIDES AND TRANS- MISSION AT SELECTED SYNAPSES}

Support for a function of the cyclic nucleotides in synaptic transmission has come from studies on the distribution of the enzymes and proteins involved in the formation, degradation and function of cyclic AMP and cyclic GMP. The enzymatic machinery associated with the metabolism of the cyclic nucleotides seems, at least in part, to be associated with the synaptic membrane subfraction of brain homogenates, as are the cyclic nucleotidedependent protein kinases. The theory predicts that certain membrane proteins are phosphorylated by cyclic nucleotide-stimulated protein kinases and that phosphorylation of these proteins leads to the membrane permeability changes causing the postsynaptic excitatory or inhibitory potentials. According to this theoretical train of events cyclic nucleotide levels would be restored to normal by the action of phosphodiesterases and the membrane potential would be restored to resting levels by the dephosphorylation of the membrane proteins and return of normal resting membrane permeability. It is assumed that these events occur sufficiently rapidly to account for the time course of the postsynaptic potential.

\section{SYMPATHETIC GANGLIA}

Much of the evidence in support of roles for cyclic AMP and cyclic GMP in synaptic transmission has been obtained from studies on the mammalian superior cervical gang]ion. This preparation is particularly suitable for experiments of this nature since it can be isolated and studied under well-controlled conditions using precise electrophysiological techniques for stimulation and recording. Also the tissue can be fixed rapidly by freezing for biochemical analysis. Electrical stimulation of the preganglionic fibers produces an increase in the cyclic AMP and cyclic GMP levels in the ganglion (McAfee et al., 1971; Weight et al., 1974; Greengard and Kebabian, 1974). The muscarinic antagonist, atropine, blocks this increase in the levels of both nucleotides, suggesting that it occurs postsynaptically as the result of activation of muscarinic receptors by $\mathrm{ACh}$ released from the presynaptic nerve terminals. The increase in cyclic AMP and cyclic GMP content can be mimicked by the application of agents capable of activating muscarinic receptors such as carbachol, bethanecol, and in the case of cyclic GMP, acetylcholine (Kalix et al., 1974; Kebabian et al., 1975).

Reference was made in Section B of this paper to the evidence that the slow EPSP and slow IPSP in mammalian sympathetic ganglion cells are mediated by muscarinic and dopaminergic (or noradrenergic) receptors respectively. The evidence suggested that acetylcholine released from the presynaptic nerve terminals evoked the slow EPSP by an action at muscarinic receptors on the postganglionic cell bodies and stimulated dopamine or norepinephrine release from internuncial cells within the ganglion. This catecholamine caused both the slow IPSP and the related increase in cyclic AMP. Immunocytochemical experiments on isolated bovine ganglia have provided further support for the existence of separate nucleotide-linked muscarinic and dopaminergic receptors on the post-ganglionic neurons. Dopamine and norepinephrine increased cyclic AMP but not cyclic GMP levels in slices of these ganglia and the increase was localized to the postganglionic neurons. Acetylcholine increased cyclic GMP but had only a slight effect on cyclic AMP levels in the postganglionic neurons (Kebabian et al., 1975). The absence of the anticipated effect of acetylcholine and bethanecol on cyclic AMP levels in these experiment was attributed to damage to the catecholamine-containing interneurons during the preparation of the tissues.

The responses of bovine superior cervical ganglia to dopamine are inhibited by $\alpha$-antagonists but not by $\beta$-antagonists. $\beta$-Antagonists do, however, reduce the effects of norepinephrine (Kebabian and Greengard, 1971). In contrast, cyclic AMP levels in cultured rat superior cervical ganglion are elevated by norepinephrine and isoproterenol, while even higher concentrations of dopamine or phenylephrine have only marginal effects. The effects of norepinephrine are antagonized by both $\alpha$ - and $\beta$-adrenergic blockers (Cramer et al., 1973). The increases in rat superior cervical ganglion cyclic AMP induced by isoproterenol are lost when the ganglionic cells are destroyed by 6-hydroxydopamine (Otten et al., 1974), indicating that the isoproterenol-sensitive cyclases are located in adrenergic cell bodies. Basal levels of cyclic AMP are only slightly reduced in ganglia from 6-hydroxydopamine treated rats.

Greengard and his colleagues have obtained electrophysiological evidence to support their hypothesis that the effects of acetylcholine and catecholamines are mediated by cyclic GMP and cyclic AMP respec- 
tively, by studying the effects of these agents on synaptic potentials and changes in membrane potential of the rabbit superior cervical ganglion using the sucrose gap technique (McAfee and Greengard, 1972; Greengard, 1976). Preganglionic stimulation of the ganglion resulted in the generation of an initial brief EPSP, followed by a slow IPSP that reached a maximum in $600 \mathrm{msec}$ and then a slow EPSP lasting about 30 sec. Exogenous dopamine $(50 \mu \mathrm{m})$ hyperpolarized the postganglionic neurons; an effect which was potentiated by theophylline. Theophylline also increased the amplitude of the slow IPSP. Prostaglandin $\mathrm{E}_{1}\left(\mathrm{PGE}_{1}\right)$, which is considered to inhibit adenylate cyclase, virtually abolished the slow IPSP and reduced the slow EPSP, but had little effect on the fast EPSP. At a concentration of 0.1 $\mu$ M PGE, also abolished or reduced the dopamine-evoked hyperpolarizations. Monobutyryl cyclic AMP ( 1 to $2.5 \mathrm{mM}$ ) hyperpolarized the ganglia; similar results were obtained with cyclic AMP and dibutyryl cyclic AMP, but not with 5'AMP, adenosine or butyric acid, which were inactive. Dibutyryl cyclic GMP (25-250 $\mu \mathrm{M})$ caused a transient hyperpolarization followed by a depolarization in each of the preparations tested. Cyclic GMP itself, however, was inactive.

The findings of these studies support the concept of a role of cyclic AMP and cyclic GMP in ganglionic transmission. The evidence indicates that cyclic GMP is involved in the generation of the slow EPSP and cyclic AMP is involved in the generation of the hyperpolarizing response to dopamine. Cyclic GMP and cyclic AMP thus appear to function in opposite directions, one enhancing and the other depressing neuronal excitability in the ganglion.

Unfortunately other investigators have not been able to reproduce these effects of the cyclic nucleotides on sympathetic ganglion cells, using either sucrose gap or intracellular recording techniques. Intracellular recordings from the paravertebral sympathetic ganglia of the bullfrog (Rana catesbiana) have failed to reveal any hyperpolarizing actions of 1-2 mM dibutyryl cyclic AMP on the resting potential or on action potentials (Kuba and Nishi, 1976). Similar results were obtained with sucrose gap techniques by Akasu and Koketsu (1977). Dun and Karczmar (1977) have compared the effects of theophylline and cyclic AMP on the superior cervical ganglion of the rabbit with the sucrose gap method. Neither cyclic AMP nor dibutyryl cyclic AMP, in concentrations of up to $2.5 \mathrm{mM}$, had any noticeable effect on membrane potential or on the compound action potential elicited by preganglionic stimulation. In curarized preparations cyclic AMP did not affect the positive (P) or late negative (LN) potentials, although the $P$ wave was potentiated by theophylline. These investigators concluded that their findings were inconsistent with the hypothesis of a cyclic AMP-related mechanism in the generation of ganglionic inhibitory potentials and suggested that the effects of theophylline might involve mechanisms other than phosphodiesterase inhibiton. Using more refined techniques, Dun (personal communication) has applied cyclic AMP and dopamine iontophoretically onto ganglion cells and recorded the responses intracellularly. No cyclic AMP-induced hyperpolarizations were detected in cells that were hyperpolarized by dopamine. Similar results have been obtained by Libet, Kobayashi and Tanaka (personal communication) who comment, "Superfusing the rabbit superior cervical ganglion with dibutyryl cyclic AMP or monobutyryl cyclic AMP at 1-2 mM for 6-10 minutes, has rarely elicited any hyperpolarizing response. In the so-called positive instances, the responses were inconsistent and were probably mostly if not entirely an artefact of the sucrose gap technique."

Extracellular applications of dibutyryl cyclic AMP and dibutyryl cyclic GMP had no effect on the intracellularly recorded membrane properties of rat superior cervical ganglion cells, but when cyclic AMP or cyclic GMP were injected intracellularly, both caused a concentration-dependent increase in membrane conductance (ShinnickGallagher et al., 1976). Since the slow IPSP and slow EPSP of ganglion cells are generated in the absence of any decrease in membrane conductance (Section B), even these findings with intracellularly injected nucleotides cannot easily be related to synaptic events.

In studies on parasympathetic ganglia of the urinary bladder of the cat, for which an adrenergic inhibitory mechanism has been described, de Groat and Theobald (1976) observed minimal depression of ganglionic transmission with cyclic AMP or dibutyryl cyclic AMP injections. Non-cyclic nucleotides, in smaller doses, produced considerable depression of ganglionic transmission. These substances also depressed bladder contractions elicited by electrical stimulation of the preganglionic nerves, but did not alter the responses to injected acetylcholine, raising the possibility that they had a presynaptic effect and depressed bladder contractions by preventing the release of acetylcholine. Noncyclic adenine nucleotides depress the release of $\mathrm{ACh}$ from skeletal motor nerve terminals (Ginsborg and Hirst, 1972), and further experimentation will be required to ascertain whether they have a similar effect in sympathetic ganglia.

In summary, it is difficult to avoid the conclusion that the roles of cyclic AMP and cyclic GMP as second messengers at synapses on sympathetic ganglion cells are less convincingly established than they appeared to be a few years ago. Reports from several laboratories have failed to confirm the initial observations of a hyperpolarizing action of cyclic AMP and a depolarizing action of cyclic GMP on ganglion cells. Until these discrepancies have been resolved, the evidence in favor of a second messenger role of cyclic nucleotides in ganglia must be considered suspect. Pending further investigations, it would be unwise to regard sympathetic ganglia as proven examples of nucleotide mediated synapses and for the present it must be assumed that the postsynaptic accumulations of cyclic 
nucleotides either result from or occur in parallel with the synaptic events.

\section{CENTRAL "AMINERGIC" \\ TRANSMISSION}

Norepinephrine-containing axons arising in the pontine nuclei, locus coeruleus and sub-coeruleus, extend to the cerebral, cerebellar and limbic cortices (Ungerstedt, 1971; Olson and Fuxe, 1971; Pickel et al., 1974). Synaptic terminals presumed to contain norepinephrine have been identified in the rat cerebellar cortex, where the principal target neurons are thought to be the Purkinje cells (Bloom et al., 1971). There is also anatomical and histochemical evidence that cells in the cerebral cortex and pyramidal neurons of the hippocampus receive norepinephrine-containing afferents from the locus coeruleus (Ungerstedt, 1971; Descarries and LaPierre, 1973; Pickel et al., 1974). Similar lines of evidence indicate that dopamine-containing axons from the pars compacta of the substantia nigra synapse extensively on cells of the caudate nucleus (Hokfelt and Ungerstedt, 1973). In a separate projection, dopamine-containing fibers arise from neurons in the substantia nigra and ventro-medial tegmentum and project to the rhinencephalic cortex, the temporal cortex and the anterior cingulate gyrus (Lindvall et al., 1974; Berger et al., 1974).

Serotonin is concentrated within neurons of the brain stem raphe nuclei which are the source of serotonin-containing fibers to the forebrain, including the hippocampus and cerebral cortex (Anden et al., 1966; Conrad et al., 1974; Kuhar et al., 1972; Lorens and Goldberg, 1974).

(1) Norepinephrine-Mediated Synapses

(a) Cerebellar Purkinje Cells and Hippocampal Pyramidal Neurons

Iontophoretically applied norepinephrine depressed the spontaneous firing of Purkinje cells and hippocampal pyramidal neurons. The inhibition in both instances is blocked by the $\beta$-adrenergic antagonist Sotalol (MJ 1999) (Hoffer et al., 1971; Segal and Bloom, 1974a), characterizing the receptors as $\beta$-adrenergic. The $\beta$-adrenoreceptor has now been visualized on Purkinje cell bodies and apical dendrites in rat cerebellum by a new fluorescent analogue of propranolol (Melamed et al., 1976). Stimulation of the nucleus locus coeruleus has an inhibitory action on Purkinje cell and hippocampal neuron firing which is also blocked by Sotalol (Hoffer et al., 1973; Segal and Bloom, 1974b). Intracellular recording has revealed that both norepinephrine and locus coeruleus stimulation hyperpolarize the target cells in the cerebellar cortex and hippocampus, often with an associated increase in membrane resistance (Hoffer et al., 1973; Oliver and Segal, 1974). The latency of the inhibition in Purkinje cells averaged $148 \mathrm{msec}$, implying conduction velocities in the afferent fibers as low as $0.075-0.1 \mathrm{~m} / \mathrm{sec}$.

After chronic pretreatment of the animals with 6-hydroxydopamine, which destroys catecholaminergic neurons, stimulation of the nucleus locus coeruleus failed to evoke significant inhibition of Purkinje cell or hippocampal pyramidal cell discharges. Similar results were obtained in animals which were treated with reserpine, which depletes catecholamine stores in brain, together with alpha-methyltyrosine, a norepinephrine synthesis blocker (Hoffer et al., 1973; Segal and Bloom, 1974b).

\section{(b) Cerebral cortex}

Norepinephrine has an inhibitory action on cerebral cortical neurons in several species (Krnjevic and Phillis, 1963; Lake et al., 1973) including identified pyramidal tract neurons (Phillis, 1970; Stone, 1973). Both $\alpha$ and $\beta$-adrenergic blockers antagonize this depression. Norepinephrine-induced hyperpolarization of feline cortical neurons generally occurs in the absence of any pronounced alteration in membrane resistance (Fig. 1). Electrophysiological evidence for a monosynaptic projection to the cortex from the nucleus locus coeruleus has been obtained in experiments on the antidromic activation of locus coeruleus neurons by cortical stimulation (Nakamura and Iwama, 1975; Faiers and Mogenson, 1976). The antidromic latencies for activation of locus coeruleus neurons by frontal cortical stimulation ranged from 20-70 msec, with conduction velocities estimated to be $0.4-1.3$ $\mathrm{M} / \mathrm{sec}$.

Studies on identified corticospinal and unidentified deep spontaneously firing neurons have revealed an inhibitory action of nucleus locus coeruleus stimulation (Fig. 2) (Phillis and Kostopoulos, 1977). The inhibitory effects of norepinephrine and locus coeruleus stimulation on these neurons were antagonized by the $\beta$-adrenergic blocker, Sotalol (Fig. 3), and pretreatment of the cerebral cortex with
A NA 200

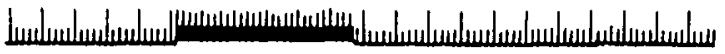

B

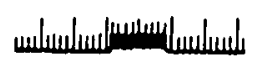

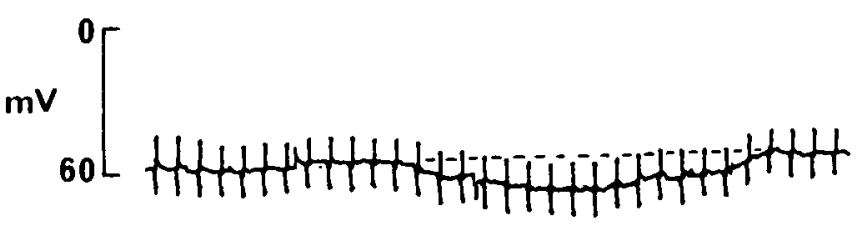

Figure I-A. Intracellular potential of a cerebral cortical neuron recorded on a chart recorder. Norepinephrine (NA, $200 \mathrm{nA}$ ) hyperpolarized the neuron. $0.5 \mathrm{nA}$ pulses of inward and outward current lasting $250 \mathrm{msec}$ were used to test the neuron's input impedance. This did not change during the norepinephrine-induced hyperpolarization. B. Recording made after the microelectrode had been withdrawn from the neuron showing the almost negligible effects of electrode polarization and bridge imbalance. Time calibrations: 1 and 5 sec. (J. P. Edstrom and J. W. Phillis, unpublished observation). 
A
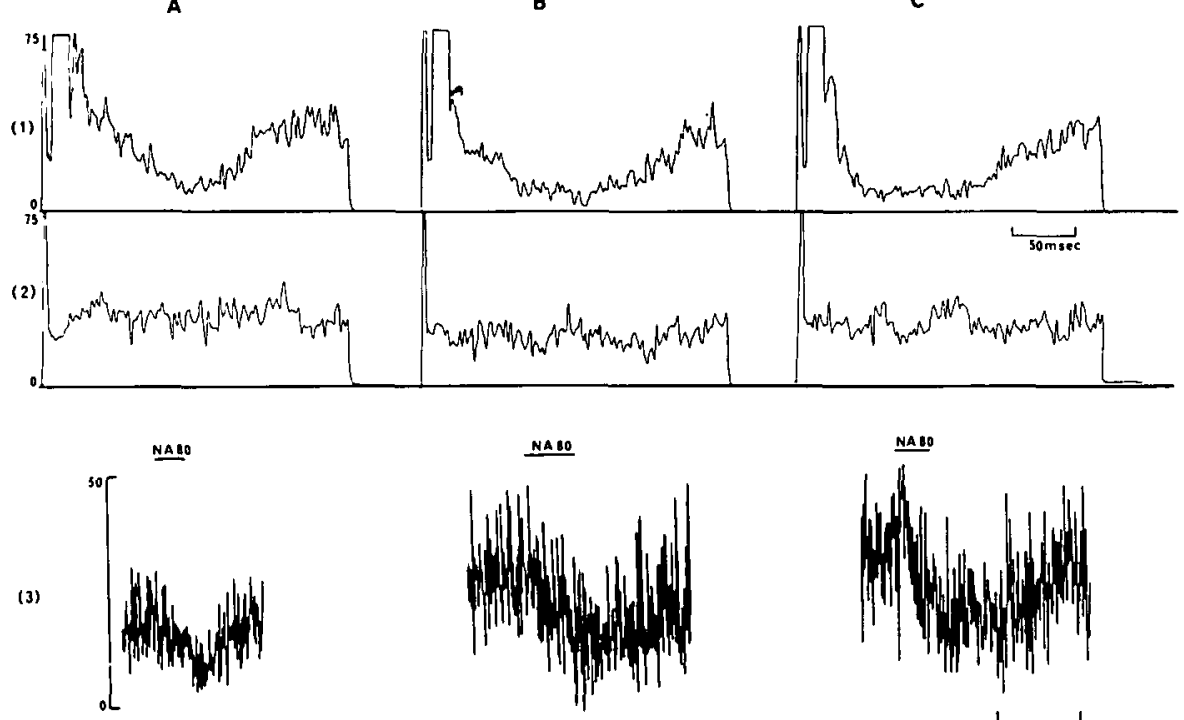

Figure 2-A. B and C. Records from three cerebral cortical neurons. B and C were identified by antidromic activation as corticospinal neurons. The records in (1) and (2) are time histograms recorded during repetitive stimulation of the locus coeruleus ( 3 pulse train) and in the absence of LC stimulation respectively. The records in (3) are recordings of neuronal firing rate and show that norepinephrine (NA, $80 \mathrm{nA}$ ) depressed the discharge rate of all three neurons. Ordinate calibrations: (1) and (2), number of neuronal discharges; (3) neuronal firing rate as spikes per second. The horizontal bars in (3) represent the periods of NA application. (From J. W. Phillis and G. K. Kostopoulos. 1977).

6-hydroxydopamine, which destroys the norepinephrine-containing nerve terminals, abolishes the inhibitory effects of locus coeruleus stimulation. The latencies of onset of locus coeruleus-evoked inhibition were $32 \pm 1.5 \mathrm{msec}$ (mean \pm S.E.M.) for corticospinal neurons and $54 \pm 2.3$ $\mathrm{msec}$ for unidentified neurons. When trains of 3 to 4 pulses were applied to the locus coeruleus, the inhibition had a mean duration of $148 \mathrm{msec}$.

These findings, in conjunction with those from anatomical, neurochemical and release (Tanaka et al., 1976) studies, argue convincingly for an inhibitory norepinephrine-mediated pathway from the locus coeruleus to the cerebral cortex.

(c) Spinal Motoneurons

The locus coeruleus projects to the spinal cord (Kuypers and Mansky, 1975) and both this and other brain stem nuclei may contribute to the descending catecholaminergic pathways in the spinal cord (Dahlstrom and Fuxe, 1965; Pickel et al., 1974; Coote and MacLeod, 1974).
Some of the terminals of these pathways make close contacts with the cell bodies and processes of spinal motoneurons. Fluorescent histochemical studies have identified a bulbospinal serotonergic pathway which arises from cell bodies in the caudal raphé nuclei and gives rise to terminals at all levels of the spinal cord (Dahlstrom and Fuxe, 1965; Pin et al., 1968; Coote and MacLeod, 1974).

Norepinephrine and serotonin hyperpolarize motoneurons (Phillis et al., 1968a; Engberg et al., 1974) with a concomitant increase in membrane resistance. There is a failure of invasion of ortho- and antidromically evoked spikes into the initial segment, soma-dendritic membrane and both EPSP's and IPSP's are reduced. Both $\alpha$ - and $\beta$-blockers antagonize the effects of norepinephrine, as do the neuroleptics, chlorpromazine and haloperidol.

Although the effects of these descending aminergic pathways have still to be established, the anatomical data suggest that they probably make extensive synaptic contacts with various groups of motoneurons. The actions of iontophoretically applied norepinephrine are likely therefore to be mediated via synaptic receptors.

(2) Dopamine-Mediated Synapses

A nigro-striatal dopamine containing projection has been demonstrated by biochemical and cytochemical techniques (Hornykiewicz, 1966; Hokfelt and Ungerstedt, 1973; York, 1975). Iontophoretically applied dopamine inhibits the firing of caudate neurons in cats and rats (Siggins et al., 1974) Connor, 1975). These effects of dopamine are antagonized by the phenothiazines, chlorpormazine, fluphenazine and alphaflupenthixol, and are mimicked by apomorphine (Siggins et al., 1974). The dopamine receptor in the caudate was not antagonized by the $\beta$-adrenergic antagonist, Sotalol (Siggins et al., 1974).

The effects elicited from caudate units by nigral stimulation have proven to be rather variable. In a study of 260 feline caudate neurons in which firing had been induced by the application of an excitatory amino acid, 46 per cent were depressed, 16 per cent were excited, and the remainder were unresponsive to short trains of stimuli applied to the substantia nigra (Connor, 1970). Neurons depressed by nigral stimulation were consistently depressed by dopamine and alphamethyldopamine antagonized the depressant responses induced by both nigral stimulation and iontophoretic dopamine. In a study of rat caudate neurons, a good correlation between the inhibitory effects of substantia nigra stimulation and the inhibitory effects of dopamine was observed. Papaverine and bulbocapnine applied iontophoretically or given intravenously blocked the effects of nigral stimulation and dopamine (Gonzalez-Vegas, 1974).

These data suggest that the depressant responses elicited from many caudate neurons by nigral stimulation are mediated by a slowly conducting monosynaptic dopaminergic pathway. Evidence for an excitatory dopaminergic projection from the 


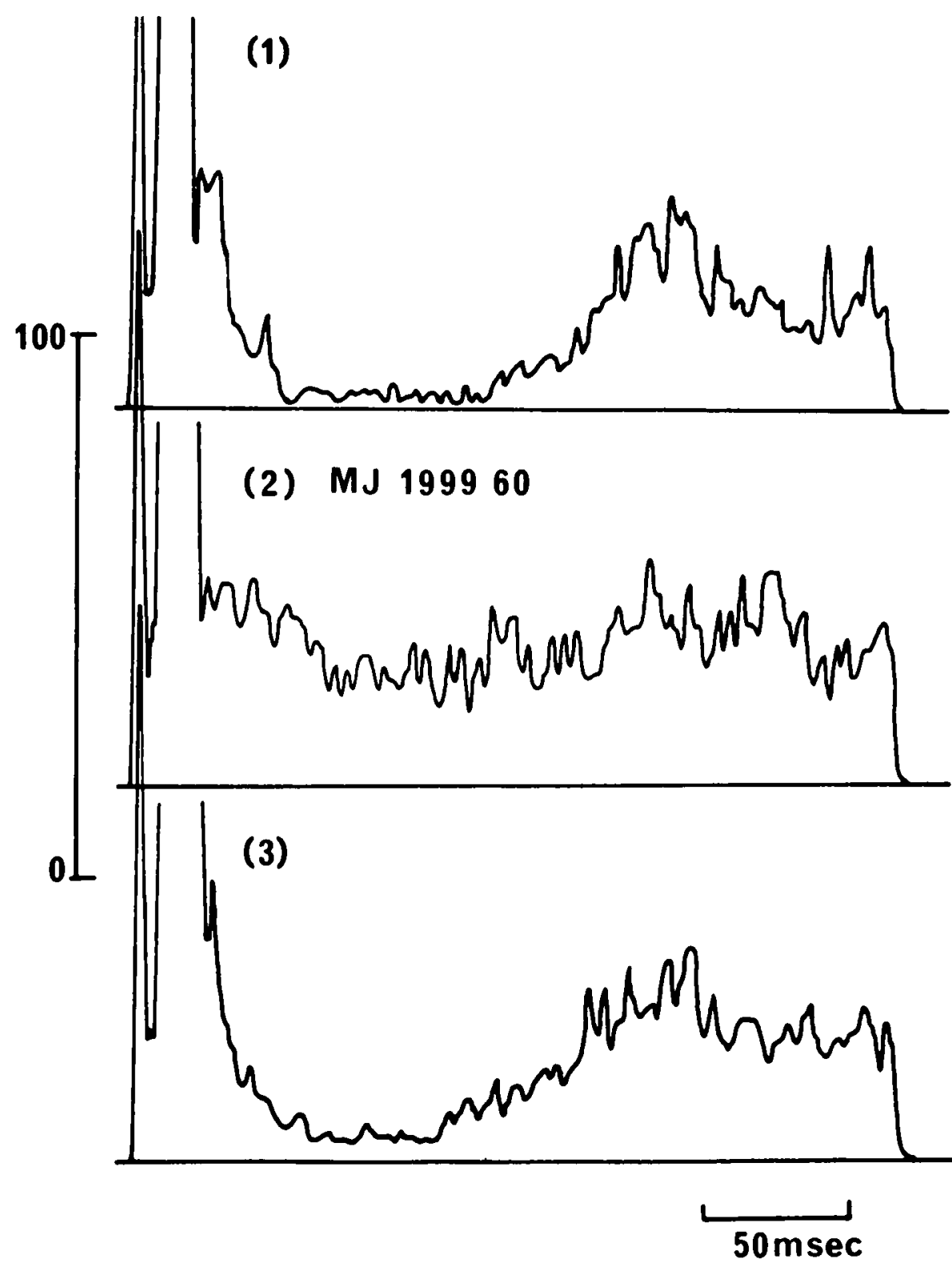

Figure 3-MJ-1999 antagonism of inhibition of the firing of a corticospinal neuron induced by repetitive ( 3 stimuli) stimulation of the ipsilateral locus coeruleus. The upper and lower traces are poststimulus histograms recorded before and $6 \mathrm{~min}$. after an application of MJ-1999 (60 $\mathrm{nA})$. The middle trace was recorded $3 \mathrm{~min}$. after the onset of the MJ-1999 application, and shows that this $\beta$-adrenergic blocker antagonized the inhibitory effects of LC stimulation. MJ-1999 also antagonized the inhibitory effects of norepinephrine on this neuron. (From J. W. Phillis and G. K. Kostopoulos, 1977).

substantia nigra to the caudate, which is antagonized by chlorpromazine, has recently been presented by Kitai et al. (1976), and this pathway may account for the excitatory effects of nigral stimulation on caudate neurons.

Dopamine depresses neuronal firing in the cerebral cortex (Krnjevic and Phillis, 1963; Bunney and Aghajanian, 1976), but the physiological significance of the recently discovered dopaminergic projection to this region of the brain remains to be evaluated (Lindvall et al., 1974; Berger et al., 1974; Fuxe et al., 1974).

(3) Serotonin-Mediated Synapses
The hippocampus receives a direct input from the raphé nuclei (Conrad et al., 1974) and its serotonin content is dependent on the integrity of the raphé nuclei (Kuhar et al., 1972; Lorens and Goldberg, 1974). Hippocampal pyramidal cells in the rat are inhibited by serotonin and by electrical stimulation of the dorsal and median raphé nuclei (Segal, 1975). The inhibitory response to raphé stimulation is absent in rats that have been pretreated with $\boldsymbol{\rho}$-chlorophenylalanine, a serotonin synthesis inhibitor, and the effects of $\boldsymbol{P}$-chlorophenylalanine are alleviated by administration of 5-hydroxytryptophan, the precursor of serotonin. The inhibitory effects of both serotonin and raphé stimulation are blocked by the serotonin antagonists, methysergide and cyproheptadine, and potentiated by chlorimipramine, a serotonin reuptake blocker. Serotonin therefore deserves serious consideration as an inhibitory transmitter acting on rat hippocampal pyramidal cells.

Comparable responses have been observed in the rat sensory-motor cortex. Serotonin depresses these neurons and its effects are selectively antagonized by the drug metergoline (Sastry and Phillis, 1977a). Metergoline also antagonizes the inhibitory response generated by raphé stimulation. The inhibitory effects of serotonin and raphé stimulation are enhanced by the selective serotonin uptake blocker (3-) $\boldsymbol{\rho}$-trifluoromethylphenoxy)- $\mathrm{N}$-methyl-3phenylpropylamine (Lilly 110140) (Sastry and Phillis, unpublished observations; Frederickson et al., 1975).

(4) Histamine-Mediated Synapses

Histamine and L-histidine decarboxylase, the enzyme which converts $\mathrm{L}$-histidine to histamine, are present in rat cerebral cortex (Schwartz, 1975). Various biochemical studies suggest that a significant portion of the amine and its synthesizing enzyme are associated with the synaptosomal fraction of brain tissue (Kataoka and De Robertis, 1967; Garbarg et al., 1976). Transection of the rat medial forebrain bundle results in a reduction in his- 


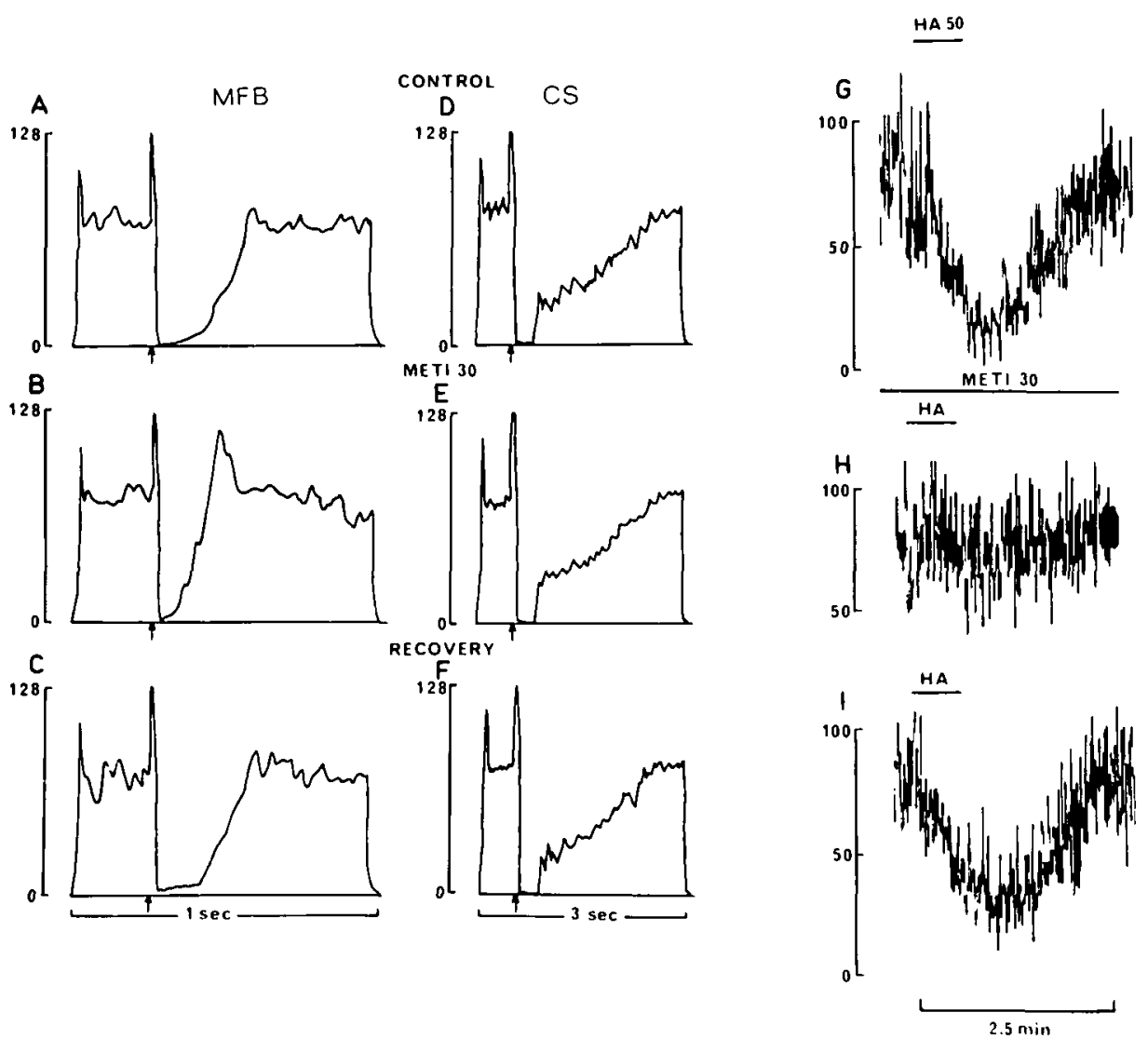

Figure 4-Metiamide (METI, $50 \mathrm{nA}$ ) effects on inhibitions of a deep cerebral cortical neuronal firing induced by stimulation of the ipsilateral medial forebrain bundle (MFB, A, B and C) and the ipsilateral cortical surface (CS, D, E and F), as well as by iontophoretically applied histamine (HA, $50 \mathrm{nA}, \mathrm{G}$ and $\mathrm{H}$ ). A and D illustrate the control post-stimulus histograms for the cortical neuronal firing after MFB and CS stimulations, respectively. B was recorded $4 \mathrm{~min}$. to $6 \mathrm{~min} .8 \mathrm{sec}$. following the onset of METI application, whereas $C$ was recorded $7 \mathrm{~min}$. $30 \mathrm{sec}$. to $12 \mathrm{~min}$. $50 \mathrm{sec}$. after initiation of $\mathrm{METI}$ ejecyion. $\mathrm{C}$ and $\mathrm{F}$ depict a recovery from $\mathrm{METI}$ antagonism (C: 8 $\min$. to $10 \mathrm{~min} .9 \mathrm{sec}$. and $\mathrm{F}$ : $11 \mathrm{~min}$. to $16 \mathrm{~min}$. $20 \mathrm{sec}$., following the termination of $\mathrm{METI}$ application). G-H portrays a continuous recording of the neuronal firing rate. In G. HA (50 $\mathrm{nA})$ decreased the discharge rate of this neuron and METI $(50 \mathrm{nA})$ antagonized this depression. $\mathrm{H}$ shows a recovery from $\mathrm{METI}$ antagonism. Ordinate calibration: A-F: no. of neuronal discharges; $\mathrm{G}-\mathrm{H}$ : neuronal firing rate as spikes per second. The horizontal bars in $\mathrm{G}$ and $\mathrm{H}$ indicate the duration of drug applications. (B. S. R. Sastry and J. W. Phillis. 1976b).

tamine levels and L-histidine decarboxylase activity in the ipsilateral cerebral cortex, suggesting that a histaminergic pathway may ascend through this tract (Garbarg et al., 1976).

Histamine inhibits the firing of cerebral cortical neurons (Phillis et al., 1968b) and studies with $\mathrm{H}_{1}$ and $\mathrm{H}_{2}$ agonists and antagonists have provided evidence for the existence of both $\mathrm{H}_{1}$ and $\mathrm{H}_{2}$ receptors on cerebral cortical neurons (Phillis et al., 1975; Sastry and Phillis, 1976a). Stimulation of the medial forebrain bundle inhibits the firing of cerebral taminergic pathway projects to the cerebral cortex. Discovery of the nucleus of origin of these histaminergic fibers will be keenly awaited.

\section{DEPRESSANT ACTIONS OF CYCLIC AND NON-CYCLIC ADENINE NUCLEOTIDES}

(1) Cerebellar Purkinje Cells

According to the criteria for acceptance of cyclic nucleotides as second messengers outlined in Section C. II., it may be possible to mimic the effects of synaptic activation by the addition of exogenous cyclic nucleotide. It is the satisfaction of this criterion, as it is in the case of the sympathetic ganglion, which has given rise to much of the controversy regarding the role of cyclic nucleotides in synaptic function in the central nervous system. Simply stated the problem is as follows: In the hands of Bloom and his colleagues cyclic AMP has been a consistent and potent depressant of neurons that were depressed by norepinephrine. In the experiences of many other investigators, cyclic AMP has proven to be a weak and inconsistent depressant of NEsensitive neurons. What is the explanation for this crucial discrepancy! Various technical considerations must be taken into account in any attempt to analyze this problem.

In order to assess the relative potencies of iontophoretically applied substances it is necessary to determine the transport number of the compounds, which relates the amount of substance released from the micropipette and the magnitude and duration of the iontophoretic delivery current. The transport number for cyclic AMP, determined with ejection currents and delivery periods approximating those used in in vivo experiments (Shoemaker et al., 1975), was found to be marginally lower than that for synaptic transmitter substances $(0.05$ versus 0.1 or more, Kelly, 1975). In addition a large amount of variation in release was found within individual cyclic AMP-containing electrodes and among various pipette barrels, but this is often even more pronounced for norephinephrine- 
containing barrels (Kelly, 1975). In 1974, in response to the repeated failures of other investigators to replicate their data with cyclic AMP on cerebellar Purkinje cells (Godfraind and Pumain, 1971; Lake and Jordan, 1974) Bloom and his colleagues disclosed an apparently critical step in their technical procedures, that of electrode "warm-up". This procedure requires the passage of large (150-200 $n A)$ currents for fairly lengthy periods of time ( $5 \mathrm{~min}$ or more) through the cyclic AMPcontaining barrel prior to its actual use of Purkinje cells. "Warm-up" is a remarkable phenomenon since it apparently induces a long-lasting increase in the transport number for cyclic AMP in any particular electrode barrel, an effect that has not been reported by other investigators, even though it is known that the amount of iontophoretic release is affected by the strength and duration of the previous retention current (Bradshaw et al., 1973; Clarke et al., 1973). There is a possibility that with these large "warm-up" currents, the current density and power dissipation in the region of the electrode tip could cause accelerated oxidation or hydrolysis of drugs in the electrode, including a breakdown of cyclic AMP to the much more potent 5'-AMP (see below). Another possibility that must be considered is that electro-osmotic movements of fluid into the pipette will occur during the passage of the "warm-up" currents and these may carry soluble phosphodiesterases into the electrode, again resulting in the formation of $5 '$-AMP from cyclic AMP.

It is interesting to have a detailed look at the criteria used by Siggins and Henriksen (1975) in a recent report on the effects of cyclic AMP on rat Purkinje cells. In addition to the normal conditions of current neutralization and constant spike amplitude it is stated that "Since the interpretation of negative data with iontophoresis is difficult, a classification of 'no effect' was given a cell only when the drug barrel had been 'warmed up' by several pulses of at least $100 \mathrm{nA}$ applied over a 2 to 5 minute period and when the neuron then did not respond by a change in rate of at least 10 per cent to at least two consecutive pulses of $200 \mathrm{nA}$ each applied for at least 1 minute." In my own laboratory, 10 per cent changes in firing rate are not reported as significant, especially in the case of a cerebellar Purkinje cell, since these neurons are exquisitely sensitive to current effects. However, the criteria described above demand that, to be considered as a negative, the neuron should NOT change its firing rate by more than 10 per cent in two consecutive trials. It is rather astonishing therefore to find that in the above investigation only 63 per cent of the Purkinje cells tested were depressed by cyclic AMP. In an investigation conducted in this laboratory, where cyclic AMP was applied by currents of up to 80 $\mathrm{nA}$ for periods of up to $2 \mathrm{~min}, 37 \mathrm{per}$ cent of the Purkinje cells were depressed (Kostopoulos et al., 1975). A comparable percentage of depressed Purkinje neurons was reported by Lake and Jordan (1974), who used currents of up to $200 \mathrm{nA}$.

Regardless of the parameters of application used, the crucial observation apparent in all these results is that cyclic AMP is a rather weak depressant of the firing of some Purkinje cells. Of further concern is the possibility that exogenously applied cyclic AMP may be converted to 5'-AMP and adenosine and that its pharmacological actions are actually mediated by these compounds. Siggins et al. (1971a) observed only excitant actions when 5'-ATP and 5'-AMP were tested on Purkinje cells, although a weak depressant effect of adenosine was subsequently reported (Bloom et al., 1975). In another study, however, pronounced depressant actions of several adenine nucleotides, including adenosine 2', 3'-monophosphate, were reported (Kostopoulos et al., 1975)

If non-cyclic nucleotides have very much more potent actions than cyclic AMP, extracellular catabolism of the latter to $5^{\prime}$-AMP and/or adenosine must be considered. The marked difference in the potencies of the $2^{\prime}, 3^{\prime}$ - and
3', 5'-cyclic nucleotides of adenosine also suggests that catabolism to 2'- or 5'-AMP and/or adenosine may be an important factor in the actions of these compounds. 2', 5'-cyclic AMP is hydrolyzed by a highly active and specific phosphodiesterase located in myelin in the brain (Drummond et al., 1971). As 2', 3'cyclic phosphodiesterase is approximately 2-10 times more active compared to 3', 5'-cyclic phosphodiesterase (Drummond and Yamamoto, 1971; Drummond and Ma, 1975), the hydrolysis of $2^{\prime}, 3^{\prime}$-cyclic AMP is likely to proceed at a considerably higher rate than that of $3^{\prime}, 5^{\prime}$-cyclic AMP. The low potency of extracellularly applied 3 , 5'-cyclic AMP may thus be a reflection of a low rate of hydrolysis to 5'-AMP. This concept also explains the low potency of extracellularly applied dibutyryl 3', 5'-cyclic AMP, as this compound is resistant to catabolism by phosphodiesterases (Drummond and Powell, 1970). The possibility that exogenous cyclic AMP may act as a precursor for adenosine has been noted by other investigators looking at its pharmacological actions on smooth muscle, and metabolic effects on cultured human lymphoblasts (Kim et al., 1968; Snyder and Seegmiller, 1976).

The role of cyclic AMP in norepinephrine inhibition has been questioned on the grounds that the percentage of Purkinje cells depressed by this agent does not match the high percentage depressed by NE. This difference has been attributed to technical factors relating to cyclic AMP release from the micropipette and to the necessity that cyclic AMP (a sparingly permeable. agent) reach intracellular protein kinases, through the regulation of which it can cause the phosphorylation of membrane proteins and thus alter the biophysical properties of the cell membrane. To overcome this latter difficulty, various analogues which are more potent that cyclic AMP itself in activating brain protein kinases were tested on Purkinje cells. The 8-parachlorophenylthio- and 8-benzylthio- analogues of cyclic AMP inhibited the firing of a higher 
TABLE 1

Depressant Potency of Various Purines and Pyrimidines on Corticospinal Cells

\begin{tabular}{lll}
\hline Pronounced & Weak & Very Weak or Nil \\
\hline Adenosine & Adenosine & Adenine \\
Adenosine 2'-monophosphate & $3^{\prime}, 5^{\prime}$-cyclic monophosphate & Cytidine \\
Adenosine 3'-monophosphate & Guanosine 5'-monophosphate & Cytidine 3' $\left(2^{\prime}\right)$-monophosphate \\
Adenosine & Guanosine 5'-diphosphate & Cytidine 5'-monophosphate \\
$2^{\prime}, 3^{\prime}$-cyclic monophosphate & Guanosine 5'-triphosphate & Cytidine 5'-triphosphate \\
Adenosine 5'-monophosphate & Guanosine & Guanosine \\
Adenosine 5'-diphosphate & $3^{\prime}, 5^{\prime}$-cyclic monophosphate & Hypoxanthine \\
Adenosine 5'-triphosphate & & Inosine \\
Adenosine 5'-tetraphosphate & & Inosine 5'-monophosphate \\
& & Inosine 5'-triphosphate \\
& & Purine riboside \\
& & Thymidine \\
& & Thymidine 5'-monophosphate \\
& & Thymidine 5'-triphosphate \\
& & Uridine \\
& & Uridine 3' $\left(2^{\prime}\right)$-monophosphate \\
& & Uridine 5'-monophosphate \\
& & Uridine 5'-triphosphate
\end{tabular}

\section{5-ATP 20 5-ADP $20 \quad 5$-AMP $20 \quad$ NA 30}

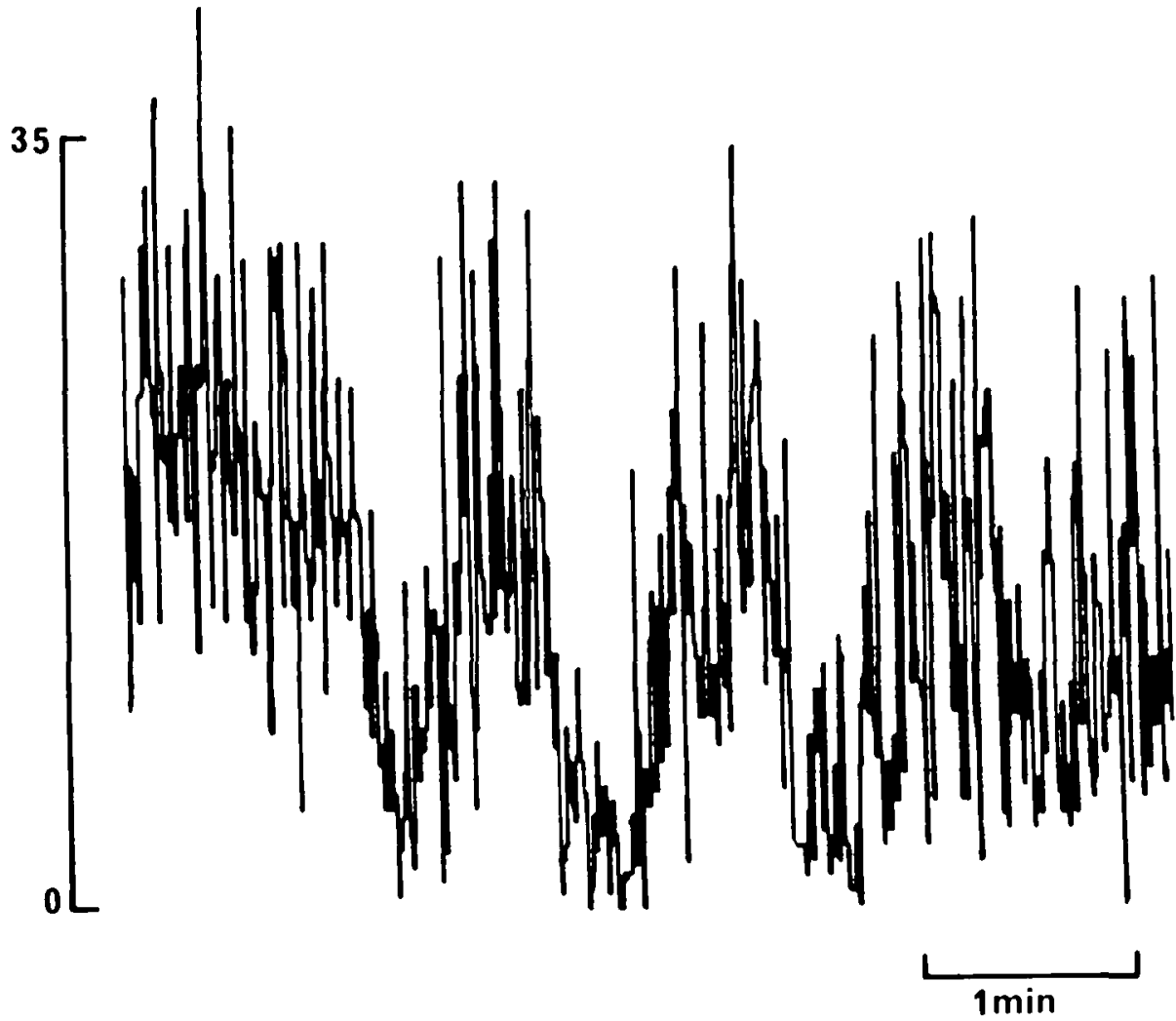

Figure 5-Potent depression of spontaneous firing of a corticospinal neuron by adenine nucleotides compared with weaker inhibitory action of norepinephrine (NA). Ratemeter record of neuronal firing. Application currents are shown in $\mathrm{nA}$. percentage of neurons than did cyclic AMP (Siggins and Henriksen, 1975), strengthening the link between adrenergic inhibition of Purkinje cells and its intracellular mediation by cyclic AMP. However, when tested on NE-depressed neurons in the cerebral cortex, these compounds had virtually no depressant activity (Phillis and Edstrom, 1976), a difference which is difficult to explain.

(2) Cerebral Cortical Neurons

An extensive range of purine and pyrimidine nucleotides has been tested on identified corticospinal and deep spontaneously firing neurons in the rat sensory-motor cortex (Table 1). Adenine nucleotides and adenosine were observed to have a pronounced depressant action, guanine nucleotides a weak depressant action, and little effect was observed with the cytidine, inosine, uridine and xanthine nucleotides (Phillis et al., 1974). Further studies have confirmed the potent depressant actions of $2^{\prime}-, 3^{\prime}-$, 5'adenosine monophosphates and $2^{\prime}, 3^{\prime}$-cyclic adenosine monophosphate, and the relatively weak depressant action of $3^{\prime}, 5^{\prime}$-cyclic AMP (Fig. 5; Table 2) (Phillis et al., 1976). 
Substitution of halogen groups in position 2 of the adenine ring of adenosine gave analogs which were either significantly more potent than adenosine ( 2 '-chloro- and 2 '-fluoroadenosine, Fig. 6) or which, in the case of 2-bromoadenosine, had a very prolonged duration of action. 2-substituted adenosine derivatives are poor substrates for adenosine deaminase and this factor may ex-

\section{TABLE 2}

Structure-Activity Relationships for Adenosine Analogs

\begin{tabular}{|c|c|c|}
\hline Substance & $\begin{array}{c}\text { Depressant } \\
\text { Activity } \\
\text { on Cerebral } \\
\text { Cortical } \\
\text { Neurons } a\end{array}$ & $\begin{array}{l}\text { Stimulation of } \\
\text { Cyclic AMP } \\
\text { Formation in } \\
\text { Cerebral Cortical } \\
\text { Slices } b\end{array}$ \\
\hline Adenine & - & 0 \\
\hline Adenosine & - - - & +++ \\
\hline Inosine & -- & 0 \\
\hline \multicolumn{3}{|l|}{ Purine Derivatives of Adenosine } \\
\hline 2-Chloroadenosine & ----- & $+t+$ \\
\hline 2-Fluoroadenosine & $---\cdots$ & ++ \\
\hline 2-Bromoadenosine & -- & \\
\hline 2-Aminoadenosine & $-1-$ & ++ \\
\hline 2-Hydroxyadenosine & - - & $+t$ \\
\hline 8-Bromoadenosine & 0 & \\
\hline \multicolumn{3}{|l|}{ Ribose Derivatives of Adenosine } \\
\hline $2^{\prime}$-Deoxyadenosine & -一- & 0 \\
\hline 3'-Deoxyadenosine & -1 & 0 \\
\hline 5'-Deoxyadenosine & --- & $+t$ \\
\hline Adenine xylofuranoside & - & 0 \\
\hline Adenosine $\mathrm{N}^{\prime}$-oxide & - & \\
\hline Adenosine $5^{\prime}$-sulphate & 0 & 0 \\
\hline Adenosine 5 '-mononicotinate & -1 & 0 \\
\hline \multicolumn{3}{|l|}{ Phosphorylated Derivatives } \\
\hline Adenosine 5'-monophosphate & ---- & +++ \\
\hline Adenosine 5'-diphosphate & ---- & ++ \\
\hline Adenosine 5'-triphosphate & ---- & $+t+$ \\
\hline Adenosine 5 -tetraphosphate & --- & \\
\hline Adenosine 2'-monophosphate & ---- & ++ \\
\hline Adenosine 3 '-monophosphate & ---- & ++ \\
\hline Adenosine $3^{\prime}, 5^{\prime}$-cyclic monophosphate & - - & $++t$ \\
\hline Adenosine $2^{\prime}, 3^{\prime}$-cyclic monophosphate & ---- & \\
\hline Adenosine 5 -imidodiphosphate & ---- & \\
\hline Homoadenosine 6 -phosphonic acid & 0 & \\
\hline$\alpha, \beta$-Methylene 5'-A TP & - & 0 \\
\hline$\beta, \gamma$-Methylene 5'-ATP & - - & 0 \\
\hline$\alpha, \beta$-Methylene $5^{\prime}$-ADP & - & \\
\hline 8-Parachlorophenylthio $3^{\prime}, 5^{\prime}$-cAMP & - & \\
\hline 8-Benzylthio 3', 5'-cAMP & 0 & 0 \\
\hline 2-Deoxyadenosine $5^{\prime}$-monophosphate & - - & \\
\hline
\end{tabular}

a Data from Phillis and Kostopoulos (1975); Phillis and Edstrom (1976).

$b$ Data from Sattin and Rall (1970); Huang et al. (1972); Huang and Daly (1974) and Mah and Daly (1976). plain their high potency and long duration of action.

The importance of adenosine deaminase in terminating the action of adenosine was investigated with two potent inhibitors of this enzyme, deoxycoformycin and erythro-9(2-hydroxy-3-nonyl) adenine. Both substances caused a pronounced potentiation of the duration of depression evoked by adenosine and

5'-AMP. As uptake into adjacent cellular elements represents an alternative mechanism for the removal of adenosine from the extracellular spaces, studies were initiated with uptake blockers, including papaverine, hexobendine and 2-hydroxy-5-nitrobenzylthioguanosine. Potentiation of the actions of adenosine and 5'-AMP by these compounds was observed. Hexobendine had a potent depressant action of its own on the spontaneous firing of cortical neurons, a property which complicated its use as an uptake blocker.

The structure-activity relationships displayed in Table 2 are remarkably consistent with those resulting from biochemical investigations on the stimulation of cyclic AMP formation in brain cerebral cortical slices by adenosine analogs. As stated previously, these biochemical results have been interpreted as being indicative of the existence of an extracellular receptor, stimulation of which by adenosine evokes cyclic AMP formation within the cell. The similarities between the agonist potencies of various adenosine analogs observed in our experiments and the biochemical studies suggest that in both instances, a similar adenosine receptor is involved. Further support for a one receptor hypothesis has been forthcoming from studies with adenine derivatives on the depression of the amplitude of evoked postsynaptic potentials and simultaneous formation of cyclic AMP in guinea-pig olfactory cortex slices (Kuroda et al., 1976a). Both actions of adenosine can be prevented by elevated calcium levels in the solution perfusing the slices (Kuroda et al., 1976b) and it has been proposed that adenosine depression of evoked postsynaptic potentials results from inhibition of the action potential initiated calcium influx into the presynaptic nerve terminal.

Methylxanthines such as caffeine and theophylline antagonize the adenosine-evoked formation of cyclic AMP in brain slices. When tested on cerebral cortical neurons, iontophoretically applied caffeine 


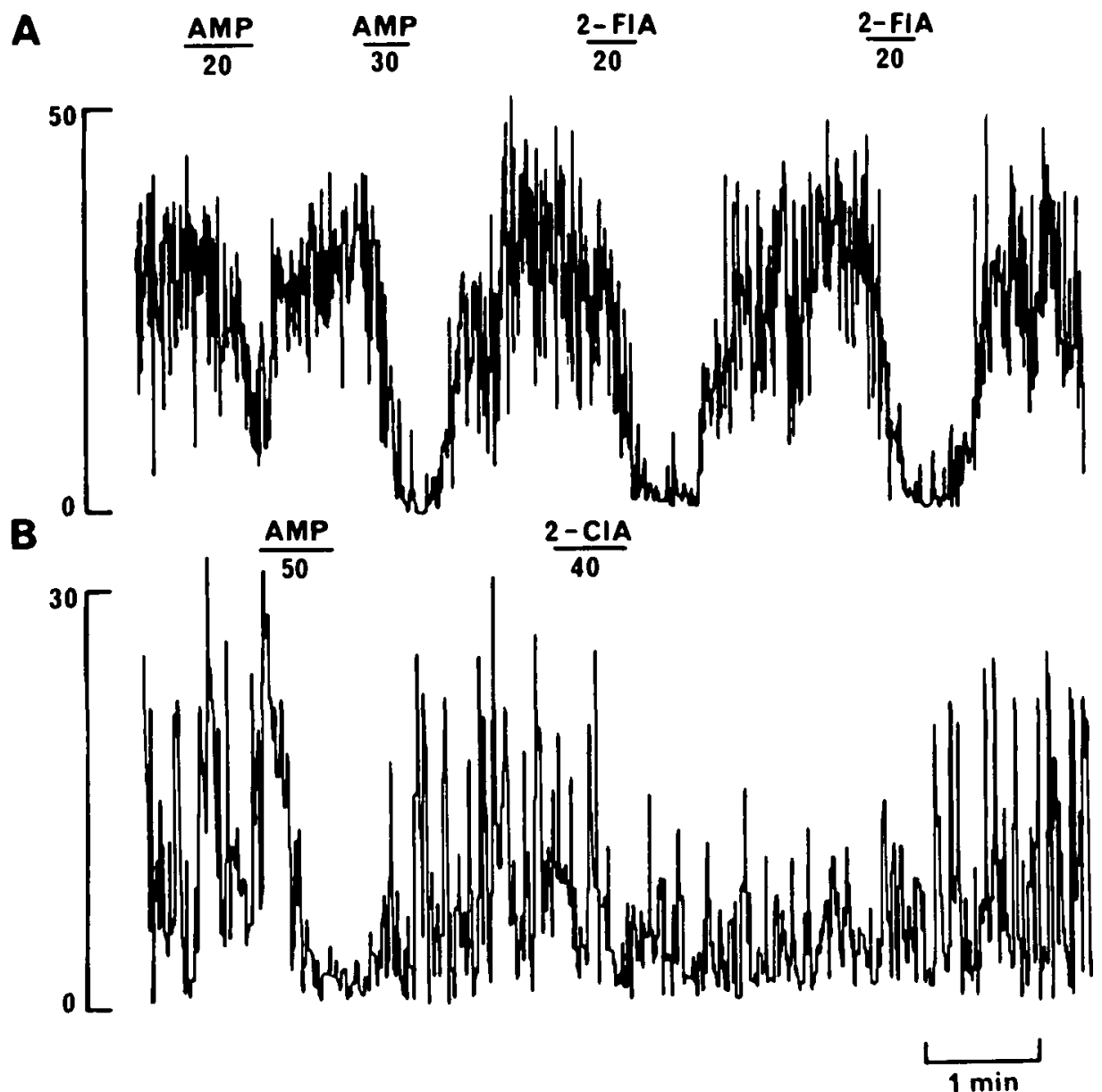

Figure 6-Depression of the spontaneous firing of a cerebral cortical neuron by adenosine 5'-monophosphate (AMP), 2-fluoroadenosine (2-F1A) and 2-chloroadenosine (2-ClA). Rate meter records of neuronal firing rate with the number of action potentials per second on the ordinate. Bars indicate periods of drug application. Application currents are shown in nA. (From J. W. Phillis and J. P. Edstrom, 1976).

blocked the depression of spontaneous firing induced by adenosine and 5'-AMP. Theophylline is so sparingly soluble as to be difficult to apply by iontophoresis. This agent (and caffeine) was therefore tested by systemic (intravenous) administration. In doses of $10-100 \mathrm{mg} / \mathrm{kgm}$ theophylline (and caffeine) blocked the effects of adenosine and $5 '$-AMP. The antagonism could be overcome if larger amounts of adenosine were applied, implying that theophylline may act as a competitive antagonist. Theophylline also antagonized the depressant actions of cyclic AMP (Fig. 7) confirming the suggestion that this cyclic nucleotide can evoke its effects through activation of the extracellular adenosine receptor. Mah and
Daly (1976) have shown that the stimulant action of exogenous cyclic AMP on endogenous cyclic AMP formation by brain slices is absent in the presence of adenosine deaminase. Cyclic AMP is not a substrate for this enzyme and its action on adenylate cyclase must be deadenosine or 5'-AMP.

Other antagonists of the adenosine-elicited accumulation of cyclic AMP in brain slices are 2'-, 3'and 5'-deoxyadenosine. Initial reports (Mah and Daly, 1976) suggested that the 2'- and 3'- compounds lacked agonist action and could thus be considered as pure antagonists. It was somewhat perplexing therefore to discover that these compounds had a weak pendent on a prior hydrolysis to adenosine-like action on cortical neurons (Phillis and Edstrom, 1976), but later biochemical studies on neuroblastoma cells and ventricular myocardium have shown that $2^{\prime}$ - and 3'-deoxyadenosine can stimulate endogenous cyclic AMP formation (Green and Stanberry, 1977; Huang and Drummond, 1976).

The question of whether prior degradation of the adenine nucleotides to adenosine is necessary before they can activate the receptor has been resolved with the use of four methylene isosteres of $5^{\prime}$-AMP, -ADP and -ATP. The phosphorus methylene bond is stable and resistant to metabolic transformations involving either hydrolysis or phosphate transfer (Yount, 1975). The $\alpha, \beta$-isosteres of ADP and ATP were very weak depressants of cortical neurons, in contrast to the $\beta, \gamma-$ analog of ATP which possessed quite pronounced depressant activity (as did 5'-adenyl-imidodiphosphate) (AMP-PMP) (Fig. 8). This finding suggested that even though the terminal bond in the ATP analogs was stable, cleavage could still occur at the $\alpha, \beta$ position. The methylene analog of $5^{\prime}$-AMP, homoadenosine 6'-phosphonic acid, had no depressant activity on cerebral cortical neurons (Fig. 8) indicating an absolute requirement for dephosphorylation to adenosine for expression of depressant activity. Similar findings have been obtained in studies on brain slices, where $\alpha, \beta$ - and $\beta, \gamma$-methylene ATP had only a weak effect on cyclic AMP formation (Mah and Daly, 1976). Reference was made earlier to the lack of depressant effects of 8-benzylthio-cyclic AMP on cerebral cortical neurons. This compound also failed to enhance cyclic AMP formation in guinea-pig cerebral cortical slices.

An insight into the mechanism by which adenosine depresses the spontaneous firing of rat cerebral cortical neurons has been gained by intracellular recording with extracellular drug application (Phillis and Edstrom, 1976; Edstrom and Phillis, 1976). For technical reasons these studies were conducted with 
5'-AMP and the most striking findings were that 5'-AMP caused a hyperpolarization of the postsynaptic neurons in the absence of any significant alteration in membrane resistance, but with a decrease in spontaneous and evoked postsynaptic potentials. The mechanism by which 5'-AMP produces these effects is still by no means clear, but seems to involve some form of interference with the synaptic mechanism. It may involve an inhibition of presynaptic excitationtransmitter release coupling, as has been shown at peripheral cholinergic and adrenergic synapses (Ginsborg and Hirst, 1972; Miyamoto and Breckenridge, 1974; Hedquist and Fredholm, 1976). Another possibility is that it may block the postsynaptic receptors and (or) inhibit the coupling between the receptor and the conductance mechanisms controlled by the receptor. Hyperpolarizing actions of cyclic AMP on cerebellar Purkinje and hippocampal cells have been described (Hoffer et al., 1973; Oliver and Segal, 1974), but these were associated with an increase in membrane resistance.

\section{(3) Other Regions of the Brain}

Adenosine and 5'-AMP have been tested on neurons that were identified by electrophysiological and/or histological means in the olfactory bulb, thalamus, hippocampus, caudate nucleus and superior colliculus. Neurons in each area were depressed in a similar fashion to cerebral cortical neurons (Fig. 9). Comparisons based on the proportion of units depressed by 5'-AMP and adenosine and of the average application currents needed to induce a $50 \%$ reduction in firing rate showed that the relative sensitivities of neurons in the different regions tested was: hippocampus $\geq$ cerebral cortex $>$ caudate and thalamus $>$ superior colliculus $>$ olfactory bulb. Adenosine and 5'-AMP-depressed synaptically evoked firing in the superior colliculus and olfactory bulb was as susceptible to adenosine and 5'-AMP-induced depression as was the spontaneous firing.

Cyclic AMP has a depressant action on caudate neurons, which are reportedly much more sensitive to

A

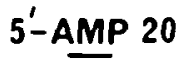

AMP $\quad 3,5^{\prime}-$ - AMP 60

CAMP

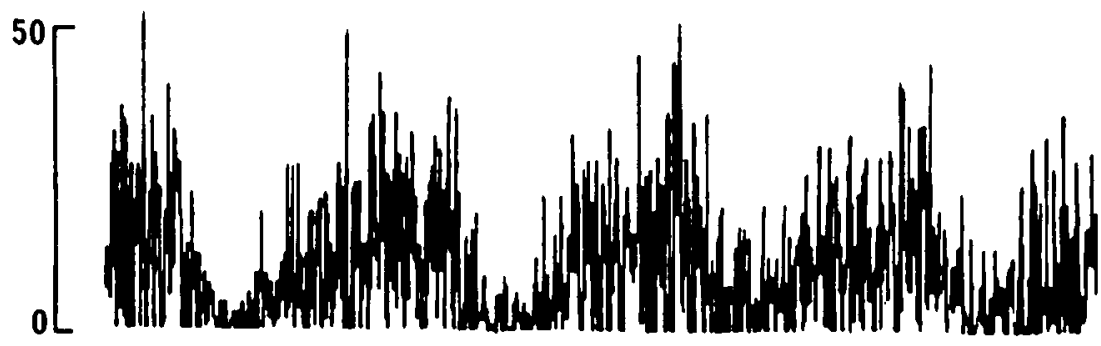

$B \quad \begin{aligned} & \text { THEOPH. AMP } \\ & 50 \mathrm{mg} / \mathrm{kg}\end{aligned}$

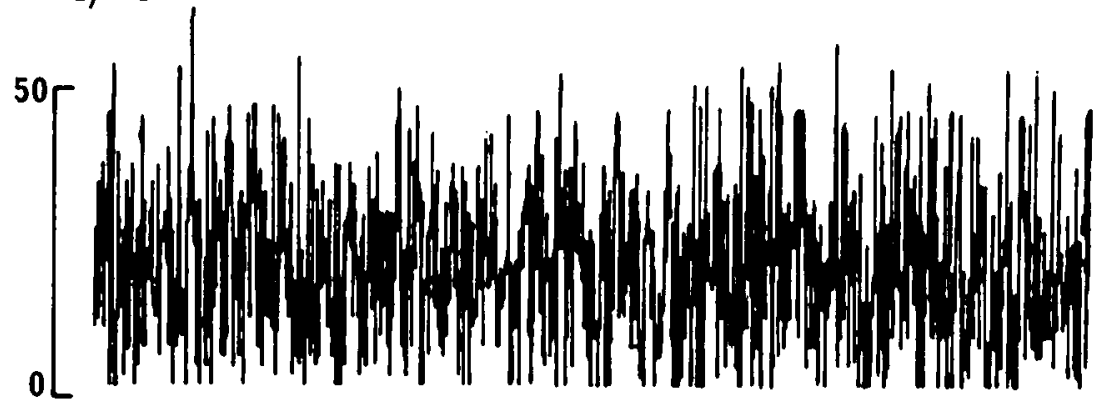

C

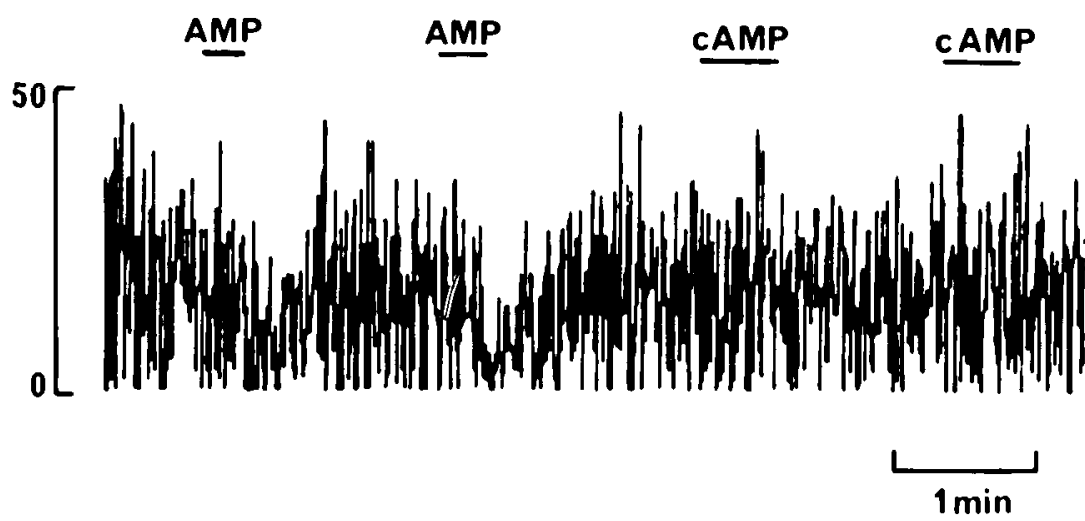

Figure 7-Theophylline antagonism of 5'-AMP (20nA) and $3^{\prime}, 5^{\prime}$-cyclic AMP $(60 n \mathrm{nA})$ depression of the spontaneous firing of a corticospinal neuron. Theophylline ( 50 $\mathrm{mg} / \mathrm{kg}$ ) was administered intravenously after the control nucleotide responses had been recorded. Trace B starts $7 \mathrm{~min}$. after the theophylline injection when both $5^{\prime}$-AMP and 3', 5'-cyclic AMP depressions were abolished. Trace C was recorded 75 min. after theophylline when the $5^{\prime}$-AMP responses were beginning to recover. $3^{\prime}$, $5^{\prime}$-cyclic AMP was still blocked.

this compound than cerebellar Purkinje cells (Siggins et al., 1974). Cyclic AMP also depressed neurons in the cat brain stem (Anderson et al., 1973), nucleus accumbens (Bunney and Aghajanian, 1973) and entopeduncular nucleus (Obata and Yoshida, 1973).

(4) Spinal Cord

Cyclic AMP has been injected into motoneurons in the feline spinal cord in the expectation that when administered at this locus it should more readily be able to initiate its postulated "second messenger" action (Krnjevic and Van Meter, 1976). The most striking effects were a speeding-up of the action potential, both its rising and falling phases, and a potentiation of the after- 
A
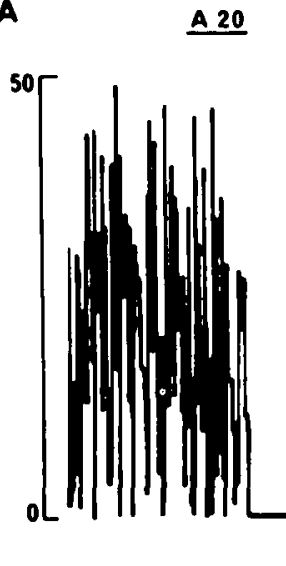

$\mathbf{8}$
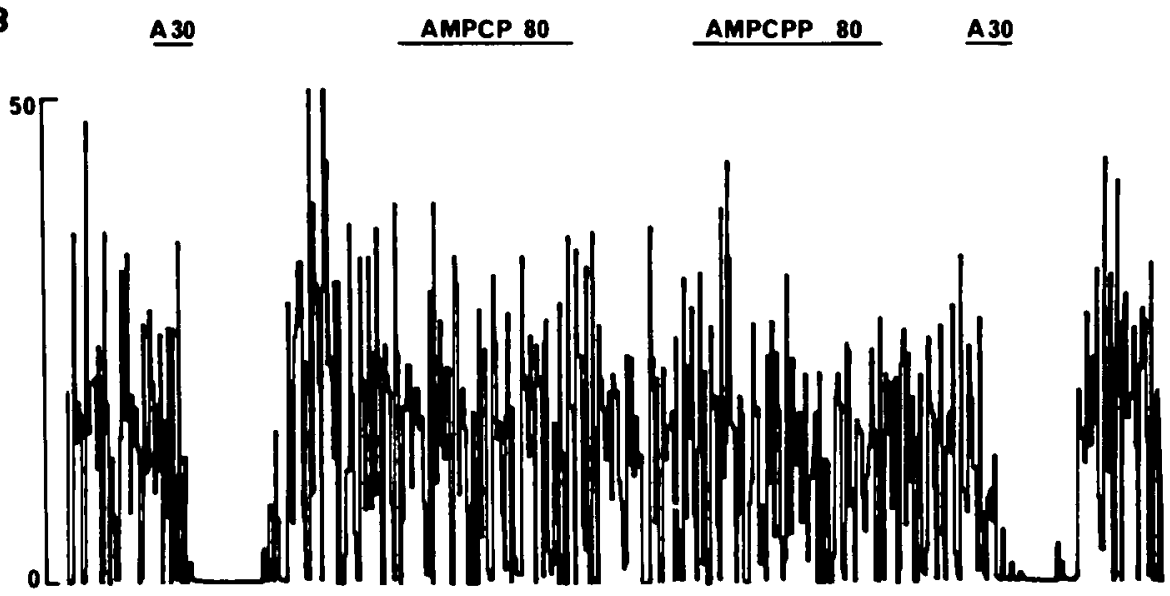

$\mathbf{C}$

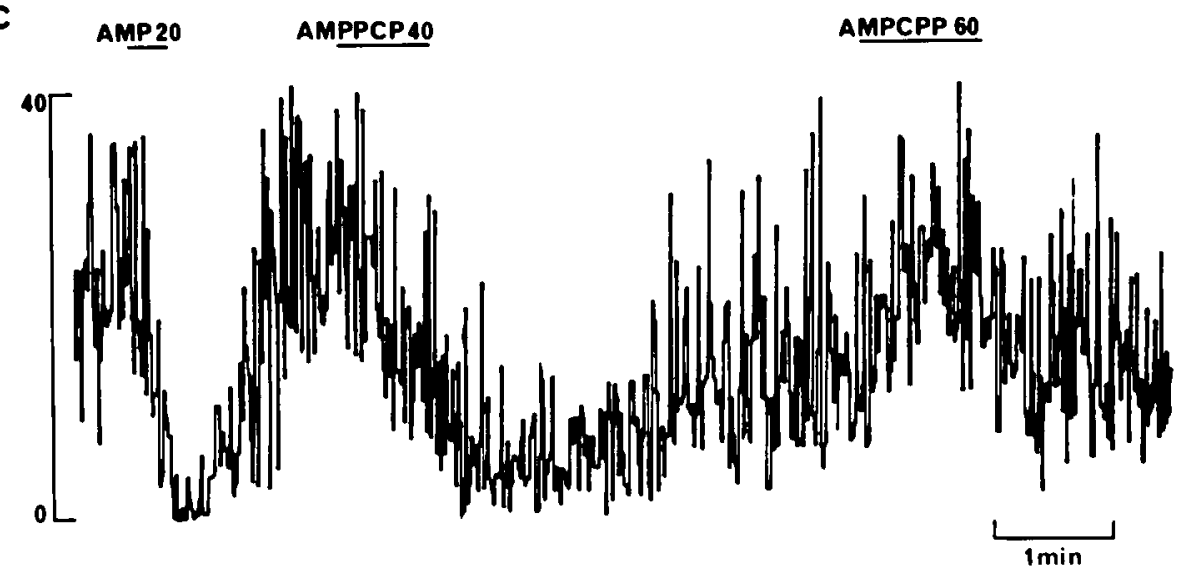

Figure 8-A, B. Examples of lack of effect of methylene isosteres of 5 '-AMP (ACP), $5^{\prime}$-ADP (AMPCP) and the $\alpha, \beta$-methylene isostere of 5'-ATP (AMPCPP) on two cerebral cortical neurons which were depressed by adenosine (A). C. The $\beta$, $\gamma$-methylene isostere of 5'-ATP (AMPPCP) had quite a pronounced depressant action on this cerebral cortical neuron, although the $\alpha, \beta$-analog was inactive. $5^{\prime}$-AMP (AMP) also depressed the neuron. The application currents in $\mathrm{nA}$ are given on the figure. hyperpolarization. Changes in resting membrane potential and resistance were less conspicuous or predictable.

These effects, which are rather different from those observed when norepinephrine is applied outside motoneurons (Phillis et al., 1968a; Engberg et al., 1974; see Section E. II (1) (c) of this chapter) are difficult to equate with the second messenger hypothesis. The experiments emphasize the extraordinary difficulties facing the investigator who attempts to satisfy the criteria for establishing a second messenger function for cyclic AMP. Even when the diffusional hazards associated with the plasma membrane are by-passed with an intracellular injection, it is conceivable that cycli AMP may activate numerous mechanisms, only one of which would be involved in the second messenger response to a specific transmitter. The sought-after effect in this instance could well be submerged in a plethora of secondary phenomena.

\section{PRESYNAPTIC ACTIONS OF CYCLIC AMP}

There is now evidence from a number of systems that under suitable conditions cyclic AMP or its dibutyryl derivative and various phosphodiesterase inhibitors can increase the release of synaptic transmitters. A role of cyclic AMP in transmitter release at the neuromuscular junction was first postulated by Breckenridge et al., (1967) on the basis of the observed enhancement by theophylline of the potentiation of neuromuscular transmission by epinephrine. In the rat phrenic nerve-diaphragm preparation dibutyryl cyclic AMP and the inhibitors theophylline and caffeine increased the amplitude of endplate potentials and the frequency of miniature endplate potentials (Goldberg and Singer, 1969). These results were considered to be consistent with the hypothesis that cyclic AMP plays a role in the release of acetylcholine and in the "defatiguing" effect of epinephrine. Miyamoto and Breckenridge (1974) confirmed that an increase in miniature endplate 
potential frequency occurs with theophylline, but were unable to observe any effect of dibutyryl cyclic AMP on miniature endplate potential frequency in normal preparations, although it caused a transient increase in $15 \mathrm{mM} \mathrm{K}^{+}$-stimulated (fatigued) preparations. These investigators concluded that cyclic AMP was probably not an obligatory factor in ACh-release from non-fatigued preparations. The effects of theophylline were tentatively ascribed to an alteration in calcium influx into the nerve terminal and the positive effects of dibutyryl cyclic AMP observed by Goldberg and Singer (1969) to osmotic factors. Miyamoto and Breckenridge (1974) also failed to confirm the earlier finding by Goldberg and Singer of an enhancement of miniature endplate potential frequency in non-fatigued muscles by epinephrine. Wilson (1974), using the same preparation, found that dibutyryl cyclic AMP caused a significant increase in the quantum content of the endplate potential and an enhancement of the releasable store of transmitter, but that it did not affect the probability of release. He suggested that cyclic AMP is involved in metabolic activity in the nerve terminal regulating the synthesis, mobilization and storage of acetylcholine rather than in the excitation-secretion coupling process itself.

Dibutyryl cyclic AMP can also initiate activity in unstimulated motor axons of the cat soleus nerve in vivo and produce 'stimulus-bound repetitive activity' in stimulated axons (Standaert et al., 1976a, b). It appears that dibutyryl cyclic AMP can depolarize nerve terminals in this preparation, causing a release of transmitter and a prolongation of action potentials. Dibutyryl cyclic GMP did not share this effect. Adenosine and the calcium antagonist, verapamil, prevented the effects of dibutyryl cyclic AMP which were attributed to an alteration in calcium fluxes in the nerve terminal.

Cyclic AMP and/or phosphodiesterase inhibitors have also been observed to increase the spontaneous release of catecholamines from adrenal medulla and from peripheral and central adrenergic strucutres (Berkowitz et al., 1970; Peach, 1972; Wooten et al., 1973; Cubbedu et al., 1975; Westfall et al., 1976).

While the evidence is generally consistent with a role for cyclic AMP in transmitter storage and release, some questions must be raised about the interpretation of the findings. Theophylline and caffeine, the two most extensively utilized phosphodiesterase inhibitors, have potent calcium mobilizing actions (Blinks et al., 1972; Serck-Hanssen, 1974; Amer and Kreighbaum, 1975). This action could explain many of the findings of enhanced transmitter release after application of these agents, as calcium entry is regarded as the basic event in excitation-
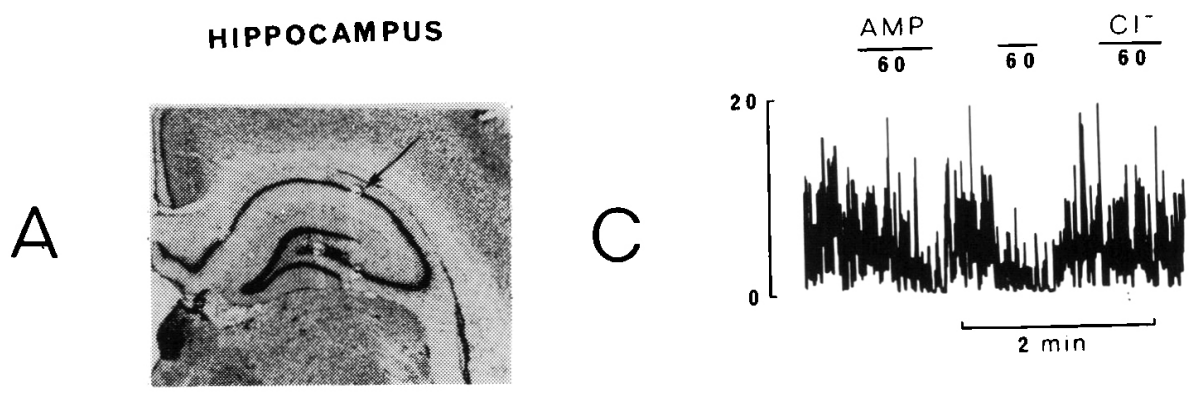

CAUDATE
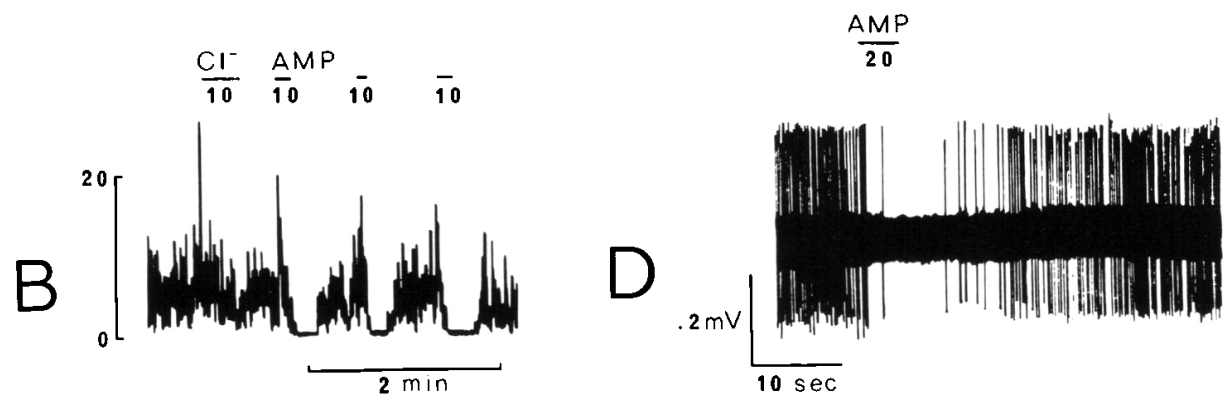

Figure 9-Examples of inhibition produced by 5'-AMP in different regions of the brain. $A$ illustrates the histologic verification of the position of a $C_{1}$ pyramidal neuron (arrow), and of two other neurons in the $\mathrm{CA}_{4}$ area of hippocampus. This $\mathrm{CA}$ । neuron was completely silenced by the microiontophoretic application of $10 \mathrm{nA} 5^{\prime}$-AMP(B). $C$ illustrates the effect of 5'-AMP on the glutamate-sustained activity of a superior colliculus neuron. This neuron responded to photic stimulation with a latency of $25-30 \mathrm{msec}$. In $\mathrm{D}$ the spontaneous activity of a caudate neuron in a decerebrate animal is readily depressed by $5^{\prime}$-AMP without appreciable attenuation of the spike amplitude. $B$ and $C$ are ratemeter records reproduced from the original paper tracing. D was recorded from an oscilloscope on slow-moving film. (From G. K. Kostopoulos and J. W. Phillis, 1977). 


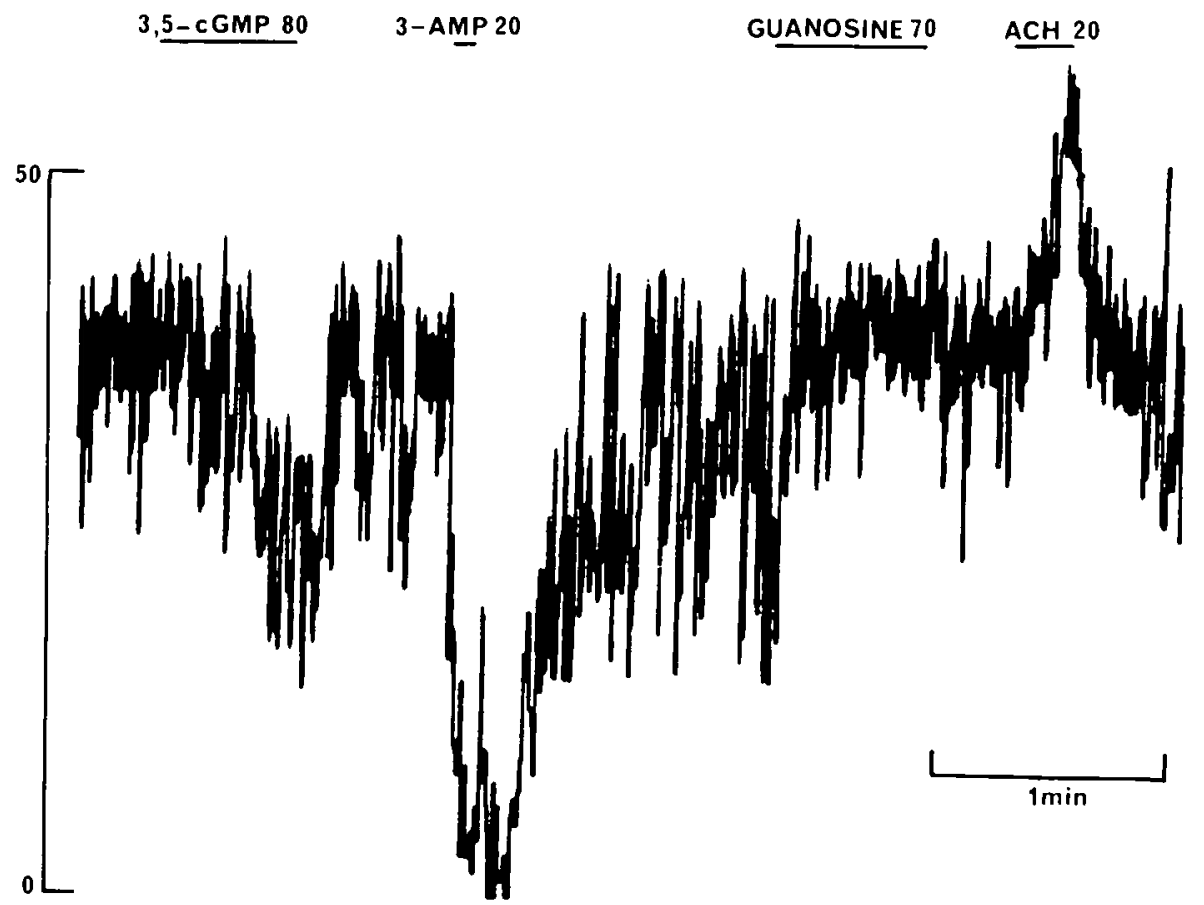

Figure 10-Ratemeter record of firing of a corticospinal neuron, Acetylcholine (ACh, $20 \mathrm{nA}$ ) excited this neuron. 3',5'-cyclic GMP (80 nA) and 3'-AMP (20 nA) depressed the spontaneous firing. Guanosine $(70 \mathrm{nA})$ was without effect.

catecholamines, perhaps acting as a signal to initiate the replacement of released transmitter (Guidotti and Costa, 1973; Nikodijevic et al., 1976).

\section{ACETYLCHOLINE AND CYCLIC GMP}

There has been much discussion of the possibility that cyclic GMP is the intracellular second messenger for muscarinic actions of $\mathrm{ACh}$ (George et al., 1970; Lee et al., 1972; Goldberg et al., 1973; Kebabian et al., 1975). This hypothesis is based on the evidence that in a number of tissues cholinergic activity is associated with a rise in the tissue content of cyclic GMP. This hypothesis has received direct support from the finding that $\mathrm{ACh}$ and cyclic GMP have mainly excitant actions on rat corticospinal neurons (Stone et al., 1975). In a study on cat cerebral cortical neurons cyclic GMP had either excitant or depressant actions, but these correlated poorly with the excitant or depressant actions of acetylcholine (Phillis, 1974c). In other tests of cyclic GMP it has had depressant actions on corticospinal (Fig. 10) and cere- bellar Purkinje cell neurons (Phillis et al., 1974; Hoffer et al., 1971).

In the belief that extracellular application may be an inappropriate second messenger function of cyclic GMP, Krnjevic et al. (1976) injected this substance directly into spinal motoneurons. Previously studies had shown that these neurons possess a muscarinic cholinergic excitatory receptor, which has rather similar properties to those of corticospinal neurons (Zieglgansberger and Reiter, 1974). The most consistent effect produced by intracellular injections of cyclic GMP in cat motoneurons was a rise in membrane conductance, acceleration in time course of spike potentials and accentuation of post-spike hyperpolarizations. Alterations in membrane potential were less consistently evoked and could be either hyperpolarizing or depolarizing. Acetylcholine, applied extracellularly, had a depolarizing action which was associated with rise in membrane resistance, together with a pronounced slowing of spike repolarization. As the effects of $\mathrm{ACh}$ technique for the demonstration of a were quite different from those of cyclic GMP, Krnjevic and his colleagues concluded that the latter was unlikely to be acting as a second messenger for $\mathrm{ACh}$.

$A$ rather different result has been obtained with cat sensorimotor cortical neurons. Both intracellularly injected cyclic GMP (2 nA) and extracellularly applied ACh caused increases in resting membrane resistance (Swartz and Woody, 1976) and the investigators concluded that cyclic GMP could mediate the $\mathrm{ACh}$ induced changes in membrane conductance. However, in experiments in other laboratories, increases in membrane resistance have not been a consistent feature of $\mathrm{ACh}$-induced depolarizations of cat cerebral cortical neurons (Fig. 11) or rat caudate neurons (Bernardi et al., 1976).

In conclusion, the effects of cyclic GMP appear to be variable. Even in the hands of Stone et al. (1975), cyclic GMP inhibited nearly 20 per cent of the rat corticospinal neurons tested and excited 60 per cent. In the author's laboratory 63 per cent of the 50 corticospinal neurons tested were depressed and only a small percentage were excited. Nonspontaneously active cortical neurons were more likely to be excited by cyclic GMP, even though these cells are often depressed by ACh (Phillis, 1974c). Cyclic GMP also depresses cerebellar Purkinje cells (Hoffer et al., 1971) which have been considered as cholinoceptive (Crawford et al., 1966). The most reasonable conclusion from these diverse findings is that cyclic GMP may have either depressant or excitant actions and that the result obtained in any particular series of experiments will be determined by various technical factors, such as the choice of anaesthetic and the level of spontaneous activity of the neurons tested.

Cyclic AMP accelerated the firing of 15 per cent of cerebellar Purkinje cells tested and it was conjectured that this resulted from pre- or postsynaptic effects of calcium chelation by the nucleotide (Siggins et al., 1971a). If cyclic GMP, which is an even less potent depressant than 
cyclic AMP, shares the same calcium chelating ability, it might be expected to have a more frequent excitant action than the latter.

\section{PHOSPHODIESTERASE INHIBITORS}

Considerable emphasis has been placed on the enhancement of the depressant actions of norepinephrine and cyclic AMP by the phosphodiesterase inhibitors, aminophylline and papaverine (Siggins et al., 1971; Hoffer et al., 1973). However, aminophylline and, to a lesser extent, papaverine, have potent depressant actions of their own (Anderson et al., 1975; Lake et al., 1973), those of aminophylline ([theophylline]-2-ethylene diamine) being due to its ethylene diamine component (Fig. 12) and occurring even in animals pretreated with 6-hydroxydopamine (Lake et al., 1973).

Studies with aminophylline and papaverine have shown that iontophoretic applications of these drugs tend to enhance the depressant actions of norepinephrine and cyclic AMP. This finding has been hailed as being consistent with the mediation of norepinephrine's actions by cyclic AMP but it might equally well be a reflection of the summative abilities of the inhibitory actions of various compounds.

In this laboratory, the phosphodiesterase inhibitor theophylline has been demonstrated to antagonize, rather than potentiate, the depressant actions of cyclic AMP on corticospinal neurons, presumably as a result of its block of the adenosine receptor.

Finally it must be stressed that phosphodiesterase inhibitors may have a variety of other actions, including calcium mobilization (Blinks et al., 1972; Serck-Hanssen, 1974; Berridge, 1975; Amer and Kreighbaum, 1975; Moritoki et al., 1976), 5'-nucleotidase inhibition (Tsuzuki and Newburgh, 1975) and adenosine receptor blockage (Huang and Daly, 1974) by the methylxanthines, including isobutylmethylxanthine. Other inhibitors such as papaverine, diazepam, chlordiazepoxide and RO 20-1724 can in-

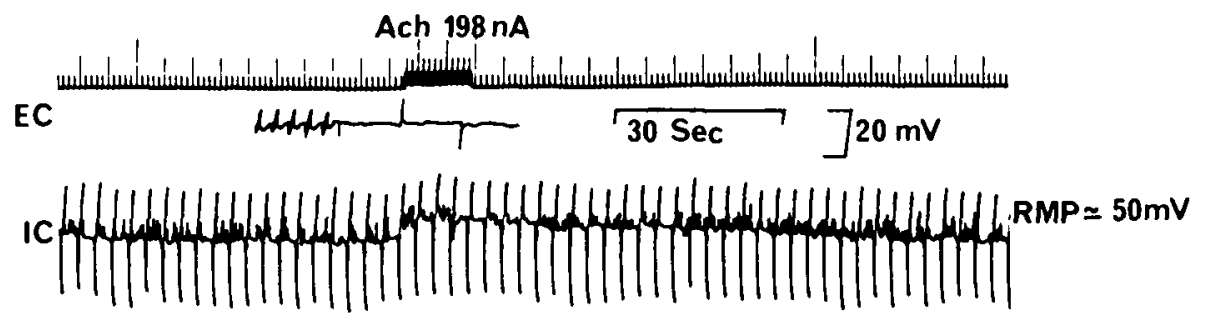

Figure /1-I.C. Intracellular potential record of a cerebral cortical neuron recorded on a chart recorder. Acetylcholine ( $\mathrm{ACh}, 198 \mathrm{nA}$ ) depolarized the neuron in the absence of any marked alteration in membrane resistance. $0.5 \mathrm{nA}$ pulses of 250 msec. duration of inward and outward current were used to test input impedance. E.C. Recording made after the electrode had been withdrawn from the neuron showing the small amount of bridge imbalance and the lack of effect of the current application on the recorded potential. (J. P. Edstrom and J. W. Phillis, unpublished observation).
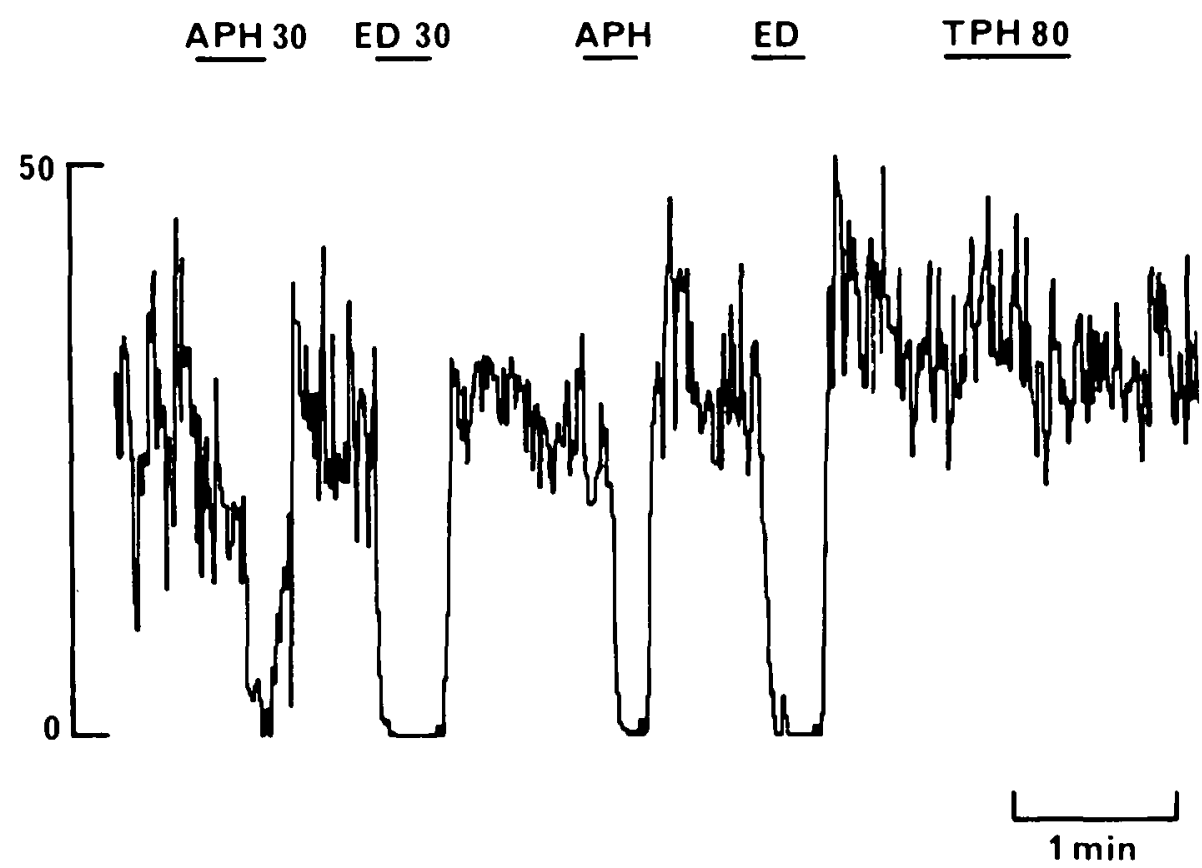

Figure 12-Ratemeter record of spontaneous firing of a cerebral cortical neuron. Aminophylline $(A P H, 30 \mathrm{nA})$ and ethylene diamine (ED, $30 \mathrm{nA})$ had potent depressant effects. Theophylline (TPH, $80 \mathrm{nA}$ ) did not depress the neuron's firing.

hibit the adenosine uptake mechanism (Mah and Daly, 1976) and papaverine stimulates $\mathrm{Na}^{+}$, $\mathrm{K}^{+}$-ATPase in crayfish nerves (Woods and Leiberman, 1976). Such alternative potential mechanisms of action must be borne in mind when phosphodiesterase inhibitors are to be used.

\section{PROSTAGLANDINS}

It has been claimed that prostaglandins of the $E$ series can selectively antagonize the depressant actions of norepinephrine on cerebellar
Purkinje cells by interfering with adenylate cyclase activation (Siggins et al., 1973). A related observation was that $P_{1} E_{1}$ and $P_{2} E_{2}$ also blocked the depressant action of iontophoretically applied aminophylline. Prostaglandin $E_{1}$ failed to affect the responses of hypothalamic neurons to norepinephrine (Stitt and Hardy, 1975) and in a study on cerebral cortical neurons, prostaglandins of the E series were found to be only weak antagonists of norepinephrine inhibition but were good antagonists of aminophylline depression (Lake 
et al., 1973). If, as suggested above, the depressant actions of aminophylline are due to ethylene diamine and not to phosphodiesterase inhibition, one can only speculate about the relationship of this antagonism to the second messenger hypothesis. Furthermore, the finding that prostaglandins enhance the formation of cyclic AMP by cortical tissue slices (Berti et al., 1972; Kuehl et al., 1972) lends no support to the hypothesis that they block norepinephrine by interfering with cyclic AMP formation. Prostaglandins of the $E$ series depress NE-secretion by sympathetic nerve terminals and there is evidence that this is a result of interference with calcium availability (Hadhazy et al., 1976; Stjärne, 1976; Hedqvist, 1976).

\section{F. AMINES, CALCIUM AND $\mathrm{NA}^{+}, \mathrm{K}^{+}$-ATPase}

Norepinephrine is the inhibitory transmitter released by sympathetic nerve fibers onto smooth muscle cells of the taenia coli of the large intestine. This tissue has been the subject of numerous investigations and therefore forms a useful model of an inhibitory adrenergic synapse. The inhibitory effects of norepinephrine are a result, in part, of a hyperpolarization due to an increased potassium conductance of the membrane ( $\alpha$-receptor activation) and, in part, by the suppression of the pacemaker potential ( $\beta$-receptor activation) (Bulbring and Tomita, 1969a and b).

The inhibitory action of catecholamines on the guinea pig taenia coli are calcium-dependent, in that these amines are ineffective in a calcium-free solution, whereas the inhibitory action of epinephrine is potentiated by an excess of calcium (Bulbring and Kuriyama, 1963; Hotta and Tsukiu, 1968). Calcium antagonists such as manganese and ruthenium red abolish the action of the catecholamines on smooth muscle cells of the taenia coli even in the presence of calcium (Bulbring and Tomita, 1969c; Tomiyama et al., 1973). Calcium produces a similar effect to the catecholamines, causing a hyperpolarization and stabilization of the membrane, and it has been suggested that the amines may act in the $\alpha$-mode by increasing calcium binding in the muscle membrane, which would somehow enhance movements of potassium. In the $\beta$-mode, catecholamines would immobilize membrane bound calcium or reabsorb free calcium and so prevent depolarization and the generation of pacemaker potentials (Bulbring and Tomita, 1969c; Magaribuchi and Kuriyama, 1972).

In the light of these observations and conclusions, it was considered worthwhile to observe the effects of agents which interfere with calcium binding on the central effects of biogenic amines. Given the difficulties inherent in altering extracellular calcium concentrations in the brain, the approach has been to use agents with a demonstrated ability to modify calcium binding to, and fluxes across, plasma membranes, as well as calcium chelators. The effects of these agents on the depressant effects of various biogenic amines on cerebral cortical neurons were therefore ascertained. The so-called calcium "antagonists" used in these studies included various metallic cations, verapamil (isoptin hydrochloride), local anaesthetics, neomycin and ruthenium red (Yarbrough et al., 1974; Phillis, 1974a, 1974b). The chelating agents were EDTA (ethylenediamine tetracetic acid) and EGTA (ethyleneglyco-bisaminoethyl-ether-tetracetic acid). With the exception of neomycin and ruthenium red, the calcium antagonists tended to depress cell excitability during and immediately following their application. Repeated applications of the agonist amines were made during and after administration of the calcium antagonists, and were continued until recovery was evident (recovery times were from 3-20 min). Calcium antagonists antagonized the depressant effects of norepinephrine, dopamine, serotonin, histamine and acetylcholine on cerebral cortical neurons, but did not alter inhibitions evoked by $\gamma$-aminobutyric acid, or acetylcholine excitations.

The metallic cations tested in our experiments included lanthanum, cobalt, manganese and nickel. Confirmation that polyvalent metallic ions with calcium antagonist properties can antagonize norepinephrineevoked inhibition has been forthcoming from experiments on cerebellar Purkinje cells, in which lanthanum and lead blocked norepinephrine-evoked inhibitions of these neurons (Nathanson et al., 1976; Taylor et al., 1976). Lead has been used as a calcium antagonist in experiments on skeletal neuromuscular junctions where, acting in a manner comparable to lanthanum, it can uncouple excitation-secretion coupling in the presynaptic nerve terminals (Manalis and Cooper, 1973). Similar results have been obtained in sympathetic ganglia where lead competitively inhibits calciumdependent synaptic transmission (Kober and Cooper, 1976).

Two difficulties have arisen from these studies with the so-called calcium 'antagonists'. In a study on cerebellar Purkinje cells, Freedman et al. (1975) failed to confirm an antagonist action of cobalt, manganese and verapamil on norepinephrine-depressions and attributed the positive findings of Yarbrough et al. (1974) to a technical factor - interruption of the agonist application sequences during the period of administration of the antagonist, and a subsequent decrease in the amount of agonist ejected. This is unlikely to have been the explanation for the positive results observed with cobalt, manganese and verapamil for two reasons. Firstly, the retaining currents used by Yarbrough et al. (1974; 8-10 nA) were substantially lower than those employed by Freedman et al. (1975; $15 \mathrm{nA}$ ), and currents of this magnitude would not have had such a pronounced effect on subsequent amine ejections. Secondly, after completion of the antagonist application, the amines were applied in a repeated sequence until recovery occurred. During this period antagonism was often pronounced for several minutes and then gradually disappeared. The positive results obtained by others with lead and 
lanthanum, referred to above, support our conclusion that polyvalent metallic cations can antagonize amine-evoked depressions. Furthermore, two calcium 'antagonists' which do not depress neuronal excitability, neomycin and ruthenium red, also block amine-induced depressions (Phillis, 1974b). It should be stressed that in these latter experiments there was no interruption of the agonist ejection sequence. A more likely explanation for the failure of Freedman et al, (1975) to replicate our results lies in the "calcium antagonist' potencies of the polyvalent metallic cations. When tested as inhibitors of the calciumdependent spike potential of barnacle muscle fibers, cobalt and manganese had approximately $1 / 10$ th and 1/50th the activity of lanthanum (Hagiwara, 1973). It is hardly surprising therefore that positive results can more readily be obtained with lanthanum than with cobalt and manganese.

The antagonism by phenothiazine derivatives (fluphenazine, flupenthixol and chlorpromazine) of norepinephrine-evoked depression of cerebellar neurons has been interpreted as suggesting that calcium is not involved in the action of this amine, since the antagonism by chlorpromazine of norepinephrine's effects in vitro occurs at concentrations some two orders of magnitude less than those required to block calcium fluxes (Freedman and Hoffer, 1975). Thus while chlorpromazine blocks the stimulation of adenylate cyclase by dopamine at a concentration of $10^{-6} \mathrm{M}$ (Miller et al., 1974), a concentration of $5 \times 10^{-4}$ is required to block calcium uptake into synaptic plasma membrane residues (Madiera and AntunesMadiera, 1973).

Several objections can be raised to this somewhat specious interpretation of their findings by Freedman and Hoffer (1975). Quite apart from the difficulties inherent in comparisons between in vivo and in vitro observations on a variety of preparations, the authors can have had no knowledge of the actual concentration of the phenothiazines attained in their experiments in the extracellular environment. It is impossible to conclude therefore that the phenothiazines were not acting as calcium antagonists in these experiments. Further, no attempt was made to ascertain whether the antagonism exerted by the phenothiazine derivatives could discriminate between different amines rather than between norepinephrine and two very different agents, $\gamma$-aminobutyric acid and cyclic AMP

A characteristic finding in our studies with the calcium 'antagonists' has been a simultaneous block of the actions of histamine, serotonin and norepinephrine, implicating a common mode of depression by the various amines. This apparent lack of pharmacological specificity in the action of the amines on spinal cord motoneurons has prompted Engberg and his colleagues to propose a common mechanism of action for all these compounds, mediated perhaps on charged groups at the membrane (Engberg et al., 1974).

The recent discovery of specific antagonists which will discriminate between the actions of histamine and those of the other amines (metiamide; Phillis et al., 1975), and between those of serotonin and the other amines (metergoline; Sastry and Phillis, 1977a) on cerebral cortical neurons strongly supports the concept of individualized receptors for each of the major groups of amines, each receptor being connected to a similar or common mechanism which, when activated, evokes a membrane hyperpolarization. It remains to be clearly established whether, when applied iontophoretically, the phenothiazines can discriminate between catecholamines and the other amines. Iontophoretically applied chlorpromazine antagonizes the depressant action of histamine on cerebral cortical neurons (Phillis et al., 1968b), and this substance will likely have to be discarded as a selective catecholamine antagonist.

A more significant problem associated with the use of calcium antagonists may lie in the specificity of their action. To a large extent, the use of these agents in physiological research was pioneered in studies on calcium fluxes in cardiac muscle, and doubts are now being voiced about their pharmacological specificity in this system (Kass and Tsien, 1975). It is becoming increasingly apparent that many calcium antagonists also affect two enzymes that may be of crucial importance in the regulation of membrane exctiability, $\mathrm{Na}^{+}, \mathrm{K}^{+}-\mathrm{ATPase}$ and adenylate cyclase. The metallic cations, lithium, lead, copper, zinc, iron, cobalt, calcium, nickel, manganese and mercury inhibit brain $\mathrm{Na}^{+}, \mathrm{K}^{+}-$ATPase (Skou, 1965; Donaldson et al., 1971; Ting-Beall et al., 1973; Specht and Robinson, 1973; Prakash et al., 1973; Hexum, 1974). Lanthanum inhibits $\mathrm{Na}^{+}$, $\mathrm{K}^{+}$-ATPase from heart muscle (Nayler and Harris, 1976), and lanthanum, manganese and ruthenium red inhibit $\mathrm{Mg}^{++}$, $\mathrm{Ca}++$-ATPase activity of rat cortex synaptic membranes (Ichida et al., 1976). Other agents which have been used as calcium antagonists and which also inhibit $\mathrm{Na}{ }^{+}$, $\mathrm{K}^{+}$-ATPase include alcohols and local anaesthetics (Seeman, 1972).

Brain adenylate cyclase is inhibited by low concentrations of lithium, lead, copper, zinc, lanthanum and mercury (Forn and Valdecasas, 1971; Taylor et al., 1976; Nathanson and Bloom, 1976; Nathanson, Freedman and Hoffer, 1976; Walton and Baldessarini, 1976). Cobalt inhibits cardiac sarcolemmal adenylate cyclase in the presence of magnesium (St. Louis and Sulakhe, 1976), and manganese reduces the stimulation of rat brain enzyme by dopamine (Walton and Baldessarini, 1976). Antagonism of norepinephrine-evoked depression of hippocampal or cerebellar neurons by lithium, lanthanum and lead has been attributed to inhibition of adenylate cyclase activity (Segal, 1974; Nathanson et al., 1976; Taylor et al., 1976).

It is difficult to escape the conclusion that agents such as the polyvalent cations described above, which possess the ability to antagonize cal- 
cium binding and fluxes in the membrane, will often also inhibit $\mathrm{Na}^{+}$, $\mathrm{K}^{+}$-ATPase and adenylate cyclase. The latter property may reflect the ability of the calcium antagonists to bind to negatively charged membrane sites, including the metalbinding regulatory sites associated with enzymic systems, displacing other metallic ions. These agents may thus interfere with a number of processes which do not normally require calcium as a co-factor. For this reason extreme caution will obviously be necessary for the interpretation of results obtained in studies which rely solely on the use of calcium antagonists. Similar considerations must apply to the use of chelating agents, which can bind other metallic cations in addition to calcium (Garvan, 1964). Nevertheless, the observation that EDTA and EGTA can abolish the depressant action of norepinephrine on cerebral cortical neurons (Phillis, 1976) is consistent with the assumption that the presence of calcium or a related metallic cation is necessary for norepinephrine to exert its effects.

The possibility that the slow inhibitory postsynaptic potential of sympathetic ganglion cells, in the generation of which catecholamines have been implicated, is evoked by activation of an electrogenic sodium pump was discussed in Section B.I.(2). $\mathrm{Na}^{+}, \mathrm{K}^{+}$-A TPase inhibitors such as ouabain, sodium cyanide, 2,4-dinitrophenol and low temperature selectively block the slow IPSP and the hyperpolarizing action of epinephrine on bullfrog ganglion cells, presumably by interference with the functioning of the electrogenic pump. Perfusion with sodium-free lithium or hydrazinium solutions, which might be expected to reduce the intracellular sodium concentrations, abolish the slow IPSP and catecholamine-induced hyperpolarization (Nishi and Koketsu, 1968; Koketsu, Shoji and Nishi, 1973; Koketsu and Nakamura, 1976). The hyperpolarizing action of serotonin on nicotinized bullfrog ganglion cells may also be mediated by an electrogenic pump, as it is blocked by ouabain, or exposure of the ganglion to sodium- free lithium solution. Extracellular potassium is necessary for the generation of a maximal hyperpolarization by serotonin (Watanabe and Koketsu, 1973; Koketsu and Shirasawa, 1974).

Comparable responses have been recorded from avian and amphibian skeletal muscles, which are hyperpolarized by catecholamines by a ouabain and potassium sensitive process (Somlyo and Somlyo, 1969; Bressler et al., 1975; Koketsu and Ohta, 1976). Frog skeletal muscle membrane contains a sodium pump which is stimulated by epinephrine, greatly increasing sodium efflux. This action of epinephrine is blocked by strophanthidin (Hays et al., 1974). Further studies on this phenomenon have revealed that $\mathrm{Na}^{+}, \mathrm{K}^{+}$-ATPase activity in the sarcolemmal fraction from rat skeletal muscle is stimulated by various catechols and their orthoquinones, including D-, L-isoproterenol and D-, L-epinephrine and pyrocatechol, all of which have comparable activity. Phenylephrine, an $\alpha$-adrenergic agonist, was unable to enhance $\mathrm{Na}^{+}, \mathrm{K}^{+}-\mathrm{ATPa}$ Te activity, as were cyclic AMP and dibutyryl cyclic AMP (Cheng et al., 1977). $\beta$-adrenergic blocking agents, propranolol and dichloroisoproterenol, had no effect on the enhancement of $\mathrm{Na}^{+}, \mathrm{K}^{+}-$ATPase activity produced by L-isoproterenol, suggesting that the effect was not mediated through classical $\beta$-receptors. In contrast, when the same investigators (Rogus et al., 1977) studied changes in sarcoplasmic $\mathrm{Na}^{+}$and $\mathrm{K}^{+}$content in intact muscles exposed to L-isoproterenol, they found evidence for a $\beta$-adrenergic stimulation of the membrane $\mathrm{Na}^{+}, \mathrm{K}^{+}$ pump. D-isoproterenol had only $3 \%$ of the activity of the L-isomer, and the response to L-isoproterenol was blocked by propranolol, but not by phentolamine. The effect of L-isoproterenol on ionic content could be mimicked by dibutyryl cyclic AMP or caffeine. The results of the second study have led to the suggestion that in intact muscle $\beta$-adrenergic agonists activate adenylate cyclase. Cyclic AMP thus formed causes the synthesis and/or release of an intracellular agent which acts directly on $\mathrm{Na}+$, $\mathrm{K}^{+}$-ATPase, enhancing its activity (Rogus et al., 1977).

$\mathrm{Na}^{+}, \mathrm{K}^{+}-$ATPase activity in mammalian brain homogenates or synaptosomal fractions is stimulated by various amines, including norepinephrine, dopamine, serotonin, histamine and acetylcholine (Schaefer et al., 1972; Yoshimura, 1973; Godfraind et al., 1974; Gilbert et al., 1975; Logan and Donovan, 1976; Sulakhe et al., 1976; Desaiah and Ho, 1976; Kometiani et al., 1976; S. L. Lee and J. W. Phillis, unpublished observations). Stimulation by norepinephrine was antagonized by the $\alpha$-adrenoreceptor blocker, phenotolamine (Iwangoff et al., 1974; Gilbert et al., 1975). Acetylcholine may also inhibit the enzyme (Gilbert et al., 1975; Kometiani et al., 1976). Cyclic AMP reportedly does not alter $\mathrm{Na}^{+}, \mathrm{K}^{+}$-ATPase activity in brain preparations (Yoshimura, 1973; Sulakhe et al., 1976), indicating that the stimulant effect of the biogenic amines is probably not a direct consequence of activation of adenylate cyclase.

Within the central nervous system $\mathrm{Na}^{+}, \mathrm{K}^{+}-$ATPase is known to be associated with synaptic membranes. Hosie (1965) and Kurokawa et al. (1965) found $\mathrm{Na}+$, $\mathrm{K}^{+}-\mathrm{ATPase}$ of high specific activity in subcellular fractions containing isolated nerve endings derived from cerebral tissues, and this enzyme represented a substantial portion of the activity of the total brain homogenate. The enzyme in rat cerebral cortex has been localized histochemically in neuronal processes, including axons and dendrites (Stahl and Broderson, 1976).

Pharmacological studies on rat cerebral cortical neurons support the hypothesis that amines depress by activating $\mathrm{Na}^{+}, \mathrm{K}^{+}$-ATPase. Thus ouabain and lithium antagonize the depressant actions of norepinephrine on these neurons (Phillis, 1974b, 1976; Phillis and Limacher, 1974), and it has recently been reported that ouabain antagonizes the depressant actions of norepine- 
phrine and dopamine on cerebellar Purkinje cells and caudate neurons respectively (Yarbrough, 1976). Further support for the hypothesis has been sought by testing the effects of a diverse series of $\mathrm{Na}^{+}$, $\mathrm{K}^{+}$-ATPase inhibitors including various glycosides, aglycones, ethacrynic acid and harmaline (Table 3) on depressions of cortical neurons evoked by the biogenic amines (Figs. 13, 14; Sastry and Phillis, 1977b). A close correlation was observed between the known potencies of the compounds tested as $\mathrm{Na}+, \mathrm{K}^{+}-$ATPase inhibitors and their ability to completely or partially antagonize amine-induced depressions. The inhibitors did not antagonize the depressant effects of calcium, $\gamma$-aminobutyric acid and AMP, implying that these agents are unlikely to exert their effects through activation of an electrogenic sodium pump.

Other agents which have been reported to inhibit $\mathrm{Na}^{+}, \mathrm{K}^{+}-\mathrm{ATPa} e$ (Roufogalis and Belleau, 1969; Israel, 1970; Seeman, 1972), and which also antagonize the depressant actions of the biogenic amines on central neurons include the barbiturate anaesthetics, ethanol, and the catecholamine antagonists, chlorpromazine, haloperidol, dibenamine and phenoxybenzamine (Phillis, 1976).

Of considerable interest to the present discussion is the report that

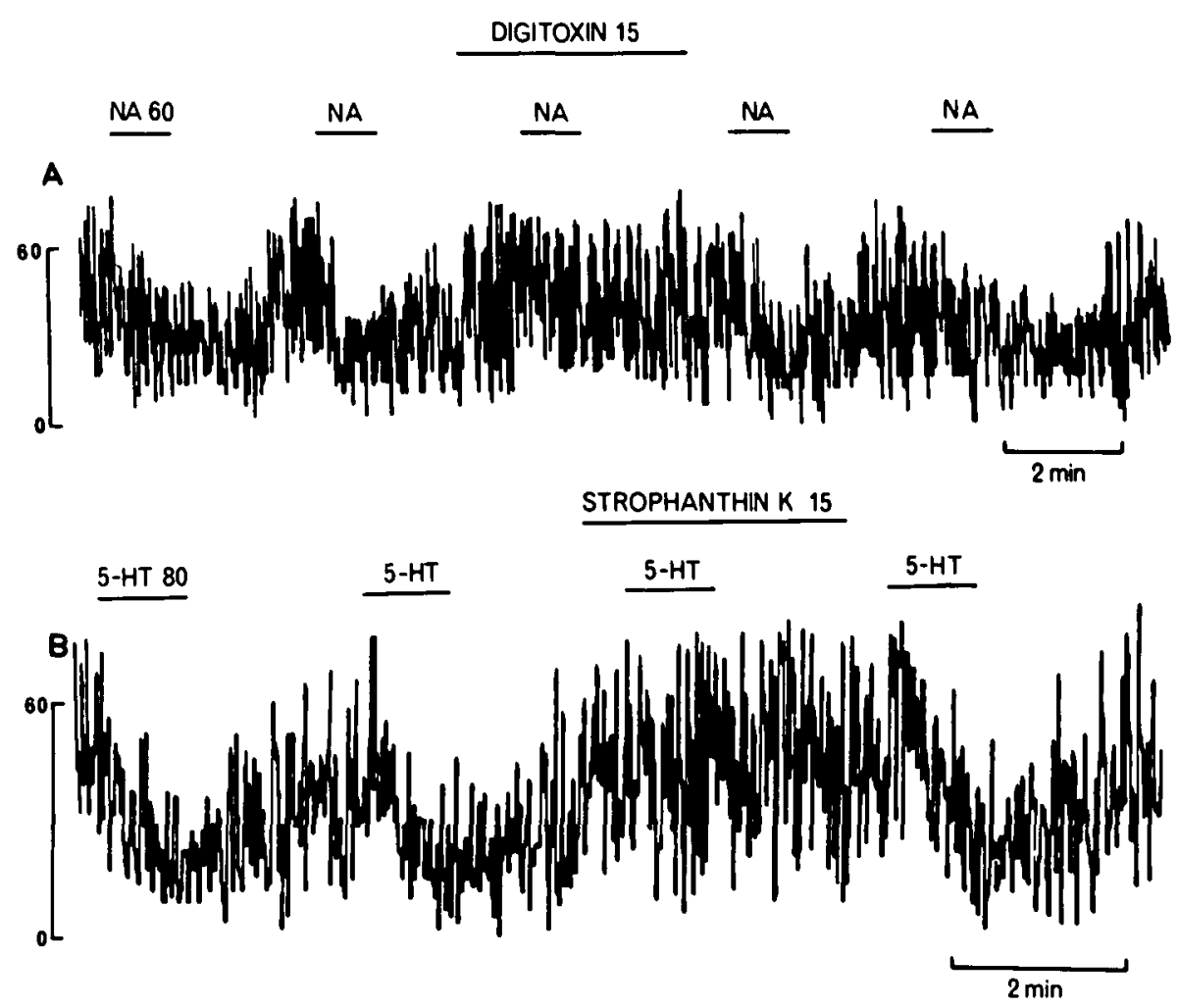

Figure 13-The antagonism of norepinephrine (A, NA, $60 \mathrm{nA}$ ) and 5-hydroxytryptamine (B, 5-HT, $80 \mathrm{nA})$ effects by digitoxin (15 $\mathrm{nA})$ and strophanthin $\mathrm{K}(15 \mathrm{nA})$ respectively. $\mathrm{A}$ and $\mathrm{B}$ are records from different deep spontaneously firing cerebral cortical neurons. In this and the subsequent figures the ordinate calibration represents neuronal firing rate as spikes per second. The horizontal bars indicate the duration of drug application periods. (From B. S. R. Sastry and J. W. Phillis, 1977b).

TABLE 3

Effects of $\mathrm{Na}^{+}, \mathrm{K}^{+}$-ATPase Inhibitors on the Depression of Cerebral Cortical Neurones by the Biogenic Amines and Other Agents

\begin{tabular}{|l|c|c|c|c|c|c|c|}
\hline & Noradrenaline & Histamine & 5-HT & GABA & Adenosine & 5'AMP & Calcium \\
\hline Ethacrynate & $31 / 36^{*}$ & $25 / 31$ & $17 / 21$ & $0 / 5$ & $0 / 9$ & $0 / 5$ & $0 / 6$ \\
\hline Ouabain & $17 / 22$ & $23 / 27$ & $16 / 19$ & $0 / 7$ & $0 / 5$ & $0 / 5$ & $0 / 5$ \\
\hline Harmaline & $18 / 19$ & $23 / 25$ & $19 / 20$ & $0 / 5$ & $0 / 8$ & $0 / 5$ & $0 / 5$ \\
\hline Digitoxin & $7 / 8$ & $6 / 6$ & $4 / 4$ & --- & --- & --- & $0 / 7$ \\
\hline Digitoxigenin & $5 / 6$ & $4 / 5$ & $3 / 4$ & --- & --- & --- & $0 / 5$ \\
\hline Strophanthin K & $5 / 5$ & $5 / 5$ & $5 / 5$ & --- & --- & --- & --- \\
\hline Strophanthidin & $4 / 6$ & $4 / 5$ & $4 / 4$ & --- & --- & --- & --- \\
\hline
\end{tabular}

* The denominator indicates the total number of cells tested and the numerator shows the number of cells in which the effect of an agonist is antagonized. (Data from Sastry and Phillis, 1977b). 
norepinephrine and cyclic AMPinduced hyperpolarizations of rat pineal gland cells are blocked by ouabain or elevated potassium (Parfitt et al., 1975). The investigators concluded that norepinephrine exerts its hyperpolarizing effects by activation of adenylate cyclase, although they could not exclude the possibility that the hyperpolarization and the increase in cyclic AMP content of the gland occurred independently. The most significant obser-
The evidence presented in this section suggests that transmembrane alterations in calcium levels may be crucial for the mediation of the actions of the biogenic amines. Calcium has multiple functions within innervated tissues, including the maintenance of membrane integrity, excitation-secretion coupling, excitation-contraction coupling and regulation of enzymic activity (Bianchi, 1968; Triggle, 1971). An involvement in the generation of post-
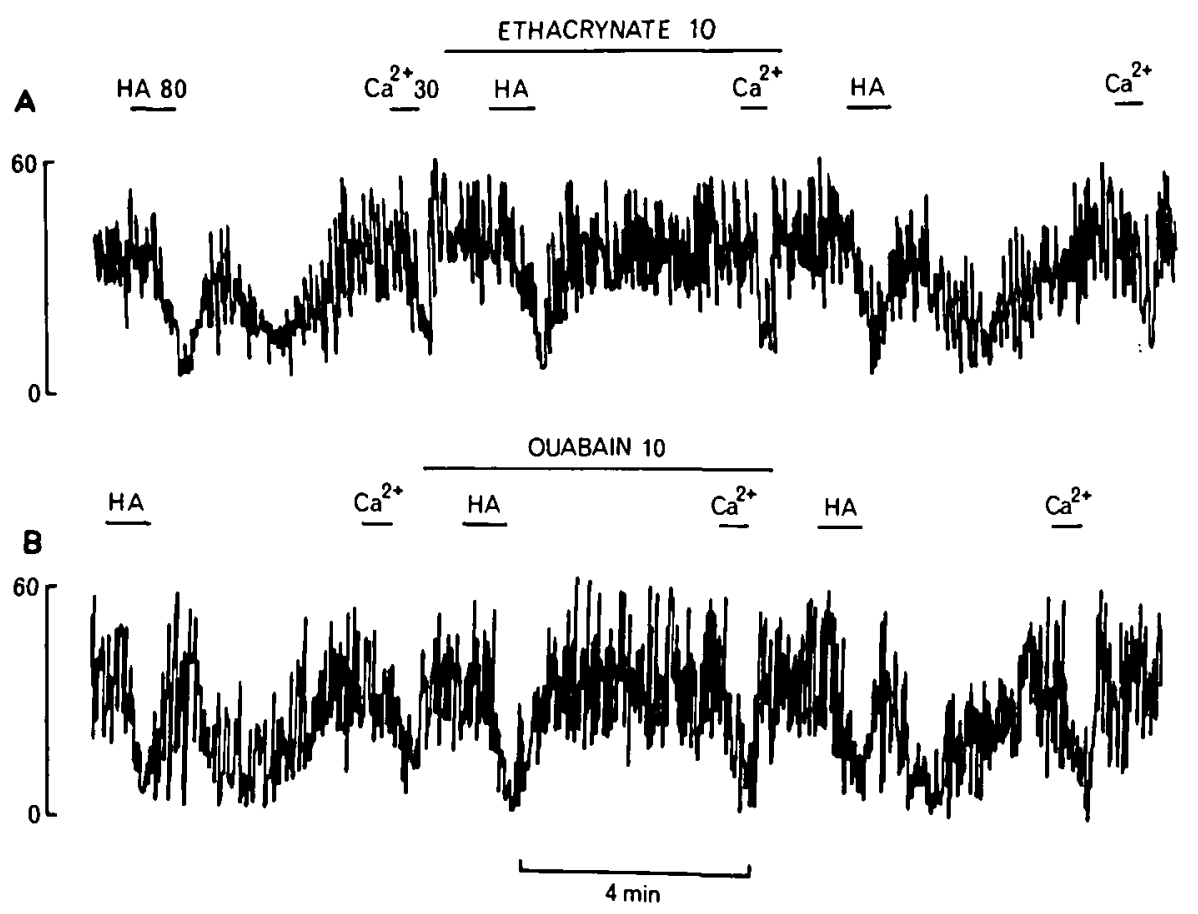

Figure 14-The antagonism of histamine (HA, $80 \mathrm{nA}$ ) - induced depression of a spontaneously active cerebral cortical neuron by ethacrynate $(A, 10 \mathrm{nA})$ and ouabain $(B, 10 \mathrm{nA})$. Both $\mathrm{HA}$ and calcium $(\mathrm{Ca}++, 30 \mathrm{nA})$ were applied in sequence at regular intervals. Note that ethacrynate and ouabain more effectively prevented the late prolonged phase of the amine-induced inhibition and did not antagonize the depression by $\mathrm{Ca}++$. A-B depicts a continuous recording of a deep cortical cell firing (From B. S. R. Sastry and J. W. Phillis, 1977b).

vation, however, was that the cyclic AMP-induced hyperpolarization was generated by a ouabain sensitive ionic mechanism, presumably reflecting activation of $\mathrm{Na}^{+}$, $\mathrm{K}^{+}$-ATPase. Reversal of the norepinephrine-evoked hyperpolarization of frog skeletal muscle by elevated potassium has been reported (Bressler et al., 1975) and was interpreted as evidence for some flexibility in the $\mathrm{Na}^{+}-\mathrm{K}+$ transport ratio of the pump. synaptic potentials must now be considered for inclusion with these actions. Elevation of intraneuronal calcium levels causes a membrane hyperpolarization which is thought to be the result of an increase in membrane potassium conductance (Krnjevic and Lisiewicz, 1972). This increase in membrane conductance precludes any suggestion that amines hyperpolarize simply by increasing intracellular calcium, since their action occurs in the absence of any alteration in (or in some instances with a decrease in) membrane conductance.

The role of cyclic nucleotides in the control of calcium binding and calcium fluxes is presently uncertain. Recent reports indicate that cyclic AMP can initiate calcium sequestration by endoplasmic reticulum of skeletal, cardiac and smooth muscle through stimulation of a calcium pump (Berridge, 1975). Mitochondria are also capable of sequestering calcium against a considerable concentration gradient (Drahota et al., 1965) and may play a considerable role in regulating intracellular calcium levels (Borle, 1973).

There is abundant evidence that cyclic AMP can also release calcium from intramembranous or intracellular stores, possibly including the mitochondria, in presynaptic terminals and secretory cells (Rasmussen, 1970; Rasmussen et al., 1972; Berridge, 1975) (see section E, IV). For instance, the stimulatory effect of cyclic nucleotides on epinephrine secretion from the adrenal medulla persists in calcium-free conditions which completely block the stimulatory effects of both high potassium and nicotine (Peach, 1972).

The methylxanthine, caffeine, can stimulate a release of calcium from adrenal medullary mitochondria (Rahwan et al., 1973) and this may account for the secretion enhancing properties of this group of phosphodiesterase inhibitors. Calcium release from intramembranous or intracytoplasmic stores by cyclic AMP may occur in both presynaptic and post-synaptic neuronal elements and could account for some of the effects of extra- or intra-cellularly applied cyclic AMP and dibutyryl cyclic AMP.

Calcium-cyclic nucleotide interactions will occur in several other respects. Calcium appears to be involved in regulation of adenylate and guanylate cyclase, and alterations in calcium levels may alter the responses of these enzymes to synaptic transmitters. Calcium ions can regulate the activities of phosphodiesterases, and changes in cal- 
cium concentration within the biological range can reverse the effects of cyclic AMP on some phosphotransferase reactions (Ueda et al., 1973).

If both adenylate cyclase and calcium are involved in the response to catecholamines, the question becomes one of whether the initial event is an alteration in calcium fluxes or binding which could then affect the activities of cyclase, phosphotransferases and phosphodiesterases, or an activation of adenylate cyclase and subsequent alteration in intracellular or intramembranous calcium concentrations. Indeed, the two series of events may occur simultaneously rather than sequentially (Berridge, 1975).

A final step in the amine-induced hyperpolarization appears to be activation of membrane $\mathrm{Nat}$, $\mathrm{K}+$-ATPase. Several tentative explanations can be provided for this event, including cyclic AMP or calcium stimulated phosphorylation of the ATPase (Dowd and Schwartz, 1975; Dowd et al., 1976; Sulakhe and St. Louis, 1976) with an increase in its activity; release or stimulation of an ATPase-activating factor by cyclic AMP (Rogus et al., 1977) or calcium; or, since calcium exerts an inhibitory action on ATPase, removal of calcium by a cyclic AMPor calcium-stimulated sequestration system.

It has been suggested that acetylcholine-evoked depolarization of corticospinal neurons results from a decrease in membrane potassium conductance (Krnjevic et al., 1971a), resulting perhaps from a reduction in internal free calcium (Krnjevic et al., 1975). However, in other experiments (Fig. 11, and Bernardi et al., 1976) this decrease in membrane conductance has not been a prominent feature of acetylcholine-evoked depolarizations. An alternative explanation for the depolarization may be that acetylcholine, directly or indirectly, inhibits the $\mathrm{Na}^{+}, \mathrm{K}^{+}$ATPase activity of corticospinal neurons. An inhibitory action of acetylcholine on brain $\mathrm{Na}^{+}, \mathrm{K}^{+}$ATPase has been reported (Gilbert et al., 1975; Kometiani et al., 1976), and this suggested mechanism of action is consistent with the observation that the $\mathrm{Na}^{+}, \mathrm{K}^{+}$-ATPase inhibitor, ouabain (Godfraind et al . 1971), and barium ions (Krnjevic et al., 1971b) excite corticospinal neurons. The action of barium in particular is very similar to that of acetylcholine in that it excites neurons which are depolarized by acetylcholine and depresses neurons which are either unaffected or inhibited by acetylcholine (Krnjevic et al., 1971b; Phillis and Limacher, 1974). Experiments on sodium ion transport in isolated toad bladder have demonstrated that barium inhibits sodium ion transport by an action on an electrogenic sodium pump (Ramsay et al., 1976). Acetylcholine inhibition of cerebral cortical neurons is prevented by various calcium 'antagonists' (Yarbrough et al., 1974) and may result from stimulation of $\mathrm{Na}^{+}, \mathrm{K}^{+}$-A TPase (Kometiani et al., 1976).

\section{G. CYCLIC NUCLEOTIDES AND MEMORY}

The possibility that alterations in the phosphorylation state of synaptic proteins might be associated with short term memory was proposed by Greengard and Kuo (1970). It was envisaged that transmitter-evoked increases in cyclic AMP might cause alteration in the degree of phosphorylation of membrane proteins and could thus lead to a short term modification of the properties of the postsynaptic neuronal membrane. In addition to changes in the phosphorylation of proteins in the membrane, short term modulation of synaptic transmission could also occur by phosphorylation processes involving enzyme induction (Guidotti et al., 1975) or regulation of enzymes involved in the metabolic functions of the cell.

Norepinephrine in the forebrain is thought to play a critical role in the associative learning process, and drugs which affect norepinephrine metabolism or release can affect the memory consolidation process (Kety, 1972). Only two examples of the numerous experiments on norepinephrine and learning will be mentioned here. The medial fore- brain bundle, through which norepinephrine-containing fibers ascend to the cerebral cortex, is apparently of considerable significance in the learning process (Crow, 1973). Destruction in rats of the locus coeruleus from which these neurons arise results in a deficit in the acquisition of runway behavior (Anlezark et al., 1973). Furthermore, central administration of norepinephrine to rats previously depleted of the catecholamine by administration of the dopamine- $\beta$-hydroxylase inhibitor diethyldithiocarbamate results in an enhancement of memory (Stein et al., 1975).

Some indication of the manner in which catecholamines are involved in short term memory may be evident in the observations of Libet et al. (1975) on rabbit superior cervical ganglion. Dopamine can produce a specific and enduring enhancement, lasting at least several hours, of the subsequent responses to acetylcholine or the muscarinic agonist, acetyl- $\beta$-methylcholine. The dopamine-induced enhancement of acetyl- $\beta$-methylcholine-depolarizations is mimicked by dibutyryl cyclic AMP applications, and the enhancement produced by cyclic AMP occludes any further enhancement by subsequent doses of dopamine. Exposure of the ganglion to dibutyryl cyclic GMP within 4 min. of the dopamine or cyclic AMP injection disrupts the expected modulatory effect. When treatment with cyclic GMP was delayed for periods of longer than $4 \mathrm{~min}$. after dopamine, progressively lesser disruptions occurred. With delays of greater than 10-15 min. there was no disruption. These features of the actions of cyclic GMP suggest that after the initial modulatory change is induced by dopamine, through a cyclic AMP mediated mechanism, a 'storage' process develops which leads to a more durable form of modulatory change. The storage process, but not the durable product, can be disrupted by cyclic GMP.

This dopamine-modulating action in the sympathetic ganglion may provide an interesting model in which the development of short and long term memory traces can be 
studied. Such amine-modulating actions may not be unique to the central nervous system. Adrenaline enhances the sensitivity of $\beta$-cells in the pancreas to subsequent doses of acetylcholine by a calciumdependent process (Burr et al., 1976), a phenomenon which may be similar to that described above for dopamine in sympathetic ganglia.

\section{H. CONCLUSIONS}

On the basis of the information presented in this paper, it is difficult to reach any firm decision regarding the role of cyclic AMP (or cyclic GMP) in synaptic transmission in the brain. While it is clear that cyclic AMP levels can be altered by the exposure of neural tissues to various neurotransmitters, it would be premature to claim that this nucleotide is, or is not, essential to the transmission process in the pre- or post-synaptic components of the synapse. In future experiments, it will be necessary to consider more critically whether extracellularly applied cyclic AMP merely provides a source of adenosine and is thus activating an extracellularly located adenosine receptor, or whether it is actually reaching the hypothetical sites at which it might act as a second messenger. The application of cyclic AMP by intracellular injection techniques should minimize this particular problem, although possibly at the expense of new difficulties. Prior blockage of the adenosine receptor with agents such as theophylline or adenine xylofuranoside may also assist in the categorization of responses to extracellularly applied cyclic AMP as being a result either of activation of the adenosine receptor or of some other mechanism. Ultimately, the development of highly specific inhibitors for adenylate cyclase should provide a firm basis from which to draw conclusions about the role of cyclic AMP in synaptic transmission.

The use of phosphodiesterase inhibitors in studies on cyclic nucleotides must also be approached with caution. The diverse actions of many of these compounds, which include calcium mobilization and block of adenosine uptake, have been mentioned on several occasions in this paper and could account for many of the results that have been reported.

Regardless of the role, or lack thereof, of cyclic nucleotides in the synaptic transmission process, there is pharmacological evidence for an involvement of calcium and $\mathrm{Na}^{+}$, $\mathrm{K}^{+}$-ATPase in the responses of central neurons to the various biogenic amines. Biochemical studies on the relationships between amines, calcium and $\mathrm{Na}^{+}$, $\mathrm{K}^{+}$-ATPase are as yet in their infancy and even the nature of the amine-receptors is but poorly defined. Further experimentation may well yield convincing evidence for a functional interrelationship between cyclic AMP, calcium and $\mathrm{Na}^{+}$, $\mathrm{K}^{+}$-ATPase. At the moment, therefore, the most judicious attitude is undoubtedly one which accepts the likelihood of an involvement of both calcium and cyclic AMP in the mediation of amine-induced inhibitions.

A frequent but perplexing observation has been that of an increase in neuronal membrane resistance during the application of amines or acetylcholine. It has generally been assumed that these were a result of direct transmitter-induced alterations in postsynaptic membrane conductances and in many instances mechanisms of action of the transmitter have been predicated on this alteration in membrane resistance. As we have seen (Section B. I. 3), both acetylcholine and the catecholamines can depress transmitter release from presynaptic terminals and this must therefore be considered as an alternative potential mechanism of action. A reduction in the release of excitatory transmitter could be associated with an increase in membrane resistance, and this may account for such increases in membrane resistance when they have been observed. The use of pulses of excitant dicarboxylic amino acids, such as L-glutamate, may provide a valuable technique for distinguishing between pre- and post-synaptic actions.
L-glutamate is thought to have a predominantly postsynaptic locus of action, and suppression of L-glutamate-evoked firing of an otherwise quiescent cell should be considered as indicative of a depressant action of a neurotransmitter on the postsynaptic neuron. Conversely, a reduction of spontaneous firing, with less of an effect on glutamate-evoked discharges, would be indicative of a presynaptic locus of action. It can be anticipated that many putative neurotransmitters will have actions on both pre- and post-synaptic membranes and that the postsynaptically recorded event will reflect the outcome of actions at both sites.

The use of glutamate-evoked firing in neuropharmacological experiments has been criticized, as has experimentation on nonphysiologically identified neurons (Bloom, 1974). Both criticisms are clearly specious and can be refuted, even though it is obviously desirable, from the point of view of reproducibility, to use identifiable cells whenever possible. To use a by now familiar example, within the cerebral cortex only the corticospinal neurons, which constitute a small minority of the total cell population, can be definitively identified by invasion of an antidromically propagating action potential. The majority of the cerebral cortical neurons cannot be identified in this manner, and to suggest that their existence should be ignored is clearly an unrealistic proposition. Unlike the corticospinal neurons which are characterized by their spontaneous activity, many of the more superficial neurons are quiescent and can only be tested with extracellular applications of an excitant, such as glutamic acid. Even though the use of glutamate may introduce another factor into the experimental situation, it appears to be clearly more desirable than the alternative of ignoring the existence of these neurons. Finally, as indicated above, the use of excitant amino acids may provide a unique technique for separating preand post-synaptic actions of iontophoretically applied pharmacological agents. Thus an early indication 
of the likely presynaptic locus of action of the adenine nucleotides was provided by the observation that they depressed spontaneous activity more effectively than glutamate-evoked firing. Conversely, monoamines, which are thought to have an action on the postsynaptic membrane, depress glutamate-evoked firing more effectively than spontaneous activity.

\section{ACKNOWLEDGEMENTS}

The helpful comments of Dr. P. V. Sulakhe and Mr. J. P. Edstrom on preliminary drafts of this manuscript are gratefully acknowledged. Miss B. J. Robson helped to compile the bibliography and bore the brunt of most of the typing. I am grateful to the publishers of the Canadian Journal of Physiology and Pharmacology, General Pharmacology, Life Sciences, and Experimental Neurology for permission to reproduce various figures.

\section{RÉSUMÉ}

(continued from page 153)

teurs à haute spécificité pour l'adenylate cyclase devrait fournir une base sîre d'où on pourra tirer des conclusions sur le rôle de l'AMP cyclique dans la transmission synaptique. Des considérations similaires s'appliquent aux actions du GMP cyclique et sur le rôle de son enzyme synthétisant, la guanylate cyclase.

L'utilisation d'inhibiteurs de la phosphodiesterase dans les études des nucleotides cycliques doit aussi se faire avec précaution. Les actions diverses de plusieurs de ses composantes, qui incluent la mobilisation du calcium et le blocage de l'uptake d'adénosine. pourraient expliquer plusieurs résultats rapportés dans ls littérature.

\section{REFERENCES}

AHN, H. S., MISHRA, R. K., DEMIRJIAN, C. and MAKMAN, M. H. (1976). Catecholamine-sensitive adenylate cyclase in frontal cortex of primate brain. Brain. Res. 116, 437-454.

AMER, M. S. and KREIGHBAUM, E. (1975). Cyclic nucleotide phosphodiesterase: properties, activators, inhibitors, structure-activity relationships and possible role in drug development. J. Pharm. Sci. 64, 1-37.

ANDÉN, N.-E., DAHLSTRÖM, A., FUXE, K., LARSSON, K., OLSON, L. and UNGERSTEDT, U. (1966). Ascending monoamine neurons to the telencephalon and diencephalon. Acta physiol. scand. 67, 313-326.

ANDERSON, E. G., HAAS, H. and HOSLl, L. (1973). Comparison of effects of norad- renaline and histamine with cyclic AMP on brain stem neurones. Brain Res. 49, 471-475.

ANLEZARK, G. M., CROW, T. J. and GREENWAY, A. P. (1973). Impaired learning and decreased cortical norepinephrine after bilateral locus coeruleus lesions. Science 181, 682-684.

APPLEMAN, M. M. and TERASAKI, W. L. (1975). Regulation of cyclic nucleotide phosphodiesterase. Advanc. Cyclic Nucleotide Res. 5, 153-162.

APPLEMAN, M. M., THOMPSON, W. J. and RUSSELL, T. R. (1973). Cyclic nucleotide phosphodiesterases. Advanc. Cyclic Nucleotide Res. 3, 66-98.

AKASU, T, and KOKETSU, K. Effects of dibutyryl cyclic AMP and theophylline on the bullfrog sympathetic ganglion cells. $\mathrm{Br}$. J. Pharmac. (in press).

ARAKI, T. and TERZUOLO, C. A. (1962). Membrane currents in spinal neurones associated with the action potential and synaptic activity. J. Neurophysiol. 25. 772-789.

ASHMAN, D. F., LIPTON, R, MELICOW, M. M. and PRICE, T. D. (1963). Isolation of adenosine $3^{\prime}, 5^{\prime}$-monophosphate and guanosine $3^{\prime}, 5^{\prime}$-monophosphate from rat urine. Biochem. Biophys. Res. Commun. 11, 330-334.

BAKER, P. F. (1972). Transport and metabolism of calcium ions. Prog. Biophys. Mol. Biol. 24, 177-223.

BAUDRY, M. MARTRES, M. P. and SCHWARTZ, J. C. (1975). $\mathrm{H}_{1}$ and $\mathrm{H}_{2}$ receptors in the histamine-induced accumulation of cyclic AMP in guinea pig brain slices. Nature 253, 362-364.

BERGER, B., TASSIN, J. P., BLANC, O., MOYNE, M. A. and THIERRY, A. M. (1974). Histochemical confirmation for dopaminergic innervation of rat cerebral cortex after destruction of the noradrenergic ascending pathways. Brain Res. 81, 332-337.

BERKOWITZ, B. A., TARVER, J. H. and SPECTOR, S. (1970). Release of norepinephrine in central nervous system by theophylline and caffeine. Eur. J. Pharmac. 10, 64-71.

BERNARDI, G., FLORIS, V., MARCIANI, M. G., MOROCUTTI, C. and STANZIONE, P. (1976). The action of acetylcholine and L-glutamic acid on rat caudate neurons. Brain Res. 114, 134-138.

BERNE, R. M., RUBIO, R. and CURNISH, $R$. (1974). Release of adenosine from ischaemic brain. Circ. Res. 35, 262-272.

BERRIDGE, M. J. (1975). The interaction of cyclic nucleotides and calcium in the control of cellular activity. Advanc. Cyclic Nucleotide Res. 6, 1-98.

BERTI, F., TRABUCCHI, M., BERNAREGGI, $V$. and FUMAGALLI, R. (1972). The effects of prostaglandins on cyclic-A MP formation in cerebral cortex of different mammalian species. Pharmacol. Res. Commun. 4, 253-259.
BEVAN, P., BRADSHAW, C. M. and SZABADI, E. (1976). Neuronal responses to adrenoceptor agonists in the cerebral cortex: evidence for excitatory $\alpha$-adrenoceptors and inhibitory $\beta$-adrenoceptors. Br. J. Pharmac. 58, 418 P.

BLINKS, J. R., OLSEN, C. B., JEWELL, B. R. and BRAVENY, P. (1972). Influence of caffeine and other methylxanthines on mechanical properties of isolated mammalian heart muscle. Evidence for a dual mechanism of action. Circ. Res. 30 , 367-391.

BLOOM, F. E. (1974). To spritz or not to spritz: the doubtful value of aimless iontophoresis. Life Sci. 14, 1819-1834.

BLOOM, F. E. (1975). The role of cyclic nucleotides in central synaptic function. Rev. Physiol. Biochem. Pharmacol. 74, 1 103.

BLOOM, F. E., HOFFER, B. J., BATTENBERG, E. R., SIGGINS, G. R., STEINER, A. L., PARKER, C. W. and WEDNER, H. J. (1972). Adenosine 3', $5^{\prime}$-monophosphate is localized in cerebellar neurons: immunofluorescence evidence. Science 177, 436-438.

BLOOM, F. E., HOFFER, B. J. and SIGGINS, G. R. (1971). Studies on norepinephrine-containing afferents to cerebellar Purkinje cells of rat cerebellum. I. Localization of the fibers and their synapses. Brain Res. 25, 501-521.

BLOOM, F. E., SIGGINS, G. R., HOFFER, B. J., SEGAL, M. and OLIVER, A. P. (1975). Cyclic nucleotides in the central synaptic actions of catecholamines. J. Cyclic Nucleotide Res. 5, 603-618.

BLUME, A. J. and FOSTER, C. J. (1975). Mouse neuroblastoma adenylate cyclase. Adenosine and adenosine analogues as potent effectors of adenylate cyclase activity. J. Biol. Chem. 250, 5003-5008.

BIANCHI, C. P. (1968). Cell Calcium. New York: Appleton-Century-Crofts.

BORLE, A. B. (1973). Calcium metabolism at the cellular level. Fedn. Proc. 32. 1944-1950.

BORLE, A. B. (1974). Cyclic AMP stimulation of calcium efflux from kidney, liver, and heart mitochondria. J. Memb. Biol. 16, 221.236.

BRADHAM, L. S., HOLT, D. A. and SIMS, M. (1970). The effect of $\mathrm{Ca}^{2}+$ on the adenyl cyclase of calf brain. Biochem. Biophys. Acta, 201, 250-260.

BRADSHAW, C. M., SZABADI, E. and ROBERTS. M. H. T. (1973). The reflection of ejecting and retaining currents in the time course of neuronal responses to microelectrophoretically applied drugs. J. Pharm. Pharmacol. 25, 513-520.

BRECKENRIDGE, B. M. (1964). The measurement of cyclic adenylate in tissues. Proc. Natl. Acad. Sci. (U.S.A.) 57. 1580-1586.

BRECKENRIDGE, B. M., BURN, J. H. and MATSCHINSKY, F. M. (1967). Theophylline, epinephrine and neostigmine facilita- 
tion of neuromuscular transmission. Proc. Natl. Acad. Sci. (U.S.A.) 57, 1893-1897.

BRECKENRIDGE, B. M. and JOHNSTON, R. E. (1969). Cyclic 3', 5'-nucleotide phosphodiesterase in brain. J. Histochem. Cytochem. 17, 505-511.

BRESSLER, B. H., PHILLIS, J. W. and KOZACHUK, W. (1975). Noradrenaline stimulation of a membrane pump in frog skeletal muscle. Eur. J. Pharmac. 33, 201-204.

BÜLBRING, E. and KURIYAMA, H. (1963). Effects of changes in ionic environment on the action of acetylcholine and adrenaline on the smooth muscle cells of guinea-pig taenia coli. J. Physiol. (Lond.) 166, 59-74.

BÜLBRING, E. and TOMITA, T. (1969a). Increase of membrane conductance by adrenaline in the smooth muscle of guinea-pig taenia coli. Proc. Roy. Soc. B. 172, 89-102.

BÜLBRING, E. and TOMITA, T. (1969b). Suppression of spontaneous spike generation by catecholamines in the smooth muscle of the guinea-pig taenia coli. Proc. Roy. Soc. B. 172, 103-119.

BÜLBRING, E. and TOMITA, T. (1969c). Effect of calcium, barium and manganese on the action of adrenaline in the smooth muscle of the guinea pig taenia coli. Proc. Roy. Soc. B. 172, 121-136.

BUNNEY, B. S. and AGHAJANIAN, G. K. (1973). Electrophysiological effects of amphetamine in dopaminergic neurons. In: Frontiers in Catecholamine Research, E. Usdin and S. H. Snyder, Eds., New York: Pergamon Press, pp. 957-962.

BUNNEY, B. S. and AGHAJANIAN, G. K. (1976). Dopamine and norepinephrine innervated cells in the rat prefrontal cortex: pharmacological differentiation using microiontophoretic techniques. Life Sci. 19, 1783-1792.

BURKARD, W. P. (1972). Catecholamine induced increase of cyclic adenosine 3', $5^{\prime}$-monophosphate in rat brain in vivo. J. Neurochem. 19, 2615-2619.

BURKARD, W. P. (1975). Adenylate cyclase in the central nervous system. Progr. Neurobiol. 4, 241-267.

BURKARD, W. P. PIERI, L. and HAEFELY. W. (1976). In vivo changes of guanosine 3'. 5'-cyclic phosphate in rat cerebellum by dopaminergic mechanisms. J. Neurochem. 27, 297-298.

BURNSTOCK, G. (1976). Do some nerve cells release more than one transmitter? Neuroscience 1, 239-248.

BURR, I. M., SLONIM. A. E., BURKE, V. and FLETCHER, T. (1976). Extracellular calcium and adrenergic and cholinergic effects on islet $\beta$-cell function. Amer. J. Physiol. 231, 1246-1249.

CHASIN. M., MAMRAK. F. and SAMAIEGO, S. G. (1974). Preparation and properties of a cell-free, hormonally responsive adenylate cyclase from guinea pig brain. J. Neurochem. 22, 1031-1038.
CHASIN, M., RIVKIN, I., MAMRAK, F., SAMANIEGO, G. and HESS, S. M. (1971). $\alpha$ - and $\beta$-Adrenergic receptors as mediators of accumulation of cyclic adenosine $3^{\prime}, 5^{\prime}$-monophosphate in specific areas of guinea pig brain. J. Biol. Chem. 246, 3037-3041.

CHENG, L. C., ROGUS, E. M. and ZIERLER, K. (1977). Catechol, a structural requirement for $\mathrm{Na}^{+}, \mathrm{K}^{+}-$-A TPase stimulation in rat skeletal muscle membrane. Biochim. Biophys. Acta. 464, 338-346.

CHLAPOWSKI, F. J., KELLY, L. A. and BUTCHER, R. W. (1975). Cyclic nucleotides in cultured cells. Advanc. Cyclic Nucleotide Res. 6, 245-338.

CHOU, W. S., HO, A. K. S. and LOH, H. H. (1971). Neurohormones on brain adenyl cyclase activity in vivo. Nature New Biol. 233, 280-281.

CHRIST, D. D. and NISHI, S. (1971). Site of adrenaline blockage in the superior cervical ganglion of the rabbit. J. Physiol. 213, 107-117.

CIANI, S. and EDWARDS, C. (1963). The effect of acetylcholine on neuromuscular transmission in the frog. J. Pharmac. Exp. Ther. 142, 21-23.

CLARK, R. B. and GROSS, R. (1974). Regulation of adenosine $3^{\prime}, 5^{\prime}$-monophosphate content in human astrocytoma cells by adenosine and the adenine nucleotides. J. Biol. Chem. 249, 5296-5302.

CLARK, R. B. and PERKINS, J. P. (1971). Regulation of adenosine 3', 5'-cyclic monophosphate concentration in cultured human astrocytoma cells by catecholamines and histamine. Proc. Natl. Acad. Sci. 68, 2757-2760.

CLARK, R. B. and SENEY, M. N. (1976). Regulation of adenylate cyclase in cultured human cell lines by adenosine. J. Biol. Chem. 251, 4239-4246.

CLEMENT-CORMIER, Y. C., KEBABIAN, J. W., PETZOLD, G. L. and GREENGARD, P. (1974). Dopaminesensitive adenylate cyclase in mammalian brain: a possible site of action of antipsychotic drugs. Proc. Nat. Acad. Sci. (Wash.) 71, 1113-1171.

CLEMENT-CORMIER, Y. C., PARRISH, R. G., PETZOLD, G. L., KEBABIAN, J. W. and GREENGARD, P. (1975). Characterization of a dopamine-sensitive adenylate cyclase in the rat caudate nucleus. J. Neurochem. 25. 143-149.

CONNOR, J. D. (1970). Caudate nucleus neurones: correlation of the effects of substantia nigra stimulation with iontophoretic dopamine. J. Physiol. (Lond.) 208, 691-703.

CONNOR. J. D. (1975). Electrophysiology of the nigro caudate dopamine pathway. Pharmac. Therap. B. 1, 357-370.

CONRAD. L. C. A., LEONARD, C. M. and PFAFF, D. W. (1974). Connections of the median and dorsal raphe nuclei in the rat: An autoradiographic and degeneration study. J. Comp. Neurol. 156, 179-206.
COOMBS, J. S., ECCLES, J. C. and FATT, $P$. (1955). The specific ionic conductances and the ionic movements across the motoneuronal membrane that produce the inhibitory post-synaptic potential. J. Physiol. (Lond.) 130, 326-373.

COOTE, J. H. and MACLEOD, V. H. (1974). The influence of bulbospinal monoaminergic pathways on sympathetic nerve activity. J. Physiol. 241, 453-475.

CRAMER. H., JOHNSON, D. G., HANBAUER, I., SILBERSTEIN, S. D. and KOPIN, I. J. (1973). Accumulation of adenosine 3', S'-monophosphate induced by catecholamines in the rat superior cervical ganglion in vitro. Brain Res. 53, 97-104.

CRAWFORD, J. M., CURTIS, D. R., VOORHOEVE, P. E. and WILSON, V. J. (1966). Acetylcholine sensitivity of cerebellar neurones in the cat. J. Physiol. (Lond.) 186, 139-165.

CROW, T. J. (1973). Catecholaminecontaining neurones and electrical selfstimulation: 2. A theoretical interpretation and some psychiatric implications. Psychological Med. 3, 66-73.

CUBBEDU, L, X., BARNES, E. and WEINER, N. (1975). Release of norepinephrine and dopamine$\beta$-hydroxylase by nerve stimulation. IV. An evaluation of a role for cyclic adenosine monophosphate. J. Pharmac. Exp. Ther. 193, 105-127.

DAHLSTRÖM, A. and FUXE, K. (1965). Experimentally induced changes in the intraneuronal amine levels of bulbospinal neurone systems. Acta Physiol. Scand. 64, suppl. 247, 5-36.

DALTON, C., CROWLEY, H. J., SHEPPARD, H. and SCHALLEK, W. (1974). Regional cyclic nucleotide phosphodiesterase activity in cat central nervous system: Effects of benzodiazepines. Proc. Soc. Exp. Biol. Med. 145, 407-410.

DALY, J. (1975). Role of cyclic nucleotides in the nervous system. In: Handbook of Psychopharmacology, L. L. Iverson, S. D. Iverson and S. H. Snyder, Eds., New York: Plenum.

DALY, J. W. (1976). Minireview. The nature of receptors regulating the formation of cyclic AMP in brain tissue. Life Sci. 18 , 1349-1358.

DALY, J. W., HUANG, M. and SHIMIZU, H. (1972). Regulation of cyclic AMP levels in brain tissue. Advanc. Cyclic Nucleotide Res. 1, 375-387.

DESAIAH, D. and HO. I. K. (1976). Effect of biogenic amines and GABA on ATPase activities in mouse tissues. Eur. I. Pharmac. 40, 255-261.

DESCARRIES. L. and LAPIERRE, Y. (1973). Noradrenergic axon terminals in the cerebral cortex of rat. I. Radioaulographic visualization after topical application of DL- $\left[{ }^{3} \mathrm{H}\right]$ norepinephrine. Brain Res. 51 . $141-160$

DISMUKES, K. and DALY, J. W. (1974). Norepinephrine-sensitive systems generating adenosine 3', 5'-monophosphate: in- 
creased responses in cerebral cortical slices from reserpine-treated rats. Molec. Pharmacol. 10, 933-940.

DISMUKES, K. and DALY, J. W. (1975). Accumulation of adenosine $3^{\prime}$, 5'. monophosphate in rat brain slices: Effects of prostaglandins. Life. Sci. 17, 199-210.

DISMUKES, R. K., GHOSH, P., CREVELING, C. R. and DALY, J. W. (1975). Altered responsiveness of adenosine $3^{\prime}$, 5 '-monophosphate-generating systems in rat cortical slices after lesions of the medial forebrain bundle. Exp. Neurol. 49, 725-735.

DISMUKES, R. K. and MULDER, A. H. (1976). Cyclic AMP and $\alpha$-receptor-mediated modulation of noradrenaline release from rat brain slices. Eur. J. Pharmac. 39, 383-388.

DISMUKES, K., ROGERS, M. and DALY, J. W. (1976). Cyclic adenosine 3', $5^{\prime}$-monophosphate formation in guinea-pig brain slices: Effects of $\mathrm{HI}$ and $\mathrm{H}_{2}$-histaminergic agonists. J. Neurochem. 26, 785-790.

DONALDSON, J., ST, PIERRE, T., MINNICH, J. and BARBEAU, A. (1971). Seizures in rats associated with divalent cation inhibition of $\mathrm{Na}$ - $\mathrm{K}+$-ATPase. Can. J. Biochem. 49, 1217-1224.

DOWD, F. J., PITTS, B. J. R. and SCHWARTZ, A. (1976). Phosphorylation of a low molecular weight polypeptide in beef heart $\mathrm{Na}^{+}, \mathrm{K}^{+}$-A TPase preparations. Arch. Biochem. Biophys. 175, 321-331.

DOWD, F. and SCHWARTZ, A. (1975). The presence of cyclic AMP-stimulated protein kinase substrates and evidence for endogenous protein kinase activity in various $\mathrm{Na}+, \mathrm{K}+$-ATPase preparations from brain, heart and kidney. J. Molec. Cell. Cardiol. 7, 483-497.

DRAHOTA, Z., CARAFOLI, E., ROSSI, C. S., GAMBLE, R. L. and LEHNINGER, A. L. (1965). The steady state maintenance of accumulated $\mathrm{Ca}+t$ in rat liver mitochondria. J. Biol. Chem. 240 , 2712-2720.

DRUMMOND, G. I., ENG, D. Y. and McINTOSH, C. A. (1971). Ribonucleoside $2^{\prime}, 3^{\prime}$-cyclic phosphate diesterase activity and cerebroside levels in vertebrate and invertebrate nerve. Brain. Res. 28, 153-163.

DRUMMOND, G. I. and MA, Y. (1971). Metabolism and functions of cyclic AMP in nerve. Progr. Neurobiol. 2, 121-176.

DRUMMOND, G. I. and POWELL. C. A. (1970). Analogues of adenosine $3^{\prime} .5^{\prime}$-cyclic phosphate as activators of phosphorylase $\beta$ kinase and as substrates for cyclic $3^{\prime}$, $5^{\prime}$-nucleotide phosphodiesterase. Mol. Pharmac. 6. 24-30.

DRUMMOND, G. I. and YAMAMOTO, M (1971). Nucleoside cyclic phosphate diesterases. The Enzymes 4. 355-371.

DUFFY, M. J., WONG, J. and POWELL, D. (1975). Stimulation of adenylate cyclase in rat and human brain by substance $P$. Biochem. Soc. Trans. 2, 1262-1264.
DUN, N. J. and KARCZMAR, A. G. (1977). A comparison of the effect of theophylline and adenosine $3^{\prime}, 5^{\prime}$-cyclic monophosphate on the superior cervical ganglion of the rabbit by means of the sucrose-gap method. J. Pharmac. Exp. Ther. (in press.).

DUN, N. and NISHI, S. (1974). Effects of dopamine on the superior cervical ganglion of the rabbit. J. Physiol. 239, 155-164.

EBADI, M. S., WEISS, B. and COSTA, E. (1971). Distribution of cyclic adenosine monophosphate in rat brain. Arch. Neurol. 24, 353-357.

ECCLES, J. C. (1963). Postsynaptic and presynaptic inhibitory actions in the spinal cord. Progr. Brain Res. 1, 1-18.

EDSTROM, J. P. and PHILLIS, J. W. (1976). The effects of AMP on the potential of rat cerebral cortical neurones. Can. J. Physiol. Pharmacol. 54, 787-790.

ENGBERG, I., FLATMAN, J. A. and KADZIELAWA, K. (1974). The hyperpolarization of motoneurones by electrophoretically applied amines and other agents. Acta physiol. scand. 91, 2-4A.

ERÄNKO, O. (1976). Histochemical demonstration of catecholamines in sympathetic ganglia. Ann. Histochim. 21, 83-100.

FAIERS, A. A. and MOGENSON, G. J. (1976). Electrophysiological identification of neurona in locus coeruleus. Exp. Neurol. 53, 254-266.

FERRENDELLI, J. A., CHANG. M. M. and KINSCHERF, D. A. (1974). Elevation of cyclic GMP levels in central nervous system by excitatory and inhibitory amino acids. J. Neurochem. 22, 535-540.

FERRENDELLI, J. A., KINSCHERF, D A. and CHANG. M. M. (1975). Comparison of the effects of biogenic amines on cyclic GMP and cyclic AMP levels in mouse cerebellum in vitro. Brain Res. 84 , 63-73.

FERRENDELLI, J. A., KINSCHERF, D. A. and KIPNIS, D. M. (1972). Effects of amphetamine, chlorpromazine and reserpine on cyclic GMP and cyclic AMP levels in mouse cerebellum. Biochem. Biophys. Res. Commun. 46, 2114-2120.

FERRENDELLI, J. A., STEINER, A. L.. McDOUGAL, D. B. and KIPNIS, D. M. (1970). The effect of oxotremorine and atropine on CGMP and cAMP levels in mouse cerebral cortex and cerebellum. Biochem. Biophys. Res. Commun. 41, 1061-1067.

FLORENDO, N. T., BARRNETT, R. J. and GREENGARD, P. (1971). Cyclic 3', 5'-nucleotide phosphodiesterase: cytochemical localization in cerebral cortex. Science 173, 745-747.

FORN. J. and KRISHNA. G. (1971). Effect of norepinephrine, histamine and other drugs on cyclic $3^{\prime}, 5^{\prime}$-AMP formation in brain slices of various animal species. Pharmacol. 5. 193-204.

FORN, J., KRUEGER, B. K. and GREENGARD. P. (1974). Adenosine $3^{\prime}$. 5 -monophosphate content in rat caudate nucleus. Demonstration of deopaminergic and adrenergic receptors. Science 186 , 1118-1119.

FORN, J. and VALDECASAS. F. G. (1971). Effects of lithium on brain adenyl cyclase activity. Biochem. Pharmac. 20, 2773-2779.

FREDERICKSON, R. C. A., HEWES. C. R. and NORRIS, F. H. (1975). Microiontophoresis of a selective neuronal uptake inhibitor [3-( $\boldsymbol{\rho}$-trifluoromethylphenoxy)$\mathrm{N}$-methyl-3-phenylpropylamine, Lilly 110140]: Assessing serotonin (5-HT) as a cortical neurotransmitter. Fedn. Proc. 34. 801.

FREEDMAN, R. and HOFFER. B. J. (1975). Phenothiazine antagonism of the noradrenergic inhibition of cerebellar Purkinje neurons. J. Neurobiol. 6, 277-288.

FREEDMAN, R., HOFFER, B. J. and WOODWARD, D. J. (1975). A quantitative microiontophoretic analysis of the responses of central neurons to noradrenaline: interactions with cobalt. manganese. verapamil and dichloroisoprenaline. Br. J. Pharmac. 54, 529-539.

FUXE, K., HOKFELT, T.. JOHANSSON. O.. JONSSON, O., LIDBRINK. P. and LJUNGDAHL. A. (1974). The origin of dopamine nerve terminals in limbic and frontal cortex. Evidence for meso-cortical dopamine neurons. Brain Res. 82, 349-355.

GARBARG. M., BARBIN, G.. BISCHOFF, S., POLLARD. H. and SCHWARTZ, J. C. (1976). Dual localization of histamine in an ascending neuronal pathway and in nonneuronal cells evidenced by lesions in the lateral hypothalamic area. Brain Res. 106. 333-348.

GARVAN, F. L. (1964). Metal chelates of ethylenediaminetetracetic acid and related substances. In: Chelating Agents and Metal Chelates. F. P. Dwyer and D. P. Mellor, Eds.. New York: Academic Press, pp. 283-333.

GEORGE, W. J.. POLSON, J. B.. O'TOOLE, A. G. and GOLDBERG. N. D. (1970). Elevation of guanosine $3^{\prime} .5^{\prime}$-cyclic phosphate in rat heart after perfusion with acetylcholine. Proc. Natl. Acad. Sci. U.S.A. 66, 398-403

GILBERT. J. C. WYLLIE. M. G. and DAVISON, D. V. (1975). Nerve terminal ATPase as possible trigger for neurotransmitter release. Nature (Lond.) 255, 237-238.

GILMAN, A. G. and NIRENBERG. M. (1971). Effect of catecholamines on the adenosine monophosphate metabolism in cultured neuroblastoma cells. Nature 234. 356-358.

GINSBORG, B. L. (1971). On the presynaptic acetylcholine receptors in sympathetic ganglia of the frog. J. Physiol. (Lond.) 216, 237-246.

GINSBORG, B. L. and HIRST, G. D. S (1972). The effect of adenosine on the release of the transmitter from the phrenic nerve of the rat. J. Physiol. (Lond.) 224. 629-645.

GODFRAIND, J. M.. KAWAMURA. H.. KRNJEVIC. K. and PUMAIN. R. (1971). Actions of dinitrophenol and some other 
metabolic inhibitors on cortical neurones. J. Physiol. (Lond.) 215, 199-222.

GODFRAIND, J. M. and PUMAIN, R. (1971). Cyclic adenosine monophosphate and norepinephrine: effect on Purkinje cells in rat cerebellar cortex. Science 174, 1257-1258.

GODFRAIND, T., KOCH, M.-C. and VERBEKE, N. (1974). The action of EGTA on the catecholamines stimulation of rat brain Na-K-ATPase. Biochem. Pharmacol. 23, 3505-3511.

GOLDBERG, A. L. and SINGER, J. J. (1969). Evidence for a role of cyclic AMP in neuromuscular transmission. Proc. Nat. Acad. Sci. U.S.A. 64, 134-141.

GOLDBERG, N. D., LUST, W. D., O'DEA, R. F., WEI, S. and O'TOOLE, A. G. (1970). A role of cyclic nucleotides in brain metabolism. Advanc. Biochem. Psychopharmacol. 3, 67-87.

GOLDBERG, N. D., O'DEA, R. F. and HADDOX, M. K. (1973). Cyclic GMP. Advanc. Cyclic Nucleotide Res. 3, 155-223.

GOLDBERG, N. D. and O'TOOLE, A. G. (1969). The properties of glycogen synthetase and regulation of glycogen biosynthesis in rat brain. J. Biol. Chem. 244, 3053-3061.

GONZALEZ-VEGAS, J. A. (1974). Antagonism of dopamine-mediated inhibition in the nigro-striatal pathway: a mode of action of some catatonia-inducing drugs. Brain Res. $80,219-228$.

GREEN, R. D. and STANBERRY, L. R. (1977). Elevation of cyclic AMP in C- 1300 murine neuroblastoma by adenosine and related compounds and the antagonism of this response by methylxanthines. Biochem. Pharmac. 26, 37-43.

GREENGARD, P. (1976). Possible role for cyclic nucleotides and phosphorylated membrane proteins in postsynaptic actions of neurotransmitters. Nature (Lond.) 260, 101-108.

GREENGARD, P. and KEBABIAN, J. W. (1974). Role of cyclic AMP in synaptic transmission in the mammalian peripheral nervous system. Fedn. Proc. 33, 1059-1067.

GREENGARD, P. and KUO, J. F. (1970). On the mechanism of action of cyclic AMP. Advan. Biochem. Psychopharmacol. 3, 287-306.

GROAT, W. C. De and THEOBALD, R. J. (1976). Effects of ATP, cyclic AMP and related nucleotides on transmission in parasympathetic ganglia. Pharmacologist $18,185$.

GUIDOTTI, A. and COSTA, E. (1973). Involvement of adenosine $3^{\prime}, 5^{\prime}$-monophosphate in the activation of tyrosine hydroxylase elicited by drugs. Science 179, 902-904.

GUIDOTTI, A., HANBAUER, I. and COSTA, E. (1975). Role of cyclic nucleotides in the induction of tyrosine hydroxylase. Advanc. Cyclic Nucleotide Res. 5, 619-639.
GUMULKA, S. W., DINNENDAHL, V. SCHONHOFER, P. S. and STOCK, K. (1976). Dopaminergic stimulants and cyclic nucleotides in mouse brain. Effects of dopaminergic antagonists, cholinolytics and GABA agonists. Arch. Pharmac. 295, 21-26.

HADHAZY, P. VIZI, E. S., MAGYAR, K. and KNOLL, J. (1976). Inhibition of adrenergic neurotransmission by prostaglandin $E_{1}\left(P E_{1}\right)$ in the rabbit ear artery. Neuropharmac. 15, 245-250.

HAGIWARA, S. (1973). Ca spike. Advan. Biophys. 4, 71-102.

HAMPRECHT, B. and SCHULTZ, J. (1973). Stimulation of prostaglandin $E_{1}$ of adenosine 3', 5'-cyclic monophosphate formation in neuroblastoma cells in the presence of phosphodiesterase inhibitors. FEBS Letters 34, 85-89.

HARDMAN, J. G. and SUTHERLAND, E. W. (1969). Guanyl cyclase, an enzyme catalyzing the formation of guanosine $3^{\prime}$, $5^{\prime}$-monophosphate from guanosine triphosphate. J. Biol. Chem. 244, 6363-6370.

HAYS, E. T., DWYER, T. M., HOROWICZ, P. and SWIFT, J. G., (1974). Epinephrine action on sodium fluxes in frog striated muscle. Amer. J. Physiol. 227, 1340-1347.

HEDQVIST, P. (1976). Further evidence that prostaglandins inhibit the release of noradrenaline from adrenergic nerve terminals by restriction of availability of calcium. $\mathrm{Br}$. J. Pharmac. 58, 599-603.

HEDQVIST, P. and FREDHOLM, B. B. (1976). Effects of adenosine on adrenergic neurotransmission; prejunctional inhibition and postjunctional enhancement. Arch. Pharmacol. 293, 217-223.

HEGSTRAND, L. R., KANOF, P. D. and GREENGARD, P. (1976). Histaminesensitive adenylate cyclase in mammalian brain. Nature 260, 163-165.

HEXUM, T. D. (1974). Studies on the reaction catalyzed by transport ( $\mathrm{Na}, \mathrm{K}$ ) adenosine triphosphatase. I. Effects of divalent metals. Biochem. Pharmac. 23, 3441-3447.

HOFFER, B. J., FREEDMAN, R., WOODWARD, D. J., DALY, J. W. and SKOLNICK, P. (1976). $\beta$-Adrenergic control of cyclic AMP generating systems in cerebellum: pharmacological heterogeneity confirmed by destruction of interneurons. Exp. Neurol. 51, 653-667.

HOFFER, B. J., SIGGINS, G. R., OLIVER, A. P. and BLOOM, F. E. (1971). Cyclic AMP mediation of norepinephrine inhibition in rat cerebellar cortex: A unique class of synaptic responses. Ann. N.Y. Acad. Sci. $185,531-549$.

HOFFER, B. J., SIGGINS, G. R., OLIVER, A. P. and BLOOM, F. E. (1973). Activation of the pathway from locus coeruleus to rat cerebellar Purkinje neurons: pharmacological evidence of noradrenergic central inhibition. J. Pharmacol. exp. Ther. 184, 553-569.
HOKFELT, T. and UNGERSTEDT, U. (1973). Specificity of 6-hydroxydopamine-induced degeneration of central monoamine neurons: electron and fluorescence microscopic study with special reference to intracerebral injection of the nigrostriatal dopamihe system. Brain Res. 60, 296-298.

HORN, A. S., CUELLO, A. C. and MILLER, R. J. (1974). Dopamine in the mesolimbic system of rat brain: endogenous levels and the effect of drugs on the uptake mechanisms and stimulation of adenylate cyclase activity. J. Neurochem. 22, 265-270.

HORNYKIEWICZ, O. (1966). Dopamine (3-hydroxy-tyramine) and brain function. Pharmac. Rev. 18, 925-964.

HOSIE, R. J. A. (1965). The localization of ATPase in morphologically characterized subcellular fractions of guinea pig brain. Biochem. J. 96, 404-412.

HOTTA, Y. and TSUKIU, R. (1968). Effect on the guinea-pig taenia coli of the substitution of strontium or barium ions for calcium ions. Nature 217, 867-869.

HUANG, M. and DALY, J. W. (1974). Adenosine-elicited accumulation of cyclic AMP in brain slices: Potentiation by agents which inhibit uptake of adenosine. Life Sci. 14, 489-503.

HUANG, $M$. and DRUMMOND, G. I. (1976). Effect of adenosine on cyclic AMP accumulation in ventricular myocardium. Biochem. Pharmac. 25, 2713-2719.

HUANG, M., HO, A. K. S. and DALY, J. W. (1973). Accumulation of adenosine cyclic 3'5'-monophosphate in rat cerebral cortical slices. Stimulatory effects of alpha and beta adrenergic agents after treatment with 6-hydroxydopamine, 2,3,5-trihydroxyphenethylamine and dihydroxytryptamines. Molec. Pharmac. 9, 711-717.

HUANG, M., SHIMIZU, H. and DALY, J. W. (1971). Regulation of adenosine cyclic $3^{\prime}, 5^{\prime}$-phosphate formation in cerebral cortical slices: Interaction among norepinephrine, histamine, serotonin. Molec. Pharmac. 7, 155-162.

HUANG, M., SHIMIZU, H. and DALY, J. W. (1972). Accumulation of cyclic adenosine monophosphate in incubated slices of brain tissue. 2. Effects of depolarizing agents, membrane stabilizers, phospho-diesterase inhibitors, and adenosine analogs. J. Med. Chem. 15, 462-466.

HUBBARD, J. I., SCHMIDT, R. F. and YOKOTA, T. (1965). The effect of acetylcholine upon mammalian motor nerve terminals. J. Physiol. (Lond.) 181. 810-829.

ICHIDA, S., KUO, C. H., MATSUDA, T. and YOSHIDA, H. (1976). Effects of $\mathrm{La}^{+++}, \mathrm{Mn}^{++}$and ruthenium red on $\mathrm{Mg}$ Ca-ATPhase activity and ATP-dependent Ca-binding of the synaptic plasma membrane. Jap. J. Pharmac. 26. 39-43.

INOUE, Y., YAMAMURA, $H$. and NISHIZUKA, Y. (1973). Protamine kinase independent of adenosine 
3',5'-monophosphate from rat brain cytosol. Biochem. Biophys. Res. Commun. 50, 228-236.

ISAACSON, A. and SANDOW, A. (1976). Quinine and caffeine effects on calcium movements in frog sartorius muscle. J. Gen. Physiol. 50, 2109-2128.

ISRAEL, Y. (1970). Cellular effects of alcohol. A review. Quart. J. Stud. Alc. 31, 293-316.

IVERSON, L. L. (1975). Dopamine receptors in the brain. Science 188, 1084-1089.

IWANGOFF, P., ENZ, A. and CHAPPUIS, A. (1974). Effect of adrenergic blockers on the activation of brain ATPase by noradrenaline. Experientia 30, 688 .

JAANUS, S. D. and RUBIN, R. P. (1974). Analysis of the role of cyclic adenosine $3^{\prime}, 5^{\prime}$-monophosphate in catecholamine release. J. Physiol. (Lond.) 237, 465-476.

JACK, J. J. B., MILLER, S., PORTER, R. and REDMAN, S. J. (1971). The time course of minimal excitatory post-synaptic potentials evoked in spinal motoneurones by group la afferent fibres. J. Physiol. 215, 353-380.

JACOBOWITZ. D. (1970). Catecholamine fluorescence studies of adrenergic neurons and chromaffin cells in sympathetic ganglia. Fedn. Proc. 29, 1929-1944.

JENKINSON, D. H., STAMENOVIC, B. A. and WHITAKER, B. D. L. (1968). The effect of noradrenaline on the end-plate potential in twitch fibres of the frog. J. Physiol. 195, 743-754.

JOHNSON, E. M., MAENO, H, and GREENGARD, P. (1971). Phosphorylation of endogenous protein of rat brain by a cyclic adenosine $3^{\prime}, 5^{\prime}$-monophosphatedependent protein kinase. J. Biol. Chem. 246. 7731-7739.

JOHNSON, G. A., BOUKMA, S. J., LAHTI, R. A. and MATHEWS, J. (1973). Cyclic AMP and phosphodiesterase in synaptic vesicles from mouse brain. J. Neurochem. 20, 1387-1392.

JOHNSON, P. N. and INESI, A. (1969). The effect of methylxanthines and local anaesthetics on fragmented sarcoplasmic reticulum. J. Pharmacol. Exp. Therp. 169, 308-314

KAKIUCHI, S. and RALL, T. W. (1968a). Studies on adenosine $3^{\circ}, 5^{\prime}$-phosphate in rabbit cerebral cortex. Mol. Pharmacol. 4, 379-388.

KAKIUCHI, S. and RALL, T. W. (1968b). The influence of chemical agents on the accumulation of adenosine $3^{\prime}, 5^{\prime}$-phosphate in slices of rabbit cerebellum. Mol. Pharmacol. 4, 367-378

KAKIUCHI, S., YAMAZAKI, R., TESHIMA, Y., UENISHI, K. and MIYAMOTO, E. (1975). $\mathrm{Ca}^{2}+/ \mathrm{Mg}^{2+}$. dependent cyclic nucleotide phosphodiesterase and its activator protein. Advanc. Cyclic Nucleotide Res. 5, 163-178.

KALIX, P., MCAFEE, D. A., SCHORDERET, M. and GREENGARD, P. (1974). Pharmacological analysis of synaptically mediated increase in cyclic adenosine monophosphate in rabbit superior cervical ganglion. J. Pharmac. Exp. Therp. 188, 676-687.

KASS, R. S. and TSIEN, R. W. (1975). Multiple effects of calcium antagonists on plateau currents in cardiac Purkinje fibers. J. Gen. Physiol. 66, 169-192.

KATAOKA, K. and DE ROBERTIS, E. (1967). Histamine in isolated small nerve endings and synaptic vesicles of rat brain cortex. J. Pharmac. Exp. Therp. 156, 114-125.

KEBABIAN, J. W., BLOOM, F. E., STEINER, A. L. and GREENGARD, $P$. (1975). Neurotransmitters increase cyclic nucleotides in postganglionic neurons: immunocytochemical demonstration. Science $190,157-159$

KEBABIAN, J. W. and GREENGARD, P. (1971). Dopamine-sensitive adenyl cyclase: possible role in synaptic transmission. Science $174,1346-1349$.

KEBABIAN, J. W., STEINER, A. L. and GREENGARD, P. (1975). Muscarinic cholinergic regulation of cyclic guanosine $3^{\prime}, 5^{\prime}$-monophosphate in autonomic ganglia: Possible role in synaptic transmission. $J$. Pharmac. Exp. Ther. 1973, 474-488.

KELLY, J. S. (1975). Microiontophoretic application of drugs onto single neurons. In: Handbook of Psychopharmacology, Vol. 2, L. Iverson, S. D. Iverson and S. H. Snyder, Eds., pp. 29-67, New York: Plenum Press.

KETY, S. (1972). Brain catecholamines: affective states and memory. Advan. Behavioral Biol. 4, 65-80.

KIM, T. S., SHULMAN, J. and LEVINE, R. A. (1968). Relaxant effect of cyclic adenosine $3^{\prime}, 5^{\prime}$-monophosphate on the isolated rabbit ileum. J. Pharmac. Exp. Ther. $163,36-42$.

KINSCHERF, D. A., CHANG, M. M., RUBIN, E. H., SCHNEIDER, D. R. and FERRENDELLI, J. A. (1976). Comparison of the effects of depolarizing agents and neurotransmitters on regional CNS cyclic GMP levels in various animals. J. Neurochem. 26, 527-530.

KITAI, S. T., SUGIMORI, M. and KOCSIS, J. D. (1976). Excitatory nature of dopamine in the nigro-caudate pathway. Exp. Brain Res. 24, 351-363

KLAINER, L. M., CHI, Y.-M., FREIDBERG, S. L., RALL, T. W. and SUTHERLAND, E. W. (1962). Adenyl cyclase: IV. The effects of neurohormones on the formation of adenosine 3', 5 '-phosphate by preparations from brain and other tissues. J. Biol. Chem. 237, 1239-1243.

KOBAYASHI, H. and LIBET, B. (1968). Generation of slow post-synaptic potentials without increases in ionic conductance. Proc. Nat. Acad. Sci. U.S.A. 60 , 1304-1311.

KOBAYASHI, H. and LIBET, B. (1970). Actions of noradrenaline and acetylcholine on sympathetic ganglion cells. J. Physiol (Lond.) 208, 353-372.
KOBAYASHI, H. and LIBET, B. (1974). Is inactivation of potassium conductance involved in slow postsynaptic excitation of sympathetic ganglion cells? Effects of nicotine. Life Sci. 14, 1871-1883.

KOBER, T. E. and COOPER, G. P. (1976). Lead competitively inhibits calciumdependent synaptic transmission in the bullfrog sympathetic ganglion. Nature (Lond.) 262, 704-705.

KOKETSU, $K$. and NAKAMURA, $M$. (1976). The electrogenesis of adrenalinehyperpolarization of sympathetic ganglion cells in bullfrogs. Jap. J. Physiol. 26, 63-77.

KOKETSU, K. and OHTA, Y. (1976). Acceleration of the electrogenic Nat pump by adrenaline in frog skeletal muscle fibres. Life Sci. 19, 1009-1014.

KOKETSU, $K$. and SHIRASAWA, Y. (1974). 5-HT and the electrogenic sodium pump. Experientia 30, 1034-1035.

KOKETSU, K., SHOJI, T. and NISHI, S. (1973). Slow inhibitory postsynaptic potentials of bullfrog sympathetic ganglia in sodium-free media. Life Sci. 13, 453-458.

KOSTOPOULOS, G. K., LIMACHER, J. J. and PHILLIS, J. W. (1975). Action of various adenine derivatives on cerebellar Purkinje cells. Brain Res. 88, 162-165.

KRNJEVIĆ, K. and LISIEWICZ, A. (1972). Injections of calcium ions into spinal motoneurons. J. Physiol. (Lond.) 225, 363-390.

KRNJEVIĆ, K. and MILEDI, R. (1958). Some effects produced by adrenaline upon neuromuscular propagation in rats. $J$. Physiol. (Lond.) 141, 291-304.

KRNJEVIĆ, K. and PHILLIS, J. W. (1963). Actions of certain amines on cerebral cortical neurones. Br. J. Pharmac. Chemother. 20, 471-490.

KRNJEVIĆ, K., PUIL, E. and WERMAN, R. (1975). Evidence for $\mathrm{Ca}^{2}+$-activated $\mathrm{K}^{+}$conductance in cat spinal motoneurons from intracellular EGTA injections. Can. J. Physiol. Pharmacol. 53, 1214-1218.

KRNJEVIĆ, K., PUIL, E. and WERMAN, R. (1976). Is cyclic guanosine monophosphate the internal 'second messenger' for cholinergic actions on central neurons? Can. J. Physiol. Pharmacol. 54, 172-176.

KRNJEVIĆ, K., PUMAIN, R. and RENAUD, L. (1971a). The mechanism of excitation by acetylcholine in the cerebral cortex. J. Physiol. (Lond.), 215, 247-268.

KRNJEVIĆ, K., PUMAIN, $R$. and RENAUD, L. (197/b). Effects of $\mathrm{Ba}^{2+}$ and tetraethylammonium on cortical neurones. J. Physiol. (Lond.) 215, 223-245.

KRNJEVIĆ, K. and VAN METER, W. G. (1976). Cyclic nucleotides in spinal cells. Can. J. Physiol. Pharmacol. 54, 416-421.

KUBA, K. and NISHI, S. (1976). Rhythmic hyperpolarizations and depolarization of sympathetic ganglion cells induced by caffeine. J. Neurophysiol. 39, 547-563.

KUEHL, F. A., HUMES, J. L., CIRILLO, V. J. and HAM, E. A. (1972). Cyclic AMP and prostaglandins in hormone actions. Advanc. Cyclic Nucleotide Res. 1, 493-502. 
KUHAR, M. J., AGHAJANIAN, G. K. and ROTH, R. H. (1972). Tryptophan hydroxylase activity and synaptosomal uptake of serotonin in discrete brain regions after midbrain raphe lesions: correlations with serotonin levels and histochemical fluorescence. Brain Res. 44, 165-176.

KUO J. F. (1974). Guanosine 3', 5'-monophosphate-dependent protein kinases in mammalian tissues. Proc. Nat. Acad. Sci. (U.S.A.) 71, 4037-4041.

KUO, J. F. and GREENGARD, P. (1969a). Cyclic nucleotide-dependent protein kinases. IV. Widespread occurrence of adenosine $3^{\prime}, 5^{\prime}$-monophosphate dependent protein kinase in various tissues and phyla of the animal kingdom. Proc. Nat. Acad. Sci. (U.S.A.) 64, 1349-1355.

KUO, J. F. and GREENGARD, P. (1969b). Adenosine $3^{\prime}, 5^{\prime}$-monophosphate dependent protein kinase from brain. Science $165,63-65$.

KUO, J. F. and GREENGARD, P. (1970a). Stimulation of adenosine 3', 5'-monophosphate-dependent protein kinases by some analogs of adenosine 3', 5'-monophosphate. Biochem. Biophys. Res. Commun. 40, 1032-1038.

KUO, J. F. and GREENGARD, P. (1970b). Cyclic nucleotide-dependent protein kinases. VII. Comparison of various histones as substrates for adenosine $3^{\prime}$, 5 '-monophosphate-dependent and guanosine 3', 5'-monophosphate-dependent protein kinases. Biochim. Biophys. Acta. $212,434-440$.

KUO, J. F. and GREENGARD, P. (1973). Stimulation of cyclic GMP dependent protein kinase by a protein fraction which inhibits cyclic-AMP-dependent protein kinases. Fedn. Proc. 30, 1089 Abs.

KUO, J. F., LEE, T.-P., REYES, P. L., WAKTON, K. G., DONNELLY, T. E. and GREENGARD, P. (1972). Cyclic nucleotide-dependent protein kinases. $X$. An assay method for the measurement of guanosine $3^{\prime}, 5^{\prime}$-monophosphate in various biological materials and a study of agents regulating its levels in heart and brain. $J$. Biol. Chem. 247, 16-22.

KURODA, Y., SAITO, $M$. and KOBAYASHI, K. (1976a). Concomitant changes in cyclic AMP level and postsynaptic potentials of olfactory cortex slices induced by adenosine derivatives. Brain Res. 109, 196-201.

KURODA, Y., SAITO, M. and KOBAYASHI, K. (1976b). High concentrations of calcium prevent the inhibition of postsynaptic potentials and the accumulation of cyclic AMP induced by adenosine in brain slices. Proc. Jap. Acad. 52, 86-89.

KUROKAWA, M., SAKAMOTO, T. and KATO, M. (1965). Distribution of $\mathrm{Na}$ plus-K-stimulated ATPase activity in isolated nerve ending particles. Biochem. J. 97, 833-844.

KUYPERS, H. G. J. M. and MAISKY, V. A. (1975). Retrograde axonal transport of horseradish peroxidase from spinal cord to brainstem cell groups in the cat. Neurosci. Lett. 1, 9-14.

LAKE, N. and JORDAN, L. M. (1974). Failure to confirm cyclic AMP as second messenger for norepinephrine in rat cerebellum. Sci. 183, 663-664.

LAKE, N., JORDAN, L. M. and PHILLIS, J. W. (1973). Evidence against cyclic adenosine 3', 5'-monophosphate (AMP) mediation of noradrenaline depression of cerebral cortical neurones. Brain. Res. 60 , $411-421$.

LEE, T.-P., KUO, J. F. and GREENGARD, P. (1972). Role of muscarinic cholinergic receptors in regulation of guanosine $3^{\prime}$, $5^{\prime}$-cyclic monophosphate content in mammalian brain, heart muscle and intestinal smooth muscle. Proc. Nat. Acad. Sci. U.S.A. $69,3287-3291$.

LIBET, B. (1970). Generation of slow inhibitory and excitatory postsynaptic potentials. Fedn. Proc. 29, 1945-1949.

LIBET, B. and KOBAYASHI, H. (1974). Adrenergic mediation of slow inhibitory postsynaptic potential in sympathetic ganglia of the frog. J. Neurophysiol. 37, 805-814.

LIBET, B., KOBAYASHI, H. and TANAKA, T. (1975). Synaptic coupling into the production and storage of a neuronal memory trace. Nature (Lond.) 258, $155-157$.

LIBET, B. and OWMAN, C. H. (1974). Concomitant changes in formaldehyde-induced fluorescence of dopamine interneurones and in slow inhibitory post-synaptic potentials of the rabbit superior cervical ganglion, induced by stimulation of the preganglionic nerve or by a muscarinic agent. J. Physiol. (Lond.) 237, 635-662.

LIBET, B. and TOSAKA, T. (1970). Dopamine as a synaptic transmitter and modulator in sympathetic ganglia: A different mode of synaptic action. Proc. Nat. Acad. Sci. U.S.A. 67, 667-673.

LINDL, T. and CRAMER, H. (1975). Evidence against dopamine as the mediator of the rise of cyclic AMP in the superior cervical ganglion. Biochem. Biophys. Res. Comm. 65, 731-739.

LINDVALL, O., BJÖRKLUND, A., MOORE, R. Y. and STENEVI, U. (1974). Mesencephalic dopamine neurons projecting to neocortex. Brain Res. 81, 325-331.

LLINAS, R. and BAKER, R. (1972). A chloride-dependent inhibitory postsynaptic potential in cat trochlear motoneurons. J. Neurophysiol. 35, 484-492.

LOGAN, J. G. and O'DONOVAN, D. J. (1976). The effects of ouabain and the activation of neural membrane ATPase by biogenic amines. J. Neurochem. 27, 185-189.

LORENS, S. A. and GOLDBERG, H. C. (1974). Regional S-hydroxytryptamine following midbrain raphé lesions in the rat. Brain Res. 78, 45-65.

LUST, W. D., PASSONNEAU, J. V. and VEECH, R. L. (1973). Cyclic adenosine monophosphate metabolites and phosphorylase in neuronal tissue. A comparison of methods of fixation. Science 181 , 280-282.

LUX, H. D. (1971). Ammonium and chloride extrusion: Hyperpolarizing synaptic inhibition in spinal motoneurons. Science 173, 555-557.

LUX, H. D., LORACHER, C. and NEHER, E. (1970). The action of ammonium on postsynaptic inhibition of cat spinal motoneurons. Exp. Brain Res. 11, 431-447.

MADIERA, V. M. and ANTUNESMADIERA, M. C. (1973). Interaction of $\mathrm{Ca}++$ and $\mathrm{Mg}++$ with synaptic plasma membranes. Biochim. Biophys. Acta. 323, 396-407.

MAENO, H. and GREENGARD, P. (1972). Phosphoprotein phosphatases from rat cerebral cortex. J. Biol. Chem. 247, 3269-3277.

MAENO, H., JOHNSON, E. M. and GREENGARD, P. (1971). Subcellular distribution of adenosine $3^{\prime}$, $5^{\prime}$-monophosphate-dependent protein kinase in rat brain. J. Biol. Chem. 246, 134-142.

MAENO, H., UEDA, T. and GREEN. GARD, P. (1975). Adenosine 3', $5^{\prime}$-monophosphate dependent protein phosphatase activity in synaptic membrane fractions. J. Cyclic Nucleotide Res. 1, 37-48.

MAGARIBUCHI, T: and KURIYAMA, $\mathbf{H}$. (1972). Effects of noradrenaline and isoprenaline on the electrical and mechanical activities of guinea pig depolarized taenia coli. Jap. J. Physiol. 22, 253-270.

MAH, H. D. and DALY, J. W. (1976). Adenosine-dependent formation of cyclic AMP in brain slices. Pharmac. Res. Commun. 8, 65-79.

MANALIS, R. S. and COOPER, G. P. (1973). Presynaptic and postsynaptic effects of lead at the frog neuromuscular junction. Nature (Lond.) 243, 354-356.

MAO, C. C., GUIDOTTI, A. and COSTA, E. (1974a). Inhibition by diazepam of the tremor and the increase of cerebellar cGMP content elicited by harmaline. Brain. Res. 83, 526-529.

MAO, C. C., GUidotTi, A. and Costa, E. (1974b). Interactions between $\gamma$-aminobutyric acid and guanosine 3', $5^{\prime}$-monophosphate in rat cerebellum. Molec. Pharmac. 10, 736-745.

MATTHEWS, M. R. and RAISMAN, G. (1969). The ultrastructure and somatic efferent synapses of small granule-containing cells in the superior cervical ganglion. J. Anat. 105, 255-282.

McAFEE, D. A. and GREENGARD, P. (1972). Adenosine $3^{\prime}, 5^{\prime}$-monosphosphate: Electrophysiological evidence for a role in synaptic transmission. Science 178 , 310-312.

McAFEE, D. A., SCHORDERET, M. and GREENGARD, P. (1971). Adenosine 3', $5^{\prime}$-monophosphate in nervous tissue: increase associated with synaptic transmission. Science 171, 1156-1158. 
McLENNAN, H. (1970). Synaptic transmission. Philadelphia: Saunders.

MELAMED, E., LAHAV. M. and ATLAS, D. (1976). Direct localization of a $\beta$-adrenoceptor site in rat cerebellum by a new fluorescent analogue of propranolol. Nature (Lond.) 261, 420-422.

MILEDI, R. (1973). Transmitter release induced by injection of calcium ions into nerve terminals. Proc. Roy. Soc. Ser. B. $183,421-425$.

MILLER, J. P., BOSWELL. K. H., MUNEYANA, K., SIMON, L. N., ROBINS, R. K. and SHUMAN, D. A. (1973). Synthesis and biochemical studies of various 8-substituted derivatives of guanosine 3'. 5'-cyclic phosphate and xanthosine 3', $5^{\prime}$-cyclic phosphate. Biochemistry 12 , 5310-5319.

MILLER, R. J., HORN, A. S. and IVERSEN, L. L. (1974). The action of neuroleptic drugs on dopamine-stimulated adenosine $3^{\prime}, 5^{\prime}$-monophosphate production in rat neostriatum and limbic forebrain. Molec. Pharmac. 10, 759-766.

MILLER. R. J. and IVERSEN. L. L. (1974). Effect of psychoactive drugs on dopamine (3, 4-dihydroxyphenethylamine) sensitive adenylate cyclase activity in corpus striatum of rat brain. Biochem. Soc. Transact. 2, 256-259.

MINNA, J, D. and GILMAN, A. G. (1973). Expression of genes for metabolism of cyclic adenosine $3^{\prime}, 5^{\prime}$-monophosphate in somatic cells. Il. Effects of prostaglandin EI and theophylline on parental and hybrid cells. J. Biol. Chem. 248, 6618-6625.

MIYAMOTO. E.. KUO, J. F. and GREENGARD, P. (1969a). Adenosine 3', 5'-monophosphate-dependent protein kinase from brain. Science 165, 63-65.

MIYAMOTO, E. KUO, J. G and GREENGARD, P. (1969b). Cyclic nucleotidedependent protein kinases. 1. Purification and properties of adenosine $3^{\prime}$. 5'-monophosphate-dependent protein kinase from bovine brain. J. Biol. Chem. 244, 63956402 .

MIYAMOTO, E., PETZOLD, G. L., HARRIS, J. S. and GREENGARD, P. (1971). Dissociation and concomitant activation of adenosine $3^{\prime}, 5^{\prime}$-monophosphate-dependent protein kinase by histone. Biochem. Biophys. Res. Commun. 44, 305-312.

MIYAMOTO, M. D. and BRECKENRIDGE. B. McL. (1974). A cyclic adenosine monophosphate link in the catecholamine enhancement of transmitter release at the neuromuscular junction. J. Gen. Physiol. 63, 609-624.

MORITOKI, H., MORITA, $M$. and KANBE, T. (1976). Effects of methylxanthines and imidazole on the contractions of guinea-pig ileum induced by transmural stimulation. Eur. J. Pharmac. 35, 185-198.

NAHORSKI, S. R. and ROGERS, K. J. (1976). Inhibition of 3'. 5'-nucleotide phosphodiesterase and the stimulation of cerebral cyclic AMP formation by biogenic amines in vitro and in vivo. Neuropharmac. 15, 609-612.

NAHORSKI, S. R., ROGERS, K. J. and SMITH, B. M. (1974). Histamine $\mathrm{H}_{2}$ receptors and cyclic AMP in brain. Life Sci. 15, 1887-1894.

NAKAMURA, S. and IWAMA, K. (1975). Antidromic activation of the rat locus coeruleus neurons from hippocampus, cerebral and cerebellar cortices. Brain Res. 99, 372-376.

NAKAZAWA, K. and SANO, M. (1974). Studies on guanylate cyclase. A new assay method for guanylate cyclase and properties of the cyclase from rat brain. J. Biol. Chem. 249, 4207-4211.

NATHANSON, J. A. and BLOOM, F. E. (1976). Heavy metals and adenosine cyclic 3', 5'-monophosphate metabolism: possible relevance to heavy metal toxicity. Molec. Pharmac. 12, 390-398.

NATHANSON, J. A., FREEDMAN, R. and HOFFER, B. J. (1976). Lanthanum inhibits brain adenylate cyclase and blocks noradrenergic depression of Purkinje cell discharge independent of calcium. Nature $261,330-332$.

NAYLER, W. G. and HARRIS, J. P. (1976). Inhibition by lanthanum of the $\mathrm{Na}^{+}$. $\mathrm{K}^{+}$-activated ouabain-sensitive adenosine triphosphatase enzyme. J. Molec. Cell. Cardiol. 8, 811-822.

NICOLL, R. A. (1976). Promising peptides. Society for Neuroscience Symposia 1, 99-122.

NIKODIJEVIC, O., NIKODIJEVIC, B. ZINDER, O., YU, M.-Y. W., GUROFF, G. and POLLARD, H. B. (1976). Control of adenylate cyclase from secretory vesicle membranes by $\beta$-adrenergic agents and nerve growth factor. Proc. Nat. Acad. Sci. U.S.A. 73, 771.774.

NISHI, S. (1970). Cholinergic and adrenergic receptors at sympathetic preganglionic nerve terminals. Fedn. Proc. 29, 1957-1965.

NISHI, S. and KOKETSU, K. (1968). Analysis of slow inhibitory post-synaptic potential of bullfrog sympathetic ganglion. J. Neurophysiol. 31, 717-728.

NISHI, S., SOEDA, H. and KOKETSU, K. (1969). Unusual nature of ganglionic slow EPSP studied by a voltage clamp method. Life Sci. 8, 33-42.

NOON, J. P., McAFEE, D. A. and ROTH, R. H. (1975). Norepinephrine release from nerve terminals within the rabbit superior cervical ganglion. Arch. Pharmac. 291, 139-162.

OBATA, K. and YOSHIDA, M. (1973). Caudate-evoked inhibition and actions of GABA and other substances on cat pallidal neurons. Brain. Res. 64, 455-459.

OLIVER, A. P. and SEGAL, M. (1974). Transmembrane changes in hippocampal neurons: hyperpolarizing actions of norepinephrine, cyclic AMP and locus coeruleus. Proc. Soc. Neurosci. 361.

OLSON, L. and FUXE, K. (1971). On the projections from the locus coeruleus noradrenaline neurons. Brain Res. 28, 165-171.
OPLER, L. A. and MAKMAN, M. H. (1972). Mediation by cyclic AMP of hormonestimulated glycogenolysis in cultured rat astrocytoma cells. Biochem. Biophys. Res. Commun. 46, 1140-1145.

OPMEER, F. A., GUMULKA, S. W., DINNENDAHL, $V$. and SCHÖNHÖFER, P. S., (1976). Effects of stimulatory and depressant drugs on cyclic guanosine $3^{\prime}$. $5^{\prime}$-monophosphate and adenosine $3^{\prime}$. 5 -monophosphate levels in mouse brain. Arch. Pharmacol. 292, 259-265.

OTTEN, U., MUELLER, R. A., OESCH, F. and THOENEN, H. (1974). Location of an isoproterenol-responsive cyclic AMP-pool in adrenergic nerve cell bodies and its relationship to tyrosine hydroxylase induction. Proc. Nat. Acad. Sci. U.S.A. 71, 22172221.

PALMER, G. C. (1973). Adenyl cyclase in neuronal and glial-enriched fractions from rat and rabbit brain. Res. Commun. Chem. Pathol. Pharmac. 5, 603-613.

PALMER, G. C. and DUSZYNSKI, C. R. (1975). Regional cyclic GMP content in incubated tissue slices of rat brain. Eur. J. Pharmac. 32, 375-379.

PALMER, G. C., SULSER, F. and ROBISON, G. A. (1973). Effects of neurohumoral and adrenergic agents on cyclic AMP levels in various areas of the rat brain in vitro. Neuropharmacol. 12. 327-337.

PARFITT, A., WELLER, J. L., KLEIN, D. C., SAKAI, K. K. and MARKS, B. H. (1975). Blockage by ouabain or elevated potassium ion concentration of the adrenergic and adenosine cyclic $3^{\prime}$. $5^{\prime}$-monophosphate-induced stimulation of pineal serotonin $\mathrm{N}$-acetyltransferase activity. Molec. Pharmac. 11, 241-255.

PEACH, M. J. (1972). Stimulation of release of adrenal catecholamine by adenosine $3^{\prime}$. 5 -monophosphate and theophylline in absense of extracellular $\mathrm{Ca}^{2+}$. Proc. Nat. Acad. Sci. U.S.A. 69, 834-836.

PENIT, J., HUOT, J. and JARD, S. (1976). Neuroblastoma cell adenylate cyclase: direct activation by adenosine and prostaglandins. J. Neurochem. 26, 265-273.

PERKINS. J. P. (1973). Adenyl cyclase. Advan. Cyclic Nucleotide Res. 3. 1-64.

PERKINS, J. P., MACINTYRE, E. H.. RILEY, W. D. and CLARK, R. B. (1971). Adenyl cyclase, phosphodiesterase and cyclic AMP dependent protein kinase of malignant glial cells in culture. Life Sci. 10. 1069-1080.

PERKINS, J. P. and MOORE. M. M. (1971). Adenyl cyclase of rat cerebral cortex. J. Biol. Chem. 246, 62-68.

PERKINS, J. P. and MOORE. M. M. (1973). Characterization of the adrenergic receptors mediating a rise in cyclic $3^{\prime}$. $5^{\prime}$-adenosine monophosphates in rat cerebral cortex. J. Pharmac. exp. Ther. 185. 371.378 .

PHILLIS, J. W. (1970). The Pharmacology of Synapses. Oxford: Pergamon Press. 
PHILLIS, J. W. (1974a). The role of calcium in the central effects of biogenic amines. Life Sci. 14, 1189-1201.

PHILLIS, J. W. (1974b). Neomycin and ruthenium red antagonism of monoaminergic depression of cerebral cortical neurones. Life Sci. 15, 213-222.

PHILLIS, J. W. (1974c). Evidence for cholinergic transmission in the cerebral cortex. Advanc. Behavioral Biol. 10, 57-77.

PHILLIS, J. W. (1976). An involvement of calcium and $\mathrm{Na}$, K-ATPase in the inhibitory actions of various compounds on central neurons. In: Taurine, R. Huxiable and A. Barbeau, Eds., pp. 209-223, New York: Raven Press.

PHILLIS, J. W. (1977). Substance P and related peptides. Soc. Neuroscience Symposia II. (in press).

PHILLIS, J. W. and EDSTROM, J. P. (1976). Effects of adenosine analogs on rat cerebral cortical neurons. Life Sci. 19, 1041-1054.

PHILLIS, J. W. and KOSTOPOULOS, G. $\mathrm{K}$. (1975). Adenosine as a putative transmitter in the cerebral cortex. Studies with potentiators and antagonists. Life Sci. 17, 1085-1094.

PHILLIS, J. W. and KOSTOPOULOS, G. K. (1977). Activation of a noradrenergic pathway from the brain stem to rat cerebral cortex. Gen. Pharmac. (in press).

PHILliS, J. W., KOSTOPOULOS, G. K. and LIMACHER, J. J. (1974). Depression of corticospinal cells by various purines and pyrimidines. Can. J. Physiol. Pharmacol. 52, 1226-1229.

PHILLIS, J. W., KOSTOPOULOS, G. K. and LIMACHER, J. J. (1975). A potent depressant action of adenine derivatives on cerebral cortical neurones. Eur. J. Pharmac. 30, 125-129.

PHILLIS, J. W. and LIMACHER, J. J. (1974). Effects of some metallic cations on cerebral cortical neurones and their interactions with biogenic amines. Can. J. Physiol. Pharmacol. 52, 566-574.

PHILLIS, J. W., TEBECIS, A. K. and YORK, D. H. (1968a). Depression of spinal motoneurones by noradrenaline, 5-hydroxytryptamine and histamine. Eur. J. Pharmac. 7, 471-475.

PHILLIS, J. W., TEBËCIS, A. K. and YORK, D. H. (1968b). Histamine and some anti-histamines: their actions on cerebral cortical neurones. Brit. J. Pharmac. 33, 426-440.

PICKEL, V. M., SEGAL, M. and BLOOM, F. E. (1974). A radioautographic study of the efferent pathways of the nucleus locus coeruleus. J. Comp. Neurol. 155, 15-42.

PIN, D., JONES, B. and JOUVET, M. (1968). Topographie des neurones monoaminergiques du tronc cerebral du chat: etude par histofluorescence. C. R. Soc. Biol. (Paris) 162, 2136-2141.

PRAKASH, N. J., FONTANA, J. and HENKIN, R. I. (1973). Effect of transitional metal ions on $\left(\mathrm{Na}^{+}+\mathrm{K}^{+}\right)$ATPase activity and the uptake of norepinephrine and choline by brain synaptosomes. Life. Sci. 12, 249-259.

PRASAD, K. N., GILMER, K. N. and SAHU, S. K. (1974). Demonstration of acetylcholine-sensitive adenyl cyclase in malignant neuroblastoma cells in culture. Nature (Lond.) 249, 765-767.

RAHWAN, K. G. and BOROWITZ, J. L. (1973). Mechanisms of stimulus-secretion coupling in adrenal medulla. J. Pharm. Sciences 62, 1911-1923.

RALL, T. W. (1972). Role of adenosine $3^{\prime}$, $5^{\prime}$-monophosphate (cyclic AMP) in actions of catecholamines. Pharmac. Rev. 24, 399-409.

RALL, T. W. and SATTIN, A. (1970). Factors influencing the accumulation of cyclic AMP in brain tissue. Advanc. Biochem. Psychopharmacol. 3, 113-133.

RALL, T. W. and SUTHERLAND, E. W. (1962). Adenyl cyclase: II. Enzymatically catalyzed formation of adenosine $3^{\prime}$, 5 -phosphate and inorganic pyrophosphate from adenosine triphosphate. J. Biol. Chem. 237, 1228-1232.

RALL, W., BURKE, R. E., SMITH, T.-G., NELSON, P. G. and FRANK, K. (1967). Dendritic location of synapses and possible mechanisms for the monosynaptic EPSP in motoneurons. J. Neurophysiol. 30, 1169-1193.

RAMSAY, A. G., GALLAGHER, D. L., SHOEMAKER, R. L. and SACHS, G. (1976). Barium inhibition of sodium ion transport in toad bladder. Biochim. Biophys. Acta. 436, 617-627.

RASMUSSEN, H. (1970). Cell communication, calcium ion and cyclic adenosine monophosphate. Science 170, 404-412.

RASMUSSEN, H., GOODMAN, D. B. P. and TENENHOUSE, A. (1972). The role of cyclic AMP and calcium in cell activation. Critical Rev. Biochem. 1, 95-148.

READER, T. A., DE CHAMPLAIN, J. and JASPER, H. (1976). Catecholamines released from cerebral cortex in the cat; decrease during sensory stimulation. Brain Res. 111, 95-108.

ROBERTIS, E. DE, ARNAIZ, G. R. D.-L., BUTCHER, R. W. and SUTHERLAND, E. W. (1967). Subcellular distribution of adenyl cyclase and cyclic phosphodiesterase in rat brain cortex. J. Biol. Chem $242,3487.3493$.

ROBISON, G. A., BUTCHER, R. W. and SUTHERLAND, E. W. (1971). Cyclic AMP. New York: Academic Press.

RODBELL, M., LIN, M. C., SALOMON, Y., LONDOS, C., HARWOOD, J. P., MARTIN, B. R., RENDELL, $M$. and BERMAN, M. (1975). Role of adenine and guanine nucleotides in the activity and response of adenylate cyclase systems to hormones. Evidence for multisite transition states. Advanc. Cyclic Nucleotide Res. 5 , 3-29.

ROGUS, E. M., CHENG, L. C. and ZIERLER, K. (1977). $\beta$-Adrenergic effect on $\mathrm{Na}++\mathrm{K}^{+}$transport in rat skeletal muscle. Biochim. Biophys. Acta. 464, 347-355.

ROUFOGALIS, B. D. and BELLEAU, B. (1969). Inhibition of sodium-potassium activated brain adenosine triphosphatase (Nat-K+-ATPase) by adrenergic blocking alkylating agents. Life Sciences 8 , 911-918.

SAHU, S. K. and PRASAD, K. N. (1975). Effect of neurotransmitters and prostaglandin $E_{1}$ on cyclic AMP levels in various clones of neuroblastoma cells in culture. J. Neurochem. 24, 1267-1269.

SASTRY, B. S. R. and PHILLIS, J. W. (1976a). Depression of rat cerebral cortical neurons by $\mathrm{H}_{1}$ and $\mathrm{H}_{2}$ histamine receptor agonists. Europ. J. Pharmac. 38, 269-273.

SASTRY, B. S. R. and PHILLIS, J. W. (1976b). Evidence for an ascending inhibitory histaminergic pathway to the cerebral cortex. Can. J. Physiol. Pharmacol. 54, 782-786.

SASTRY, B. S. R. and PHILLIS, J. W. (1977a). Metergoline as a selective 5-hydroxytryptamine antagonist in the cerebral cortex. Can. J. Physiol. Pharmacol. 55, 130-133.

SASTRY, B. S. R. and PHILLIS, J. W (1977b). Antagonism of biogenic amineinduced depression of cerebral cortical neurones by $\mathrm{Na}+, \mathrm{K}^{+}$-A TPase inhibitors. Can. J. Physiol. Pharmacol. 55, 170-179.

SATTIN, A. and RALL. T. W. (1970). The effect of adenosine and adenine nucleotides on the cyclic adenosine $3^{\prime}, 5^{\prime}$-phosphate content of guinea pig cerebral cortex slices. Molec. Pharmacol. 6, 13-23.

SATTIN, A., RALL, T. W. and ZANELLA, J. (1975). Regulation of cyclic adenosine $3^{\prime}$.' 5 -monophosphate levels in guinea pig cerebral cortex by interaction of alpha adrenergic and adenosine receptor activity. J. Pharmacol. Exp. Ther, 192, 22-32.

SCHAEFER, A., UNYI, G. and PFEIFER, A. K. (1972). The effects of a soluble factor and of catecholamines on the activity of adenosine triphosphatase in subcellular fractions of rat brain. Biochem. Pharmac. 21, 2289-2294.

SCHMIDT, M. J., PALMER, E. C., DETTBARN, W.-D. and ROBISON, G. A. (1970). Cyclic AMP and adenyl cyclase in the developing rat brain. Develop. Psychobiol. 3, 53-67.

SCHMIDT, M. J., SCHMIDT, D. E. and ROBISON, G. A. (1971). Cyclic adenosine monophosphate in brain areas: Microwave irradiation as a means of tissue fixation. Science 173, 1142-1143.

SCHMIDT, M. J. and SOKOLOFF, L. (1973). Activity of cyclic AMP-dependent microsomal protein kinase and phosphory. lation of ribosomal protein in rat brain during postnatal development. J. Neurochem. 21, 1193-1205.

SCHMIDT, R. F. (1971). Presynaptic inhibition in the vertebrate central nervous system. Ergebn. Physiol. 63, 20-107. 
SCHUBERT, D., TARIKAS, H. and LACORBIERE, M. (1976). Neurotransmitter regulation of adenosine $3^{\prime}$, $5^{\prime \prime}$-monophosphate in clonal nerve, glia and muscle cell lines. Science 192, 471-472.

SCHULTZ, J. and DALY, J. W. (1973a). Accumulation of cyclic adenosine $3^{\prime}$, $5^{\prime}$-monophosphate in cerebral cortical slices from rat and mouse: stimulatory effect of $\alpha$ - and $\beta$-adrenergic agents and adenosine. J. Neurochem. 21, 1319-1326.

SCHULTZ, J. and DALY, J. W. (1973b). Adenosine $3^{\prime}, 5^{\prime}$-monophosphate in guinea pig cerebral cortical slices: effects of $\alpha$ and $\beta$-adrenergic agents, histamine, serotonin and adenosine. J. Neurochem. 21, 573-579.

SCHULTZ, J. and HAMPRECHT, B. (1973). Adenosine $3^{\prime}, 5^{\prime}$-monophosphate in cultured neuroblastoma cells: Effect of adenosine phosphodiesterase inhibitors and benzapines. Arch. Pharmacol. 278, 215-225.

SCHWARTZ, J. C. (1975). Histamine as a transmitter in brain. Life Sci. 17, 503-518.

SCHWARTZ, J. P. (1976). Catecholaminemediated elevation of cyclic GMP in the rat C-6 glioma cell line. J. Cyclic Nucleotide Res. 2, 287-296.

SCHWARTZ, J. P., MORRIS, N. R. and BRECKENRIDGE, B. M. (1973). Adenosine $3^{\prime}, 5^{\prime}$-monophosphate in glial tumor cells. J. Biol. Chem. 248, 2699-2704.

SEEDS, N. W. (1971). Biochemical differentiation in reaggregating brain cell culture. Proc. Nat. Acad. Sci. U.S.A. 68 , 1858-1861.

SEEMAN, P. (1972). The membrane actions of anaesthetics and tranquilizers. Pharmac. Rev. 24, 583-655.

SEGAL, M. (1974). Lithium and the monoamine neurotransmitters in the rat hippocampus. Nature 250, 71-73.

SEGAL, M. (1975). Physiological and pharmacological evidence for a serotonergic projection to the hippocampus. Brain Res. 94, 115-131.

SEGAL, M. and BLOOM, F. E. (1974). The activation of norepinephrine in the rat hippocampus. II. Activation of the input pathway. Brain Res. 72, 99-114.

SERCK-HANSSEN, G. (1974). Effects ' of theophylline and propranolol on acetylcholine-induced release of adrenal medullary catecholamines. Biochem. Pharmac. 23, 2225-2234.

SHANTA, T. R., WOODS, W. D., WAITZMAN, M. B. and BOURNE, G. H. (1966). Histochemical method for localization of cyclic $3^{\prime}, 5^{\prime}$-nucleotide phosphodiesterase. Histochemie 7, 177-190.

SHIMIZU, H., ICHISHITA, $H$. and ODAGIRI, H. (1974). Stimulated formation of cyclic adenosine $3^{\prime}, 5^{\prime}$-monophosphate by aspartate and glutamate in cerebral cortical slices of guinea pig. J. Biol. Chem. 249, 5955-5962.

SHIMIZU, H., TANAKA, S., SUZUKI, T. and MATSUKADO, Y. (1971). The response of human cerebrum adenyl cyclase to biogenic amines. J. Neurochem. 18, 1157-1161.

SHINNICK-GALLAGHER, P., WILLIAMS, B. J. and GALLAGHER, J. P. (1976). Biochemical and electrophysiological studies of cyclic nucleotides and their effects in the rat superior cervical ganglion. Proc. Soc. Neurosci. 800.

SHOEMAKER, W. J., BALENTINE, L. T., SIGGINS, G. R., HOFFER, B. J., HENRIKSEN, S. J. and BLOOM, F. E. (1975) Characteristics of the release of adenosine $3^{\prime}, 5^{\prime}$-monophosphate from micropipets by microiontophoresis. J. Cyclic Nucleotide Res. 1, 97-106.

SIGGINS, G. R., BATTENBERG, E. F., HOFFER, B. J., BLOOM, F. E. and STEINER, A. L. (1973). Noradrenergic stimulation of cyclic adenosine monophosphate in rat Purkinje neurons: An immunocytochemical study. Science 179 , 585-588.

SIGGINS, G. R. and HENRIKSEN, S. J. (1975). Analogs of cyclic adenosine monophosphate: correlation of inhibition of Purkinje neurons with protein kinase activation. Science $189,559-561$.

SIGGINS, G. R., HOFFER, G. J. and BLOOM, F. E. (1971a). Studies on norepinephrine-containing afferents to Purkinje cells of rat cerebellum. III. Evidence for mediation of norepinephrine effects by cyclic 3,' 5'-adenosine monophosphate. Brain Res. 25, 535-553.

SIGGINS, G. R., HOFFER, B. and BLOOM, F. (197lb). Prostaglandin-norepinephrine interactions in brain: microelectrophoretic and histochemical correlates. Ann. N. Y. Acad. Sci. 180, 302-323.

SIGGINS, G. R., HOFFER, B. J. and UN GERSTEDT, U. (1974). Electrophysiolog ical evidence for involvement of cyclic adenosine monophosphate in dopamine responses of caudate neurons. Life Sci. 15 , 779-792.

SIMON, L. N., SHUMAN, D. A. and ROBINS, R. K. (1973). The chemistry and biological properties of nucleotides related to nucleoside $3^{\prime}, 5^{\prime}$-cyclic phosphates. Advanc. Cyclic Nucleotide Res. 3, 225-353.

SKOLNICK, P., DALY, J. W., FREED. MAN, R. and HOFFER, B. J. (1976). Interrelationship between catecholamine. stimulated formation of adenosine $3^{4}$ $5^{\prime}$-monophosphate in cerebellar slices and inhibitory effects on cerebellar Purkinje cells. Antagonism by neuroleptic compounds. J. Pharm. Exp. Ther. 197, 280-292.

SKOLNICK, P., HUANG, M., DALY, J. and HOFFER, B. J. (1973). Accumulation of adenosine $3^{\prime}, 5^{\prime}$-monophosphate in incubated slices from discrete regions of squirrel monkey cortex: effect of norepinephrine, serotonin and adenosine. $J$ Neurochem. 21, 237-240.

SKOU, J. C. (1965). Enzymatic basis for active transport of $\mathrm{Na}^{+}$and $\mathrm{K}^{+}$across cell membrane. Physiol. Rev. 45, 596-617.

SMITH, T. G., WUERKER, R. B. and FRANK, K. (1967). Membrane impedance changes during synaptic transmission in cat spinal motoneurons. J. Neurophysiol. 30, 1072-1096.

SNYDER, F. F. and SEEGMILLER, J. E. (1976). The adenosine-like effect of exogenous cyclic AMP upon nucleotide and PP-ribose-P concentrations of cultured human lymphoblasts. FEBS Letters 66, 102-106.

SOMLYO, A. P. AND SOMLYO. A. V. (1969). Pharmacology of excitationcontraction coupling in vascular smooth muscle and in avian slow muscle. Fedn. Proc. 28, 1634-1642.

SPECHT, S. C. and ROBINSON, J. D. (1973). Stimulation of the $\left(\mathrm{Na}^{+}+\right.$ $\mathrm{K}^{+}$)-dependent adenosine triphosphatase by amino acids and phosphatidylserine: chelation of trace metal inhibitors. Arch. Biochem. Biophys. 154, 314-323.

STAHL, W. L. and BRODERSON, S. H (1976). Localization of $\mathrm{Na}^{+}, \mathrm{K}^{+}$-A TPase in brain. Fedn. Proc. 35, 1260-1265.

STANDAERT, F. G., DRETCHEN. K. L.. SKIRBOLL, L. R. and MOGENROTH, V. H. (1976a). Effects of cyclic nucleotides on mammalian motor nerve terminals. J. Pharmac. Exp. Ther. 199, 544-552.

STANDAERT, F. G., DRETCHEN, K. L., SKIRBOLL, L. R. and MOGENROTH, V. H. (1976b). A role of cyclic nucleotides in neuromuscular transmission. J. Pharmacol. Exp. Ther. 199, 553-564.

STEIN, L., BELLUZZI, J. D. and WISE, C D. (1975). Memory enhancement by central administration of norepinephrine. Brain Res. 84, 329-335.

STEINER, A. L., FERRENDELLI, J. A. and KIPNIS, D. M. (1972). Radioimmunoassay for cyclic nucleotides. III. Effect of ischemia, changes during development and regional distribution of adenosine $3^{\prime}, 5^{\prime}$-monophosphate and guanosine $3^{\prime}$. $5^{\prime}$-monophosphate in mouse brain. J. Biol. Chem. 247, 1121-1124.

STITT, J. T. and HARDY, J. D. (1975). Microelectrophoresis of PGE1 onto single units in the rabbit hypothalamus. Amer. $J$. Physiol. 229, 240-245.

STJÄRNE, L. (1976). Relative importance of calcium and cyclic AMP for noradrenaline secretion from sympathetic nerves of guinea-pig vas deferens and for prostaglandin E-induced depression of noradrenaline secretion. Neuroscience 1, 19-22.

ST. LOUIS, P. and SULAKHE, P. V. (1976). Adenylate cyclase, guanylate cyclase and cyclic nucleotide phosphodiesterases of guinea-pig cardiac sarcolemma. Biochem. J. $158,535-541$.

STONE, T. W. (1973). Pharmacology of pyramidal tract cells in the cerebral cortex. Noradrenaline and related substances. Arch. Pharmacol. 278, 333-346.

STONE, T. W., TAYLOR, D. A. and BLOOM, F. E. (1975). Cyclic AMP and cyclic GMP may mediate opposite neuronal responses in the rat cerebral cortex. Science $187,845-846$. 
STURGILL, T. W., SCHRIER, B. K. and GILMAN, A. G. (1975). Stimulation of cyclic AMP accumulation by 2-chloroadenosine: lack of incorporation of nucleoside into cyclic nucleotides. J. Cyclic Nucleotide Res. 1, 21-30.

SULAKHE, P. V., JAN, S.-H. and SULAKHE, S. J. (1977). Studies on the stimulation of $\left(\mathrm{Na}^{+}-\mathrm{K}^{+}\right)$ATPase of neural tissues by catecholamines. Gen. Pharmac. 8, 37-41.

SULAKHE, P. V. and ST. LOUIS, P. J. (1976). Membrane phosphorylation and calcium transport in cardiac and skeletal muscle membranes. Gen. Pharmac. 7, 313-319.

SULAKHE, P. V.. SULAKHE, S. J., LEUNG, N. L.-K., ST. LOUIS, P. J. and HICKIE, R. A. (1976). Guanylate cyclase. Subcellular distribution in cardiac muscle, skeletal muscle, cerebral cortex and liver. Biochem. J. 157, 705-712.

SUTHERLAND, E. W. and RALL, T. W. (1958). Fractionation and characterization of a cyclic adenine ribonucleotide formed by tissue particles. J. Biol. Chem. 232. 1077-1091

SUTHERLAND, E. W., RALL. T. W. and MENON, T. (1962). Adenyl cyclase: I. Distribution, preparation and properties. $\mathrm{J}$. Biol. Chem. 237, I220-1227.

SUTHERLAND, E. W., ROBISON, G. A. and BUTCHER, R. W. (1968). Some aspects of the biological role of adenosine $3^{\prime}$, 5 -monophosphate (cyclic AMP). Circulation 37. 279-306.

SWARTZ, B. and WOODY, C. D. (1976). Correlated effects of acetylcholine (ACh) and cyclic GMP (cGMP) on input resistance $(\mathrm{Rm})$ of neocortical neurons in awake cats. Neuroscience Abstr. II 1156. p. 802.

SWISLOCKI, N. I. and TIERNEY, J. (1973). Solubilization, stabilization, and partial purification of brain adenylate cyclase from rat. Biochemistry 12, 1862-1866.

SZERB, J. C. and SOMOGYI, G. T. (1973). Depression of acetylcholine release from cerebral cortical slices by cholinesterase inhibition and by oxotremorine. Nature New Biol. (Lond.) 241, 121-122.

TANAKA, C.. INAGAKI, C. and FUJIWARA, H. (1976). Labeled noradrenaline release from rat cerebral cortex following electrical stimulation of locus coeruleus. Brain Res. 106, 384-389.

TAXI, J. and MIKULAJOVA, M. (1976) Some cytochemical and cytological features of the so-called SIF cells of the superior cervical ganglion of the rat. J. Neurocytol. 5, 283-295.

TAYLOR, D., NATHANSON, J., HOFFER, B., OLSON, L. and SEIGER, A. (1976). Lead blockade of noradrenergic inhibition in cerebellar Purkinje neurons. Neuroscience Abstracts II, (1), 507.

TING-BEALL, H. P., CLARK, D. A., SUELTER, C. H. and WELLS, W. W. (1973). Studies on the interaction of chick brain microsomal $\left(\mathrm{Na}^{+}+\mathrm{K}^{+}\right.$)-ATPase with copper. Biochim. Biophys. Acta. 291 , 229-236.

TOMIYAMA, A., TAKAYANAGI, I., SAEKI, M. and TAKAGI, K. (1973). Beta-adrenergic blocking action of ruthenium red. Jap. J. Pharmacol. 23, 889-891.

TRIGGLE, D. J. (1971). NeurotransmitterReceptor Interactions. New York: Academic Press.

TSUZUKI, J. and NEWBURGH, R. W. (1975). Inhibition of $5^{\prime}$-nucleotidase in rat brain by methylxanthines. J. Neurochem. $25,895-896$.

UEDA, T., MAENO, $H$. and GREENGARD, P. (1973). Regulation of endogenous phosphorylation of specific proteins in synaptic membrane fractions from rat brain by adenosine $3^{\prime}, 5^{\prime}$-monophosphate. J. Biol. Chem. 248, 8295-8305.

UNGERSTEDT, U. (1971). Stereotaxic mapping of the monoamine pathways in the rat brain. Acta physiol. scand. Suppl. 367. $1-48$

UZUNOV, P. and WEISS, B. (1972). Psychopharmacological agents and the cyclic AMP system of rat brain. Advanc. Cyclic Nucleotide Res. I, 435-453.

UZUNOV, P., SHEIN, H. M. and WEISS, B. (1973). Cyclic AMP phosphodiesterase in cloned astrocytoma cells: norepinephrine induces a specific enzyme form. Science $180,304-306$

VON HUNGEN, $K$. and ROBERTS, S. (1974). Neurotransmitter-sensitive adenylate cyclase systems in the brain. Rev. Neurosci. 1, 231-281.

VON HUNGEN, K., ROBERTS, S, and HILL, D. F. (1974). Developmental and regional variations in neurotransmittersensitive adenylate cyclase systems in cellfree preparations from rat brain. J. Neurochem. 22, 811-819.

VON HUNGEN, K., ROBERTS, S. and HILL, D. F. (1975). Serotonin-sensitive adenylate cyclase activity in immature rat brain. Brain Res. 84, 257-267.

WALTON, K. G. and BALDESSARINI, R. J. (1976). Effects of $\mathrm{Mn}^{2}+$ and other divalent cations on adenylate cyclase activity in rat brain. J. Neurochem. 27, 557-564.

WATANABE, S. and KOKETSU, K. (1973). 5-HT hyperpolarization of bullfrog sympathetic ganglion cell membrane. Experientia $29,1370-1372$.

WEIGHT, F. F. and PADJEN, A. (1973a). Slow synaptic inhibition in sympathetic ganglion cells: evidence for synaptic inactivation of sodium conductance in sympathetic ganglion cells. Brain Res. 55, 219-224.

WEIGHT, F. F. and PADJEN, A. (1973b). Acetylcholine and slow synaptic inhibition in frog sympathetic ganglion cells. Brain Res. 55, 225-228.

WEIGHT, F. F., PETZOLD, G. and GREENGARD, P. (1974). Guanosine 3'. 5 '-monophosphate in sympathetic ganglia: increase associated with synaptic transmission. Science. N.Y.. 186, 942-944.

WEIGHT, F. F. and VOTAVA, J. (1970). Slow synaptic excitation in sympathetic ganglion cells: Evidence for synaptic inactivation of potassium conductance. Science. N.Y., 755-758.

WEIR, M. C. L. and MCLENNAN. H. (1963). The action of catecholamines in sympathetic ganglia. Can. J. Biochem. Physiol. 41, 2627-2636.

WEISS, B. (1973). Selective regulation of the multiple forms of cyclic nucleotide phosphodiesterase by norepinephrine and other agents. In: Frontiers in Catecholamine Research, Edit. E. Usdin and S. H. Snyder. New York: Pergamon Press, pp. 327-333.

WEISS, B. (1975). Differential activation and inhibition of the multiple forms of cyclic nucleotide phosphodiesterase. Advanc. Cyclic Nucleotide Res. 5, 195-211.

WEISS, B. and COSTA, E. (1968). Regional and subcellular distribution of adenyl cyclase and $3^{\prime}, 5^{\prime}$-cyclic nucleotide phosphodiesterase in brain and pineal gland. Biochem. Pharmacol. 17. 2107-2116.

WEISS, B. and STRADA. J. J. (1972). Neuroendocrine control of the cyclic AMP system of brain and pineal gland. Advanc. Cyclic Nucleotide Res. I, 357-374.

WELLER, M. and RODNIGHT, R. (1973). Protein kinase activity in membrane preparations from ox brain: stimulation of intrinsic activity by adenosine $3^{\prime}, 5^{\prime}$-cyclic monophosphate. Biochem. J. 132, 483-492.

WELLMANN, W. and SCHWABE, U. (1973). Effects of prostaglandins $E_{1}, E_{2}$ and F2a on cyclic AMP levels in brain in vivo. Brain Res. 59, 371-378.

WESTFALL, T. C., KITAY, D. and WAHL, G. (1976). The effect of cyclic nucleotides on the release of ${ }^{3} \mathrm{H}$-dopamine from rat striatal slices. J. Pharmac. Exp. Ther. 199, 149-157.

WERMAN, R. (1966). A Review - Criteria for identification of a central nervous system transmitter. Comp. Biochem. Physiol. 18, 745-766.

WILliAMS, T. H., BLACK, A. C.. CHIBA, T, and BHALLA, R. C. (1975). Morphology and biochemistry of small intensely fluorescent cells of sympathetic ganglia. Nature 256, 315-317

WILSON, D. F. (1974). The effects of dibutyryl cyclic adenosine $3^{\prime}$. 5'-monophosphate, theophylline and aminophylline on neuromuscular transmission in the rat. J. Pharmacol. Exp. Ther. 188. 447-452.

WOODS, W. T. and LIEBERMAN, E. M. (1976). The effects of papaverine on sodium-potassium adenosine triphosphatase and the ouabain sensitive electrical properties of crayfish nerve. Neuroscience 1. 383-390.

WOOTEN, F. G., THOA. N. B., KOPIN, 1. $\mathrm{J}$. and AXELROD. J. (1973). Enhanced release of dopamine $-\beta-$ hydroxylase and 
norepinephrine from sympathetic nerves by dibutyryl cyclic adenosine $3^{\prime}$, 5-monophosphate and theophylline. Molec. Pharmacol. 9, 178-183.

YARBROUGH, G. G. (1976). Ouabain antagonism of noradrenaline inhibitions of cerebellar Purkinje cells and dopamine inhibitions of caudate neurons. Neuropharmac. 15, 335-338.

YARBROUGH, G. G., LAKE, N. and PHILLIS, J. W. (1974). Calcium antagonism and its effect on the inhibitory actions of biogenic amines on cerebral cortical neurones. Brain Res. 67, 77-88.

YORK, D. H. (1975). Amine receptors in CNS. II. Dopamine. In: Handbook of Psychopharmacology, Vol. 6. L. L. Iverson, S. D. Iverson and S. H. Snyder, Eds., pp. 23-61, New York: Plenum Press.

YOSHIMURA, K. (1973). Activation of Na-K activated ATPase in rat brain by catecholamine. J. Biochem. (Tokyo) 74, 389-391.
YOUNT, R. G. (1975). ATP analogs. Advances in Enzymology, 43, 1-56.

ZANELLA, J. and RALL, T. W. (1973). Evaluation of electrical pulses and elevated levels of potassium ions as stimulants of adenosine $3^{\prime}, 5^{\prime}$-monophosphate (cyclic AMP) accumulation in guinea pig brain. $J$. Pharmac. Exp. Ther. 186. 241-252.

ZIEGLGÄNSBERGER, W. and REITER. Ch. (1974), A cholinergic mechanism in the spinal cord of cats. Neuropharmacol. $13,519-527$. 